\author{
Universidade de São Paulo \\ FFCLRP - DEPARTAMENTO DE FísICA \\ Pós-graduaÇÃo Em Física aplicada À Medicina E Biologia
}

JULIO GODELI NETO

\title{
Mamografia Digital Por Dupla Energia Usando Simulação Monte Carlo: Otimização da Quantificação da Morfologia de Microcalcificações e Componentes do Tecido Mamário
}

Tese apresentada à Faculdade de Filosofia, Ciências e Letras de Ribeirão Preto da Universidade de São Paulo, como parte das exigências para a obtenção do título de Doutor em Ciências, Área: Física aplicada à Medicina e Biologia.

Ribeirão Preto - SP 2021 


\section{JULIO GODELI NETO}

\section{Mamografia Digital Por Dupla Energia Usando Simulação Monte Carlo: Otimização da Quantificação da Morfologia de Microcalcificações e Componentes do Tecido Mamário}

Tese apresentada à Faculdade de Filosofia, Ciências e Letras de Ribeirão Preto da Universidade de São Paulo, como parte das exigências para a obtenção do título de Doutor em Ciências.

Área de Concentração:

Física aplicada à Medicina e Biologia.

Orientador:

Martin Eduardo Poletti.

Versão corrigida

Versão original disponível na FFCLRP - USP

Ribeirão Preto - SP

2021 
Autorizo a reprodução e divulgação total ou parcial deste trabalho, por qualquer meio convencional ou eletrônico, para fins de estudo e pesquisa, desde que citada a fonte.

\section{FICHA CATALOGRÁFICA}

Godeli Neto, Julio

Mamografia Digital Por Dupla Energia Usando Simulação Monte Carlo: Otimização da Quantificação da Morfologia de Microcalcificações e Componentes do Tecido Mamário / Julio Godeli Neto; orientador Martin Eduardo Poletti. Ribeirão Preto - SP, 2021.

137 f.:il.

Tese (Doutorado - Programa de Pós-graduação em Física aplicada à Medicina e Biologia) - Faculdade de Filosofia, Ciências

e Letras de Ribeirão Preto da Universidade de São Paulo, 2021.

1. Mamografia Digital. 2. Dupla-Energia. 3. Otimização. 4. Simulação. 5. Quantificação. 
Nome: Godeli Neto, Julio

Título: Mamografia Digital Por Dupla Energia Usando Simulação Monte Carlo: Otimização da Quantificação da Morfologia de Microcalcificações e Componentes do Tecido Mamário

Tese apresentada à Faculdade de Filosofia, Ciências e Letras de Ribeirão Preto da Universidade de São Paulo, como parte das exigências para a obtenção do título de Doutor em Ciências.

Aprovado em:

\section{Banca Examinadora}

$\operatorname{Prof}(\mathrm{a}) \cdot \operatorname{Dr}(\mathrm{a})$.

Instituição:

Julgamento:

Assinatura:

$\operatorname{Prof}(\mathrm{a}) \cdot \operatorname{Dr}(\mathrm{a})$.

Instituição:

Julgamento:

Assinatura:

$\operatorname{Prof}(\mathrm{a}) . \operatorname{Dr}(\mathrm{a})$.

Instituição:

Julgamento:

Assinatura:

$\operatorname{Prof}(\mathrm{a}) \cdot \operatorname{Dr}(\mathrm{a})$.

Instituição:

Julgamento:

Assinatura:

$\operatorname{Prof}(\mathrm{a}) \cdot \operatorname{Dr}(\mathrm{a})$.

Instituição:

Julgamento:

Assinatura: 
Dedico este trabalho ao meu orientador, Dr. Martin Eduardo Poletti, por me guiar durante todos esses anos em minha pesquisa e por me incentivar a ser uma boa pessoa. 


\section{Agradecimentos}

À minha noiva, Tatiane, pelo suporte, carinho, companheirismo e a me incentivar lutar pelos meus interesses;

À minha mãe, Cleusa e minhas irmãs, Adriana e Laura, pelo apoio e conforto familiar que me proporcionaram ao longo dos anos;

Ao meu orientador, Prof.Dr.Martin Eduardo Poletti, pela orientação, paciência e dedicação que me proporcionou na realização deste trabalho;

Aos companheiros de laboratório, Leonardo, Daniel, Michel, Alessandra, Jéssica, Matheus, Beatriz, Flávia e Carolina, pelas experiências compartilhadas em todos os momentos;

Aos meus amigos, Renan, Rodrigo, Jéssica, Daniel, Euclydes e Mariana, pelo companheirismo que me proporcionaram desde a graduação;

Aos professores do curso de graduação em Física Médica, pelo departamento de Física da Faculdade de Filosofia, Ciências e Letras de Ribeirão Preto, que contribuíram significativamente para minha formação;

Ao STI e ao CIRP, pela autorização do uso de seus respectivos Clusters computacionais;

À CAPES pelo apoio financeiro; 


\section{Resumo}

\section{GODELI, J. Mamografia Digital Por Dupla Energia Usando Simulação}

Monte Carlo: Otimização da Quantificação da Morfologia de Microcalcificações e Componentes do Tecido Mamário. 2021. 137 f. Tese (Doutorado - Programa de Pós-graduação em Física aplicada à Medicina e Biologia) - Faculdade de Filosofia, Ciências e Letras de Ribeirão Preto, Universidade de São Paulo, Ribeirão Preto - SP, 2021.

A técnica de mamografia por dupla energia, que consiste na combinação de imagens mamográficas convencionais, pode ser utilizada para realçar, suprimir e quantificar características da mama, que indiquem precocemente a formação de carcinomas. O objetivo deste trabalho é o estudo e a otimização de imagens mamográficas geradas por dupla energia, para a verificação e quantificação de microcalcificações e frações de tecido glandular. As simulações computacionais das imagens produzidas por um mamógrafo digital completo, foram realizadas a partir do código PENELOPE (Penetrarion and Energy Loss of Positrons and Electrons) adaptado. O modelo geométrico implementado permite considerar diferentes espectros, modelos de mama e detectores de imagem. As adaptações do código PENELOPE para geração de imagens e cálculos de grandezas dosimétricas foram devidamente validadas. As imagens simuladas passaram por um pré-processamento para correção de espalhamento, o qual foi capaz de reduzir até $95 \%$ da contribuição dos feixes espalhados. O ruído propagado pelas imagens combinadas foi estudado e corrigido através da aplicação de um filtro mediana. Esta técnica foi capaz de reduzir até $60 \%$ do ruído propagado e a melhor ponderação de doses para a combinação das imagens foi encontrada. Após isso, as imagens mamográficas já processadas, foram devidamente combinadas e otimizadas. Para esta etapa, fantomas de calibração 
foram simulados. Com enfoque no realce de microcalcificações, foi encontrada uma região ótima de combinações de energias, centralizada em 28 e 44 kVp. Já para a acurácia de quantificação, foi encontrada uma região ótima centralizada em 28 e $75 \mathrm{kVp}$, com a qual, foi obtida uma exatidão superior à 93\%. Já para a fração glandular, praticamente todas as combinações de energias se mostraram ótimas, com uma acurácia superior à $90 \%$.

Palavras-chave: 1. Mamografia Digital. 2. Dupla-Energia. 3. Otimização. 4. Simulação. 5. Quantificação. 


\section{Abstract}

GODELI, J. Digital Dual-Energy Mammography Using Monte Carlo Simulation: Optimization of the Quantification of Microcalcifications Morphology and Breast Tissue Components. 2021. 137 f. Thesis (Ph.D. Postgraduate program in Physics applied to Medicine and Biology) - Faculty of Philosophy, Sciences and Literature, University of São Paulo, Ribeirão Preto - SP, 2021.

The dual-energy mammography imaging technique, which consists of the combination of two conventional mammographic images, can be used to enhance, suppress and quantify breast characteristics that indicate early cancer formation. This work aims to study and optimize the dual-energy images for the verification and quantification of microcalcifications and glandular tissue fractions. Computer simulations of images generated by a digital mammography system were performed using an adapted PENELOPE code (Penetrarion and Energy Loss of Positrons and Electrons). The implemented geometric model allows to consider different spectra, breast models and image detectors. The PENELOPE code adaptations for image generation and calculations of dosimetric quantities were properly validated. The simulated images underwent a pre-processing for scattering correction, which was able to reduce up to $95 \%$ of the scattered beam contribution. The noise propagated in the combined images was studied and corrected through the application of a median filter. This technique was able to reduce up to $60 \%$ of the propagated noise and an optimum dose weighting for the combination of images was found. After that, the mammographic images, already processed, were properly combined and optimized. For this step, calibration phantoms were simulated. Focusing on the microcalcifications enhancement, an optimal region of energy combinations 
was found, centered at 28 and $44 \mathrm{kVp}$. As for the quantification accuracy, an optimal region centered at 28 and $75 \mathrm{kVp}$ was found, in which, was obtained an accuracy higher than 93\%. For glandular fraction estimation, practically all energy combinations proved to be excellent, with an accuracy greater than $90 \%$.

Key-words: 1. Digital Mammography. 2. Dual-Energy. 3. Optimization. 4. Simulation. 5. Quantification. 


\section{Lista de Figuras}

2.1 (a) Diagrama simplificado da produção de raios X e (b) a intensidade relativa de um feixe, em função das energias dos raios $\mathrm{X}$ produzidos para um ânodo de tungstênio. Imagem retirada e adaptada de Zink [1]. 8

2.2 Esquematização clássica do efeito fotoelétrico. . . . . . . . . . . . 9

2.3 Esquematização clássica do efeito Rayleigh. . . . . . . . . . . . . . . . 10

2.4 Esquematização clássica do efeito Compton. . . . . . . . . . . . . . . 11

2.5 Esquematização do processo de formação da imagem radiográfica, considerando a radiação transmitida primária e espalhada. Imagem retirada e adaptada de Barnes [2] . . . . . . . . . . . . . . 15

2.6 Definição de $S C$ em imagens radiográficas, considerando: (a) somente as contribuições de partículas primárias, relacionadas com o tecido circundante e o objeto contrastante, $q_{1_{p}}$ e $q_{2_{p}}$, respectivamente; e (b) a contribuição das radiações primária e espalhada, $q_{1_{p+s}}$ e $q_{2_{p+s}}$. Imagem retirada e adaptada de Carlson et al. [3] . . . . . . . . . . . . . 16

2.7 Curvas características de um receptor tela-filme e de um receptor digital. Imagem retirada de Mahesh [4]. . . . . . . . . . . . . . 20

2.8 Eficiências quânticas dos detectores de aSe e CsI. Imagem retirada e adaptada de Dance et al. [5]. . . . . . . . . . . . . . . . . . 22

2.9 Imagens simuladas em (a) baixa energia (18 keV), (b)alta energia(47 keV) e (c) imagem subtraída. Figura retirada de Bliznakova et al [6].

2.10 Modelo geométrico de uma mama comprimida de espessura $\mathrm{T}$, com calcificações de tamanho $t_{c}$, e tecidos adiposo e glandular de espessuras $t_{a}$ e $t_{b}$, respectivamente, onde $t_{1}+t_{2}=t_{a}+t_{b}$. Imagem retirada e adaptada de Lemacks et al [7]. . . . . . . . . . . . . 29 
3.1 Modelo geométrico do ambiente de simulação de imagens . . . . . . . 32

3.2 Modelo geométrico da mama para a geração de imagens de microcalcificações (esquerda) e frações glandulares (direita). . . . . . 33

3.3 Modelo de simulação para a determinação da eficiência dos detectores de CsI e aSe. . . . . . . . . . . . . . . . . . . . . . . 38

3.4 Mapas de eficiência quântica dos detectores de (a) iodeto de césio e (b) selênio amorfo. . . . . . . . . . . . . . . . . . 38

3.5 Comparativos entre feixes de (a) $35 \mathrm{kVp}$ e (b) $50 \mathrm{kVp}$, simulados neste trabalho, com aqueles fornecidos pela literatura. . . . . . . . . . . . . 42

3.6 Esquematização para o processo de formação de imagens quantitativas. 43

3.7 Esquema de aplicação do método de pinhole para a estimativa do perfil de espalhamento da imagem.

3.8 Vistas superior (esquerda) e lateral (direita) do fantoma de calibração utilizado neste trabalho . . . . . . . . . . . . . . . . . . . . . 46

4.1 DgN em função da energia de feixes monoenergéticos. Comparação entre os valores obtidos neste trabalho e os adquiridos por Fedon et al. [8], utilizando uma mama com $4 \mathrm{~cm}$ de espessura e $50 \%$ de glandularidade. . . . . . . . . . . . . . . . . . . . . 54

4.2 Valores de DgN em função do HVL para feixes de (a) baixa energia e (b) alta energia, utilizando uma mama de $2 \mathrm{~cm}$ de espessura e $50 \%$ de glandularidade. . . . . . . . . . . . . . . . . . . . 55

4.3 Valores de FOM em função do $\mathrm{kVp}$, utilizando um fantoma CIRS simulando uma mama com $4 \mathrm{~cm}$ e $50 \%$ de glandularidade. . . . . . . 57

4.4 Análises de (a) contraste, (b) ruído e (c) CNR de calcificação com $600 \mu \mathrm{m}$ de espessura inseridas em uma mama com $2 \mathrm{~cm}$ de espessura e $50 \%$ de glandularidade. Imagens foram geradas para feixes de diferentes kVps, utilizando detectores de CsI e aSe. . . . . . . . . . 58

4.5 Sinal médio do detector em função da energia média do feixe de raios $\mathrm{X}$ utilizado. Foi considerada uma mama com $4 \mathrm{~cm}$ de espessura e $50 \%$ de glandularidade. . . . . . . . . . . . . . . . . . 60 
4.6 Imagens geradas para uma mama de $4 \mathrm{~cm}$ de espessura e glandularidade de 50\%, com presença de microcalcificações de diferentes morfologias, utilizando: (a) feixe de $49 \mathrm{kVp}$ e detector de aSe; (b) feixe de $60 \mathrm{kVp}$ e detector de aSe; (c) feixe de $49 \mathrm{kVp}$ e detector de CsI; (d) feixe de $60 \mathrm{kVp}$ e detector de CsI. . . . . . . . . . 61

4.7 Imagens geradas para uma mama de $4 \mathrm{~cm}$ de espessura, seccionada em camadas homogêneas de diferentes frações glandulares, utilizando: (a) feixe de $49 \mathrm{kVp}$ e detector de aSe; (b) feixe de $60 \mathrm{kVp}$ e detector de aSe; (c) feixe de $49 \mathrm{kVp}$ e detector de CsI; (d) feixe de $60 \mathrm{kVp}$ e detector de CsI. . . . . . . . . . . . . . . . . . . . . . .

4.8 Processo de correção de espalhamento de uma imagem gerada utilizando um detector de aSe e uma mama de $4 \mathrm{~cm}$ e $50 \%$ de glandularidade, irradiada por um feixe de $24 \mathrm{kVp}$. São mostradas na figura: (a) A imagem gerada apenas com a componente primária; (b) a imagem total com componentes primária e espalhada; (c) o perfil estimado da componente de espalhamento; (d) a imagem corrigida. 66

4.9 Valores de $\mathrm{D}_{l}$ (traços contínuos) e $\mathrm{D}_{h}$ (traços pontilhados), em função da espessura de microcalcificações. Foram utilizados diversos feixes, irradiando uma mama com $4 \mathrm{~cm}$ de espessura e $50 \%$ de glandularidade. Foram consideradas imagens geradas através de um fantoma CIRS, como referência para a construção das imagens. . . . . 67

4.10 Estudo da influência do tipo de sinal de referência nas características de $\mathrm{D}_{l}$ e $\mathrm{D}_{h}$. (a) Valores de $\mathrm{D}_{l}$, em função da espessura de microcalcificações, gerados com um feixe de $24 \mathrm{kVp}$ e diferentes tipos de sinais de referência. (b) Coeficiente angular das retas construídas em função da energia do feixe utilizado. Foram comparadas imagens de $\mathrm{D}_{l}$ e $\mathrm{D}_{h}$ geradas a partir da utilização das referências $I_{0}$, tecido mamário $100 \%$ adiposo e fantoma CIRS (100\% adiposo). . . . . . . . 68

4.11 Valores de (a) $\mathrm{Dc}_{l}$ e (b) $\mathrm{Dc}_{h}$ obtidos para um disco de alumínio de $800 \mu \mathrm{m}$, em função da energia média do feixe e da dose glandular absorvida. Foi considerado um fantoma de calibração com $6 \mathrm{~cm}$ de espessura. . . . . . . . . . . . . . . . . . 70 
4.12 Mapas de $\mathrm{Dc}_{l}$ construídos a partir de um fantoma de calibração com $6 \mathrm{~cm}$ de espessura, irradiado por um feixe de $34 \mathrm{kVp}$ (Mo/Mo). (a) Mapa construído a partir de uma dose glandular de 0,12 mGy e (b) o perfil dos valores de $\mathrm{Dc}_{l}$ dos discos de alumínio. (c) Mapa construído a partir de uma dose glandular de 1,2 mGy e (d) o perfil dos valores de $\mathrm{Dc}_{l}$ dos discos de alumínio. . . . . . . . . . . . . . . . . . 71

4.13 Comparação dos valores de $\mathrm{Dc}_{j}$, sendo $\mathrm{j}=\mathrm{l}, \mathrm{h}$, obtidos: (a) Em função da fração glandular, considerando tecidos reais e fantomas simuladores CIRS; (b) Em função da espessura de discos de $\mathrm{CaCO}_{3}$ e alumínio. Foi considerado um fantoma de calibração com $6 \mathrm{~cm}$ de espessura. . . . . . . . . . . . . . . . 72

4.14 Propagação de ruído em imagens quantitativas, determinados pelo $\mathrm{CV}$, geradas através da utilização dos métodos de (a) mínimos quadrados e (b) regressão linear com regularização Tikhonov. . . . . . 73

4.15 (a) Valores dos coeficientes de calibração para a combinação de 24 + $49 \mathrm{kVp}$ adquiridos através dos métodos de mínimos quadrados e regularização Tikhonov; Perfil do tamanho de microcalcificações em imagens geradas a partir do método regularizado, (b) sem e (c) com a aplicação de um offset. . . . . . . . . . . . . . . . 75

4.16 Variância calculadas dos grupos de microcalcificações, em função do percentual de $\mathrm{Dg}_{l}$ absorvido pelas mamas de (a) $2 \mathrm{~cm}$, (b) $4 \mathrm{~cm}$ e (c) $6 \mathrm{~cm} \ldots \ldots \ldots \ldots \ldots \ldots 77 \ldots \ldots \ldots \ldots$

4.17 Imagens geradas a partir da combinação de $24+49 \mathrm{kVp}$, (a) sem filtro e (b) com a aplicação do filtro mediana. (c) Valores de CNR das microcalcificações de imagem gerada em $24 \mathrm{kVp}$ e de imagens combinadas com $24+49 \mathrm{kVp}$, com e sem a aplicação do filtro mediana. 78

4.18 Valores de CNR, em função da espessura de microcalcificações, de imagens obtidas através dos algoritmos de realce por subtração e de geração de imagens quantitativas, em conjunto aos resultados apresentados por Bliznakova et al $[6]$. . . . . . . . . . . . . . . . . . 80 
4.19 Valores de CNR de microcalcificações com espessuras de $600 \mu \mathrm{m}$ em imagens geradas a partir das técnicas de (a) realce por subtração e (b) quantificação. . . . . . . . . . . . . . . . . . . . . . . . . . . 82

4.20 Mapas de CNR de microcalcificações de $600 \mu \mathrm{m}$, presentes em imagens quantitativas de mamas com espessuras de (a) 2, (b) 4 e (c) 6 cm. . . 84

4.21 Mapas de CNR de microcalcificações de $600 \mu \mathrm{m}$, de imagens quantitativas adquiridas a partir de escolhas de baixa energia gerados por feixes de (a) Mo/Mo e (b) Rh/Rh. . . . . . . . . . . . . . . 86

4.22 Mapas de precisão da quantificação de espessuras de microcalcificações de (a) $600 \mu \mathrm{m}$ e (b) $200 \mu \mathrm{m}$, presentes em uma mama com $4 \mathrm{~cm}$ de espessura. . . . 88

4.23 Mapas de exatidão da quantificação de espessuras de microcalcificações de $600 \mu \mathrm{m}$ presentes em mamas com (a) 2, (b) 4 e (c) $6 \mathrm{~cm}$ de espessura. . . . . . . . . . . . . . . . . . 89

4.24 Mapas de exatidão da quantificação de espessuras de microcalcificações de $600 \mu \mathrm{m}$, presentes em uma mama com 4 cm de espessura. Os mapas mostrados foram construídos a partir de imagens geradas por detectores de (a) aSe e (b) CsI. . . . . . . . . . . 92

4.25 Mapas de exatidão de um tecido com $50 \%$ de glandularidade, em mamas com espessuras de (a) 2, (b) 4 e (c) 6 cm. . . . . . . . . . 95

4.26 Mapas de exatidão de um tecido com $50 \%$ de glandularidade, em mamas com espessuras de (a) 2, (b) 4 e (c) 6 cm. . . . . . . . . 96

4.27 Mapas de coeficiente de variação $(C V)$, para imagens combinadas com a utilização das referências (a) CIRS e (b) $I_{0}$. Em conjunto, são mostradas imagens combinadas por feixes de $26+49 \mathrm{kVp}$, utilizando referências (c) CIRS e (d) $I_{0} \ldots \ldots \ldots$. . . . . . . . . . . . 98 


\section{Lista de Tabelas}

3.1 Composição elementar dos tecidos adiposo e mamário e pele. . . . . . 34

3.2 Composição elementar dos fantomas CIRS, simuladores de tecidos glandular, adiposo e mistura homogênea com $50 \%$ de glandularidade. $\quad 40$

3.3 Feixes polienergéticos utilizados para a aquisição das imagens. . . . . 41

3.4 Modelo padrão utilizado para as análises e otimizações da geração de imagens quantitativas. . . . . . . . . . . . . . . . 51

4.1 Comparação dos valores de CNR adquiridos neste trabalho com aqueles encontrados na literatura, para a visualização de discos de alumínio de $200 \mu \mathrm{m}$ de espessura presentes em diferentes condições de simulação. . . . . . . . . . . . . . . . . . . 56 56

4.2 Valores de RMSpe entre imagens geradas apenas com a contribuição da componente primária e imagens antes e depois da aplicação do algoritmo de correção de espalhamento. Foram comparadas imagens geradas para os detectores de aSe e CsI. . . . . . . . . . . . . 64

4.3 Escolhas ótimas de baixa e alta energias, propostas por este trabalho e pela literatura . . . . . . . . . . . . . . . . . . 93 


\section{Sumário}

Lista de Figuras $\quad$ x

$\begin{array}{ll}\text { Lista de Tabelas } & \text { XV }\end{array}$

1 Introdução 1

2 Fundamentos Teóricos $\quad 7$

2.1 Geração de Raios X . . . . . . . . . . . . . . . . . . . . 7

2.2 Interação da Radiação com a Matéria . . . . . . . . . . . . . . . 8

2.2 .1 Efeito Fotoelétrico _. . . . . . . . . . . . . . 9

2.2.2 Espalhamento Rayleigh . . . . . . . . . . . . . 10

2.2.3 Efeito Compton . . . . . . . . . . . . . . 11

2.2.4 Coeficiente de Atenuação Linear . . . . . . . . . . . . . . . . 12

2.2.5 Regra das Misturas . . . . . . . . . . . . . . . 13

2.2.6 Atenuação Exponencial . . . . . . . . . . . . . . . . . . . . 13

2.3 Imagem Radiográfica . . . . . . . . . . . . . . . . . . . . . . . . . . 14

2.3.1 Qualidade da Imagem Radiográfica . . . . . . . . . . . . . 14

2.3.1.1 Contraste Objeto . . . . . . . . . . . . . 15

2.3.1.2 Degradação do Contraste por Espalhamento . . . . . 18

2.3.2 Razão Contraste-Ruído . . . . . . . . . . . . . . . 18

2.4 Receptores de Imagem . . . . . . . . . . . . . . . . . . . . . . . . . . 19

2.4.1 Tipos dos detectores . . . . . . . . . . . . . . . 19

2.4 .2 Resposta dos detectores . . . . . . . . . . . . . . . 19

2.4.3 Eficiência quântica . . . . . . . . . . . . . . . 21

2.5 Grandezas Dosimétricas . . . . . . . . . . . . . . . . . 22

2.5.1 Kerma ...................... . . 23 
2.5 .2 Exposição . . . . . . . . . . . . . . . . . . . 23

2.5.3 Dose Absorvida . . . . . . . . . . . . . . . . . . . . . . 24

2.5.4 Dose Glandular Média . . . . . . . . . . . . . . . . . 25

2.6 Técnica de Radiografia por Dupla-Energia . . . . . . . . . . . . 26

2.6 .1 Decomposição de $\mu$. . . . . . . . . . . . . . . . . 26

2.6 .2 Realce por subtração . . . . . . . . . . . . . . . . . . . 27

2.6.3 Geração de Imagens Quantitativas . . . . . . . . . . . . . 28

3 Materiais e Metodologia $\quad 32$

3.1 Construção do Modelo Geométrico . . . . . . . . . . . . . . . 32

3.1.1 Ambiente de aquisição (simulação) de imagens . . . . . . . . . 32

3.1.2 Modelos geométricos da mama . . . . . . . . . . . . . . . 33

3.2 Adaptação e Validação do Código PENELOPE . . . . . . . . . . . . 34

3.2 .1 Grandezas dosimétricas . . . . . . . . . . . . . . . . . . . . 35

3.2.2 Aplicação de detectores de CsI e aSe para a simulação de imagens 37

3.3 Simulação de Imagens Mamográficas . . . . . . . . . . . . . . . 40

3.3.1 Determinação da dose glandular média . . . . . . . . . . . . 40

3.3.2 Escolha dos feixes de raios X . . . . . . . . . . . . . . . . 41

3.3 .3 Avaliação das imagens simuladas . . . . . . . . . . . . . . 42

3.4 Formação de Imagens Quantitativas . . . . . . . . . . . . . . . . . 43

3.4.1 Pré-Processamento: Algoritmo de Correção de Espalhamento . 43

3.4.2 Sinais de referência e mapas de $\mathrm{D}_{l}$ e $\mathrm{D}_{h} \ldots \ldots \ldots \ldots . \ldots 46$

3.4.3 Fantoma de calibração e mapas de $\mathrm{DC}_{l}$ e $\mathrm{DC}_{h} \ldots \ldots \ldots .46$

3.4.4 Determinação dos coeficientes de calibração . . . . . . . . . 47

3.4.5 Análise da Propagação de Ruído e Sua Correção . . . . . . . . 49

3.5 Análises e Critérios de Otimização das Imagens Combinadas . . . . . 50

3.5.1 Identificação e estimativa da morfologia de microcalcificações . 50

3.5.1.1 Comparação de técnicas de combinação por dupla

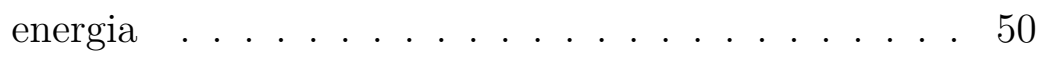

3.5.1.2 Análise e otimização do realce de microcalcificações em imagens quantitativas . . . . . . . . . . . 5 50 
3.5.1.3 Otimização da estimativa da morfologia de microcalcificações . . . . . . . . . . . . . . . 51

3.5.2 Estimativa e otimização da quantificação de frações glandulares 52

4 Resultados

4.1 Validações das Modificações no Código PENELOPE e da Construção do Modelo Geométrico . . . . . . . . . . . . . . . . . . . . 53

4.1.1 Grandezas dosimétricas . . . . . . . . . . . . . . . . 53

4.1 .2 Geração de imagens . . . . . . . . . . . . . . . . 56

4.2 Análise das Imagens Simuladas . . . . . . . . . . . . . . . . . 57

4.2.1 Estudos da influência dos tipos de detectores . . . . . . . . . . 57

4.2.2 Verificação qualitativa das imagens geradas . . . . . . . . . . . 61

4.3 Formação de Imagens Quantitativas . . . . . . . . . . . . . . . . . . . 64

4.3.1 Pré-Processamento: Algoritmo de Correção de Espalhamento . 64

4.3 .2 Mapas de $\mathrm{D}_{l}$ e $\mathrm{D}_{h} \ldots \ldots \ldots \ldots$. . . . . . . . . . 65

4.3.3 Mapas de $\mathrm{Dc}_{l} \mathrm{e} \mathrm{Dc}_{h} \quad \ldots \ldots \ldots$. . . . . . . . . . 69

4.3.4 Aplicação do Algoritmo de Combinação de Imagens . . . . . . 73

4.3.5 Análise da Propagação de Ruídos Aplicação do Algoritmo de Pós-Processamento . . . . . . . . . . . . . 76

4.3.5.1 Propagação de ruído em imagens combinadas . . . . 76

4.3.5.2 Correção de Ruído . . . . . . . . . . . . . . 77

4.4 Avaliação e Otimização de Imagens Quantitativas em Microcalcificações 79

4.4.1 Realce e identificação de microcalcificações . . . . . . . . . . . 79

4.4.1.1 Comparação entre as metodologias de combinação de imagens . . . . . . . . . . . . . . . . . . 80

4.4.1.2 Otimização da visualização de microcalcificações . 83

4.4 .2 Quantificação de microcalcificações . . . . . . . . . . . 87

4.4.2.1 Precisão da quantificação de microcalcificações .. 88

4.4.2.2 Exatidão da quantificação de microcalcificações . . . 88

4.4 .3 Considerações gerais . . . . . . . . . . . . . . 93

4.5 Avaliação e Otimização de Imagens Quantitativas em Frações

Glandulares . . . . . . . . . . . . . . . . . . . . . 994 
5 Conclusões e Perspectivas Futuras $\quad 99$

5.1 Conclusões . . . . . . . . . . . . . . . . . . . . . . . . . 99

5.1.1 Sobre a adaptação e utilização do código PENELOPE para a geração de imagens. . . . . . . . . . . . . . . . . . . . . . . . 99

5.1.2 Sobre a aplicação do algoritmo de pré-processamento . . . . . 99

5.1.3 Sobre o algoritmo de combinação . . . . . . . . . . . . . . . 100

5.1.4 Sobre a análise e correção da propagação de ruído . . . . . . 100

5.1.5 Sobre a otimização das imagens . . . . . . . . . . . . . . . 100

5.1.5.1 Quantificação de microcalcificações . . . . . . . . . 100

5.1.5.2 Quantificação de frações glandulares . . . . . . . . 101

5.1.5.3 Considerações gerais sobre otimização . . . . . . . . 101

5.2 Perspectivas Futuras . . . . . . . . . . . . . . . . . . . 101

Referências Bibliográficas

103 


\section{Capítulo 1}

\section{Introdução}

O câncer de mama é o tipo de carcinoma mais diagnosticado em mulheres, sendo estimado que no triênio de 2020 a 2022, aproximadamente 66 mil novas incidências sejam registradas, representando $29,7 \%$ do total de casos entre as mulheres [9]. Em 2017 foram registradas 16.724 mortes devido ao câncer de mama [9]. A alta mortalidade desta doença no Brasil é devido a seu diagnóstico frequentemente tardio [10].

A mamografia é uma das técnicas mais indicadas para o diagnóstico e a prevenção de câncer [9]. De acordo com as Diretrizes para a Detecção Precoce do Câncer de Mama no Brasil [11], a mamografia de rastreamento é recomendada para mulheres com idades entre 50 e 69 anos, de forma bienal. Este exame de rotina se mostrou eficaz em auxiliar na redução da mortalidade por câncer de mama, ao se investigar características na mama que indiquem precocemente a tendência da formação de carcinomas, como a morfologia de microcalcificações e o volume glandular mamário.

Ao estudar a espessura, formato, número e composição de microcalcificações, pode se ter um indício precoce de câncer de mama [12, 13]. Baker et al. [13] mostraram que há uma relação direta entre a taxa de formação e crescimento de microcalcificações e a formação de carcinomas.

Pesquisas mostram também que há relação entre o aumento de volume glandular mamário e a incidência de câncer de mama $[14,15,16]$. De acordo com Kuchiki et al. [17], um estudo feito com mulheres, tanto em pós-menopausa, como pré-menopausa, foi notada uma maior incidência de câncer de mama nas paciente 
que possuíam um volume maior de tecido glandular. O estudo também mostrou que mulheres que possuem um histórico familiar de câncer, possuem um volume glandular maior, sendo este, um indicativo de que o fator genético que determina a densidade glandular, também determine o risco de câncer.

Uma limitação encontrada na mamografia convencional é sua baixa capacidade de detecção de microcalcificações, devido ao ruído estrutural mamário, proveniente do sinal observado nas imagens, originados de vasos sanguíneos e tecidos mamários, os quais sobrepõe os sinais de microcalcificações [18]. Além disso, o método de aquisição de imagens convencionais possui capacidade limitada de quantificar tecidos glandulares [19]. Uma alternativa para se contornar estes problemas é a aplicação da técnica de dupla energia, que consiste na aquisição e combinação de duas imagens geradas com diferentes energias, a fim de destacar a característica de interesse [7, 20].

A técnica de dupla energia tem como precursores os trabalhos realizados por Jacobson [21] e Roos \& Sköldborn [22]. Os autores propuseram métodos de combinar imagens adquiridas por duas exposições distintas, a fim de destacar vasos sanguíneos e componentes minerais do tecido ósseo, respectivamente. Alvarez e Macovski [23] estenderam a combinação de duas imagens para a prática de tomografia computadorizada, utilizando um método de decompor o coeficiente de atenuação de um tecido, em duas funções dependentes da energia do feixe utilizado e de materiais conhecidos. Com base nesta proposta, Lehmann et al. [24], determinaram que o coeficiente de atenuação linear de um material qualquer pode ser decomposto em dois coeficientes de atenuação de dois materiais base (como por exemplo, lucite e alumínio), multiplicados por suas respectivas espessuras. Com isso, a partir de aquisições de imagens em energias diferentes, é possível determinar, aproximadamente, o coeficiente de atenuação de qualquer material, possibilitando a obtenção de imagens radiográficas que destaquem algum determinado tecido de interesse. Johns et al. [20, 25] propuseram então, a utilização desta técnica em mamografia, visando aprimorar a detecção de microcalcificações presentes na mama.

Estudos posteriores propuseram um método de subtração ponderada de imagens mamográficas, o qual permite realçar um tecido de interesse ao se suprimir o sinal de seu entorno $[26,27]$. Estudos mostraram que a técnica de mamografia 
por subtração em dupla-energia pode ser capaz de detectar microcalcificações com maior eficiência, se comparada à aquisições convencionais [6, 28, 29].

Estudos realizados na década de 1990 com diferentes detectores mostraram que a técnica de dupla energia não apresentava resultados satisfatórios na identificação de microcalcificações e outros tecidos [30, 31]. Porém, com o avanço da tecnologia aplicada em novos detectores e do processamento de imagens, os estudos foram retomados [7].

Pesquisas recentes aplicam a técnica de dupla energia a fim de se construir imagens quantitativas, fornecendo estimativas de espessura de microcalcificações e densidade glandular mamária [7, 18, 32, 33, 34]. Lemacks et al. [7] propuseram um método de quantificação simples, consistindo em estimar as espessuras de microcalcificações e de tecido glandular, através de equações analíticas. Porém, os autores consideraram apenas feixes monoenergéticos, o que impede sua aplicação clínica. Kappadath et al. [18] e Dutote \& Molloi [19, 32, 35], generalizaram a técnica de quantificação para a utilização de feixes polienergeticos, fornecendo a capacidade de se aplicar a técnica experimentalmente. Porém, estes métodos exigem a aplicação da uma calibração para sua execução.

A simulação computacional tem sido aplicada em pesquisas recentes para investigação experimental de casos práticos. Desta forma, proporcionando resultados promissores para o entendimento do surgimento e prevenção de câncer, assim como os estudos de outras características da mama, como lesões, calcificações e densidade de tecidos [36, 37, 38, 39]. A aplicação de simulação Monte Carlo é vantajosa pois além de ser capaz de reproduzir um ambiente clínico de forma precisa, também permite que diversas condições de estudos, as quais não são alcançadas facilmente através de técnicas experimentais, sejam aplicadas. Além disso, simulações computacionais são uma ótima ferramenta de validação para futuras aplicações experimentais [6].

Estudos mais recentes aplicam a técnica de dupla energia por meio de simulação computacional, como um meio de se estudar e otimizar a geração de imagens que quantifiquem a morfologia de calcificações e a fração glandular mamária $[33,40]$. Outros estudos $[41,42,43]$ estendem a aplicação da técnica de dupla energia, destacando três componentes do tecido mamário (proteína, lipídio e água). 
Com isso, é possível caracterizar massas tumorais de forma mais precisa, podendo evitar biopsias desnecessárias [42, 43]. Apesar de existir uma vasta gama de estudos computacionais envolvendo mamografia por dupla energia, não há registros de estudos envolvendo a otimização de geração de imagens quantitativas, os quais, poderiam ser cruciais para uma futura aplicação clínica da técnica.

No geral, trabalhos que envolvem simulação são realizados através de códigos construídos pelos próprios autores $[6,29,31,36,44,45,46,47,48]$. No entanto, estes códigos podem conter limitações, como por exemplo, a desconsideração do transporte de partículas carregadas, gerando uma possível inacurácia nos dados coletados . Códigos já estabelecidos e validados, como GEANT4 [49] e PENELOPE [50], podem ser adaptados e utilizados para a simulação de sistemas radiográficos, possibilitando uma alta precisão e confiabilidade nos dados coletados. O código de simulação Monte-Carlo PENELOPE (Penetration and Energy Loss of Positrons and Electrons) [50] foi desenvolvido para simular as interações das radiações ionizantes (elétrons, pósitrons e raios X) com a matéria, usando uma base de dados atualizada e abrangendo energias entre 50 e $10^{9} \mathrm{eV}$, podendo assim, ser facilmente aplicado na área de mamografia.

Neste trabalho, o código PENELOPE previamente adaptado e validado [40], foi utilizado para simular imagens mamográficas, a fim de se aplicar a técnica de dupla energia na geração de imagens quantitativas, para a verificação da morfologia de microcalcificações e da fração glandular, visando o estudo da otimização desta técnica para tal fim.

Este trabalho tem como objetivos específicos:

1. Revisar, atualizar e revalidar um código PENELOPE previamente adaptado para geração de imagens mamográficas;

2. Estudar características das imagens geradas, de acordo com os diferentes parâmetros de simulação considerados;

3. Implementar um algoritmo de pré-processamento nas imagens geradas, visando a correção de espalhamento, tornando-as aptas para serem utilizadas na combinação por dupla energia; 
4. Estudar e otimizar imagens de calibração utilizadas no processo de combinação por dupla energia;

5. Aplicar o algoritmo de combinação de imagens

6. Otimizar a técnica de combinação de imagens através do estudo das características dos ruídos propagados no processo de combinação e aplicação do algoritmo de pós-processamento para a eliminação de ruído;

7. Avaliar as imagens quantitativas com base nas combinações de qualidades de feixes que otimizem tanto o realce, quanto as estimativas de morfologia de microcalcificações e frações glandulares.

Esta tese é separada em cinco capítulos (sendo a introdução, o capitulo 1). No capítulo 2 são apresentados os embasamentos teóricos para os estudos realizados neste trabalho. Primeiramente são apresentados os princípios físicos e os métodos envolvidos na geração de raios X em ambiente clínico. Após isso, são mostrados os fundamentos que envolvem a interação da radiação com a matéria, levando em consideração o intervalo de energia da radiação utilizada em técnicas convencionais (mamografia digital) e não-convencionais (dupla energia). Assim, são apresentados os efeitos fotoelétrico e os espalhamentos coerente e incoerente. Após isso, o coeficiente de atenuação linear da radiação em um meio material (homogêneo ou mistura) foi definido. Com isso, foram apresentados conceitos de formação de imagens de radiodiagnóstico, como a definição de contraste e ruído, além de serem discutidas as características de detectores de imagens utilizados em mamografia. Foram apresentados também grandezas dosimétricas pertinentes para este projeto, como as definições de dose e kerma. Por fim, foram mostrados os princípios da formação da imagem pelas técnicas de dupla energia, destacando a técnica combinação para geração de imagens quantitativas, a qual este trabalho se sustenta.

O capitulo 3 apresenta a metodologia utilizada neste projeto para a aquisição de dados. Primeiramente, foi realizada a descrição detalhada do modelo geométrico construido para a aquisição das imagens. A seguir, foram descritas as adaptações do realizadas no código PENELOPE para a aquisição das imagens para diferentes 
detectores e para cálculos de grandezas dosimétricas. A próxima etapa foi definir os algoritmos de pré-processamento, combinação e pós-processamento utilizados nas imagens simuladas. Por fim, foram definidos os passos tomados para a escolha das imagens otimizadas.

No capítulo 4 são apresentados os resultados obtidos. Primeiramente, foi mostrada a validação do código adaptado. Em seguida, foi feito um estudo das imagens simuladas. As imagens pré-processadas são mostradas em seguida e comparadas com os resultados sem processamento, a fim de se validar seu uso. A combinação das imagens foi mostrada, seguida da aplicação do algoritmo de pós-processamento. O método de combinação é discutido e as imagens otimizadas são escolhidas com base em determinados parâmetros.

O capitulo 5 destaca as conclusões alcançadas na discussão dos resultados obtidos e as perspectivas de futuros trabalhos que podem ser realizados a partir deste projeto. 


\section{Capítulo 2}

\section{Fundamentos Teóricos}

\subsection{Geração de Raios X}

Os raios X são produzidos a partir da aceleração de um elétron em direção a um alvo metálico. Em um ambiente clínico, um tubo de raios X é utilizado de forma que uma nuvem eletrônica seja gerada em um cátodo, através do efeito termoiônico $[1,51]$. Com a aplicação de uma diferença de potêncial, estes elétrons são acelerados em direção a um ânodo, o qual, é comumente composto por tungstênio, molibdênio ou ródio $[52,53]$. Parte da energia dos elétrons é perdida em forma de calor e outra, na produção de raios X. A figura 2.1 ilustra este processo, além de exemplificar o perfil energético de um feixe de raios $\mathrm{X}$ produzido.

Como observado na figura 2.1(b), o espectro apresenta dois perfis distintos. O primeiro, de característica contínua, é chamado de radiação Bremsstrahlung, ou radiação de freamento. Este tipo de radiação ocorre com a interação coulombiana inelástica entre o elétron e o núcleo do átomo em seu caminho. Esta interação faz com que o elétron perca energia cinética, a qual, é emitida em forma de raio X. A probabilidade de produção de radiação bremsstrahlung em um material absorvedor é proporcional ao quadrado de seu número atômico [51].

O segundo perfil visto na figura 2.1(b), de natureza discreta, é classificado como radiação característica. Este tipo de radiação é produzido quando parte dos fótons gerados pelo processo descrito anteriormente, são reabsorvidos pelos átomos ao redor, ejetando um elétron de camadas de valência mais internas (os tipos de interação da radiação com a matéria são descritos na seção 2.2). A vacância criada pelo elétron ejetado é preenchida outro de uma camada mais externa, gerando um 


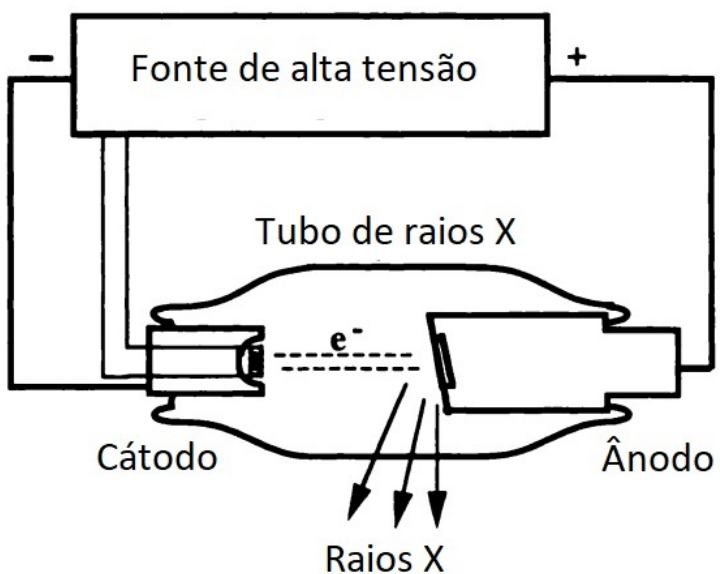

(a)

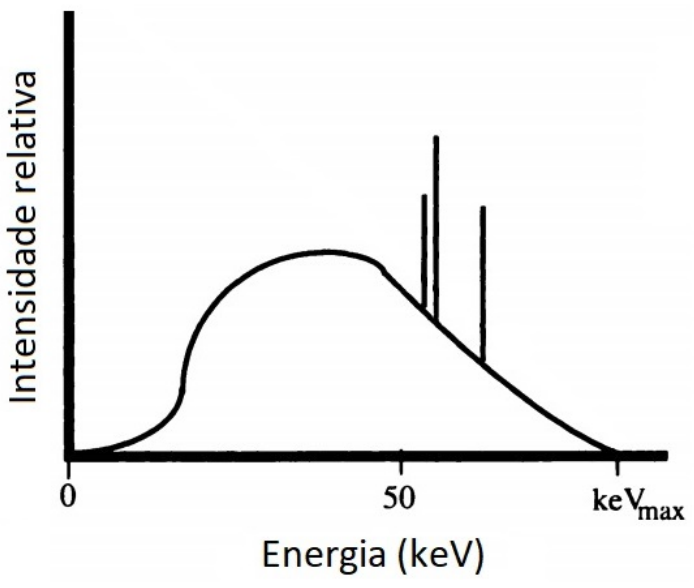

(b)

Figura 2.1: (a) Diagrama simplificado da produção de raios $X$ e (b) a intensidade relativa de um feixe, em função das energias dos raios $X$ produzidos para um ânodo de tungstênio. Imagem retirada e adaptada de Zink [1].

raio X característico com energia igual a diferença entre as energias de ligação das camadas de valência [54]. Os feixes característicos também são gerados quando um elétron originado no filamento (cátodo) atinge um elétron orbital do material alvo (ânodo), o qual é ejetado. Assim como explicado anteriormente, a vacância deixada por este elétron é preenchido por outro de uma camada mais externa, gerando um raio X característico [55].

\subsection{Interação da Radiação com a Matéria}

As interações da radiação eletromagnética ionizante são classificadas em quatro tipos: Efeito fotoelétrico, espalhamento Rayleigh, efeito Compton e produção de pares. Este ultimo é irrelevante para este trabalho, por ocorrer apenas para energias com fótons acima de $1,02 \mathrm{MeV}$ [56], fora da faixa de energias utilizadas em técnicas de mamografia (entre 8 e $49 \mathrm{keV}$ ) [53, 57, 58]. Os três tipos de interações considerados são descritos a seguir. 


\subsubsection{Efeito Fotoelétrico}

O efeito fotoelétrico consiste na ejeção de um elétron orbital, devido a transferência total da energia de um fóton para o átomo. A energia de ejeção $\left(E_{\tau}\right)$ é dada por $E_{\tau}=h \nu-E_{b}$, onde $E_{b}$ é a energia de ligação do elétron e sua camada orbital e $h \nu$ a energia do fóton incidente. A figura 2.2 ilustra este efeito.

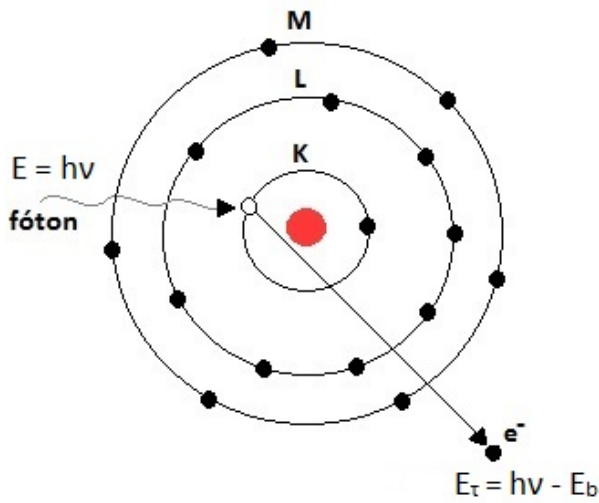

Figura 2.2: Esquematização clássica do efeito fotoelétrico.

Para energias baixas $(h \nu<100 \mathrm{keV})$, a seção de choque atômica para o efeito fotoelétrico $(\tau)$ é proporcional ao número atômico $Z$ do material alvo e à energia do fóton $h \nu$ de acordo com a relação a seguir [57]:

$$
\tau\left(\frac{\mathrm{cm}^{2}}{\text { átomo }}\right) \propto \frac{Z^{4}}{(h \nu)^{3}}
$$

De acordo com a equação 2.1, a probabilidade da ocorrência do efeito fotoelétrico é predominante em baixas energias e em materiais de altos números atômicos. Em tecidos moles do corpo humano $(Z \approx 7,4)$, o efeito fotoelétrico é a interação de maior contribuição na atenuação de fótons com energias de até $30 \mathrm{keV}$ $[59,60]$.

Após a interação, a vacância deixada pelo elétron ejetado é preenchida por outro de uma camada mais externa, emitindo um raio $\mathrm{X}$ característico, como explicado anteriormente na sessão 2.1. Porém, há a possibilidade da energia liberada pelo elétron ocupante ser transferida para outro, ejetando-o em forma de elétron 
Auger. A energia de ejeção do elétron Auger $\left(E_{\text {Auger }}\right)$ é dado por $E_{\text {Auger }}=E_{\tau}-E_{b}$ $[51,59]$.

\subsubsection{Espalhamento Rayleigh}

O espalhamento Rayleigh, também chamado de espalhamento coerente ou elástico, ocorre quando um fóton interage com a matéria, mudando sua trajetória, porém, sua energia não é modificada. Descrevendo de forma mais detalhada, quando um fóton interage com a matéria, o campo elétrico associado a ele (onda eletromagnética, com comprimento $\lambda$ ) origina uma vibração nos elétrons desta matéria. A aceleração destas partículas carregadas gera um fóton (onda eletromagnética) com o mesmo comprimento de onda $\lambda[61,62]$. O efeito é ilustrado na figura 2.3.

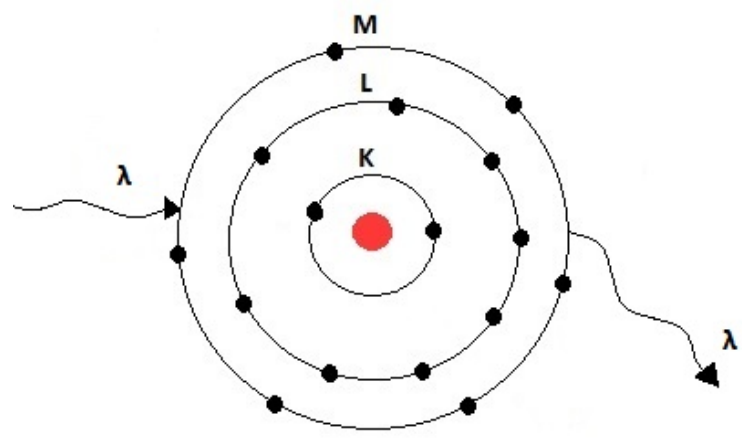

Figura 2.3: Esquematização clássica do efeito Rayleigh.

A distribuição angular dos fótons elasticamente espalhados em um material é dada pela seção de choque diferencial, $(\mathrm{d} \sigma / \mathrm{d} d \Omega)_{r}$ e descrita a seguir:

$$
\left(\frac{d \sigma}{d \Omega}\right)_{r}=F^{2}\left(x_{m}\right)\left(\frac{d \sigma}{d \Omega}\right)_{T h}
$$

sendo $\mathrm{F}\left(x_{m}\right)$ o fator de forma do meio, proposto por Hubbell et al. [63]. Este fator é dado em função de uma grandeza $\left(x_{m}\right)$, proporcional ao momento transferido, 
dada por: $x_{m}=\lambda^{-1} \operatorname{sen}(\theta / 2)$. Sendo $\lambda$, o comprimento da onda do fóton e $\theta$, o ângulo polar de espalhamento. O termo $(d \sigma / d \Omega)_{T h}$ é a seção de choque diferencial Thomson para o espalhamento de um elétron livre [61, 62].

Para energias baixas $(h \nu<100 \mathrm{keV})$, a seção de choque Rayleigh $\sigma_{r}$ possui uma proporcionalidade com o número atômico de um material puro e energia do fóton, dada por [57]:

$$
\sigma_{r}\left(\frac{c m^{2}}{\text { átomo }}\right) \propto \frac{Z^{2}}{(h \nu)^{2}}
$$

Essa proporcionalidade indica que este efeito tem maior ocorrência para feixes de baixas energias e materiais de maior número atômico, porém, ocorrem em menor frequência que o efeito fotoelétrico.

\subsubsection{Efeito Compton}

O efeito Compton, também conhecido como espalhamento incoerente ou inelástico, ocorre quando um fóton interage com a matéria, se desviando de sua trajetória original por um ângulo $\theta$ e transferindo parte de sua energia para os elétrons do meio, na forma de energia cinética. Este efeito, mostrado na figura 2.4, foi estudado inicialmente por Compton, que tratou a radiação incidente como pacotes de ondas quantizados com energia $h \nu[62]$.

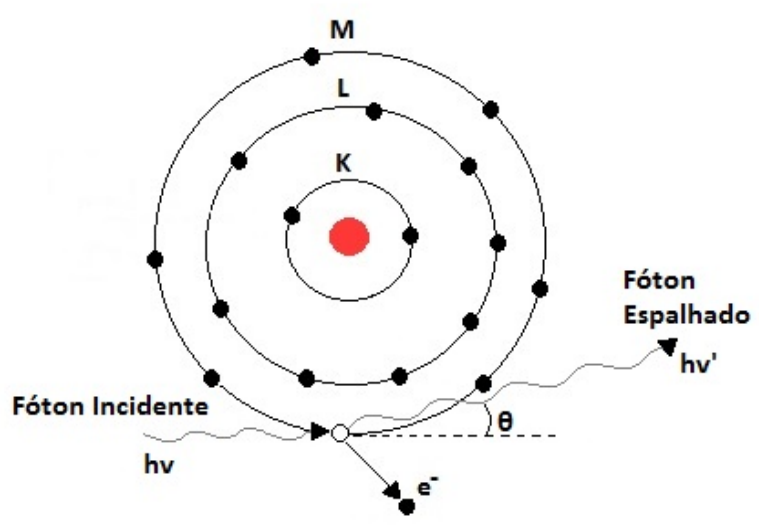

Figura 2.4: Esquematização clássica do efeito Compton. 
As energias do fóton $h \nu^{\prime}$ e do elétron $\left(E_{e}\right)$ espalhados são dadas pelas seguintes equações $[64,65]$ :

$$
\begin{aligned}
h \nu^{\prime} & =h \nu \cdot \frac{1}{1+\alpha(1-\cos \theta)} \\
E_{e} & =h \nu \cdot \frac{\alpha(1-\cos \theta)}{1+\alpha(1-\cos \theta)}
\end{aligned}
$$

onde $\alpha=h \nu / m_{0} c^{2}$, sendo $m_{0} c^{2}$ a energia de repouso do elétron $(0,511 \mathrm{MeV})$.

O espalhamento inelástico para um átomo (ou molécula) pode ser descrito a partir de uma aproximação análoga à utilizada para o espalhamento elástico, utilizando agora um fator $S\left(x_{m}\right)$, chamado de função de espalhamento inelástico [63], sendo que a seção de choque para este processo pode ser escrita como:

$$
\left(\frac{d \sigma}{d \Omega}\right)_{c}=S\left(x_{m}\right)\left(\frac{d \sigma}{d \Omega}\right)_{K N}
$$

onde $(\mathrm{d} \sigma / \mathrm{d} d \Omega)_{K N}$ descreve a seção de choque diferencial Klein-Nishina para o elétron livre [57]. Considerando um material puro, a seção de choque total para o espalhamento inelástico por átomo $\sigma_{c}$ é proporcional ao número atômico Z e aumenta suavemente com a energia dos fótons, se tornando a interação predominante em tecidos humanos para energias maiores que $30 \mathrm{keV}$ [59].

\subsubsection{Coeficiente de Atenuação Linear}

A seção de choque atômica total, $\sigma_{T}$, indica a probabilidade da ocorrência de uma interação qualquer entre um fóton e a matéria, sendo dada pela soma das seções dos processos individuais citados na seção anterior e descrita como:

$$
\sigma_{T}=\tau+\sigma_{r}+\sigma_{c}
$$

O coeficiente de atenuação linear $(\mu)$ está relacionado com a seção de choque total e com o número de átomos por unidade de volume $\left(n_{v}\right)$ através da seguinte equação $[51,57]$ :

$$
\mu=n_{v} \sigma_{T}
$$


O coeficiente de atenuação linear depende do estado físico ou fase do material. Assim, ao se dividir o coeficiente de atenuação linear pela densidade do material $(\rho)$, é definido o coeficiente de atenuação mássico $\mu / \rho$, o qual não depende do estado físico do material [51, 62].

O coeficiente de atenuação mássico é relacionado à seção de choque total por átomo $\sigma_{T}$ por:

$$
\frac{\mu}{\rho}=\sigma_{T}\left(\frac{N_{A}}{A}\right)
$$

sendo $N_{A}$ o número de Avogadro e $A$ o peso atômico do elemento que compõe o material.

\subsubsection{Regra das Misturas}

A regra das misturas permite obter o coeficiente de atenuação mássico de uma mistura com composição química conhecida a partir dos coeficientes de atenuação mássico $(\mu / \rho)_{i}$, tabelados para cada elemento que compõe o material. Para um composto homogêneo, o coeficiente de atenuação mássico pode ser estimado pela seguinte equação [57]:

$$
\left(\frac{\mu}{\rho}\right)_{\text {mistura }}=\sum_{i} w_{i}\left(\frac{\mu}{\rho}\right)_{i}
$$

sendo $w_{i}$, a fração de fração de massa do $i$-ésimo elemento constituinte com coeficiente de atenuação mássico $(\mu / \rho)_{i}$.

A regra das misturas fornece um meio de se obter valores dos coeficientes de atenuação para diversos compostos químicos e serve como uma boa aproximação para descrever a interação da radiação com estes compostos, além de verificar e validar resultados experimentais. Entretanto, a regra das misturas é uma aproximação que ignora qualquer efeito de mudança ma função de onda do átomo como resultado do arranjo molecular, químico e cristalino [66].

\subsubsection{Atenuação Exponencial}

Quando um feixe de radiação incide com uma fluência de fótons $\phi_{0}$ sobre um material de espessura $t$, parte interage, sendo absorvida ou espalhada e parte 
é transmitida, sem interagir. A fluência de fótons $\phi$ do feixe transmitido pode ser calculado de acordo com a seguinte equação:

$$
\phi=\phi_{0} \cdot e^{-\mu . t}
$$

A equação acima descreve a lei de atenuação exponencial, conhecida como Lei de Lambert-Beer [55, 62].

\subsection{Imagem Radiográfica}

Quando um feixe de raios X incide sobre qualquer material, interações podem ocorrer entre a radiação incidente e o objeto, removendo parte da energia do feixe de radiação por absorção ou espalhamento [55, 67]. A radiação transmitida sem interação (primária), carrega informações sobre o material na forma de uma distribuição espacial de intensidades, perpendicular ao eixo do feixe, responsável pelo contraste primário [2].

Parte do feixe de radiação transmitido pelo objeto, desta vez proveniente de fótons que interagem (principalmente por espalhamento), pode atingir o receptor da imagem [62]. Esta fração é classificada como radiação espalhada (ou secundária) e também atua na formação da imagem, adicionando um "background"quase constante ao longo da distribuição espacial dos fótons transmitidos. Este processo faz com que o receptor sofra uma maior exposição, degradando o contraste da imagem [2].

A figura 2.5 ilustra as contribuições dos feixes primário e espalhado na formação da imagem radiográfica

\subsubsection{Qualidade da Imagem Radiográfica}

O contraste em uma imagem radiográfica é o resultado de diferentes etapas que ocorrem durante a aquisição, processamento e visualização das imagens. Diferentes definições de contraste são empregadas para descrever cada etapa da formação da imagem, como descrito a seguir. 

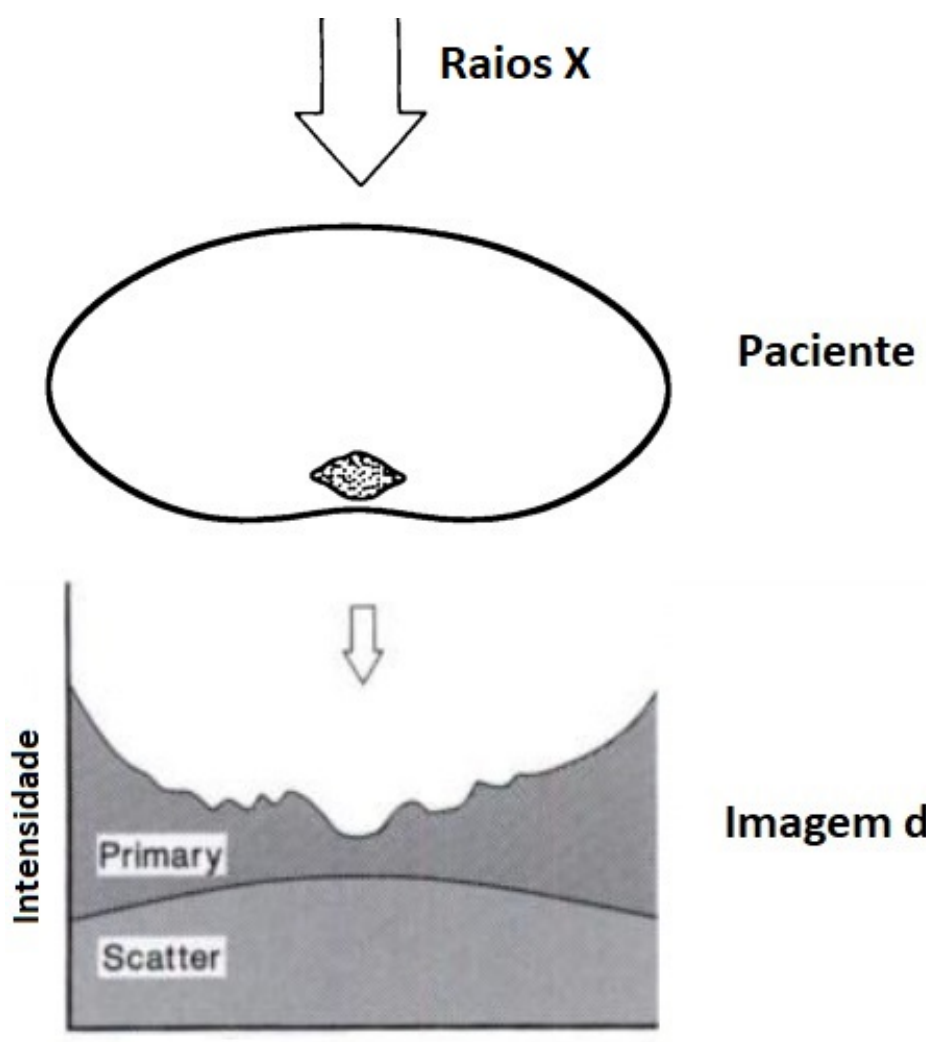

Imagem de raios $\mathrm{X}$

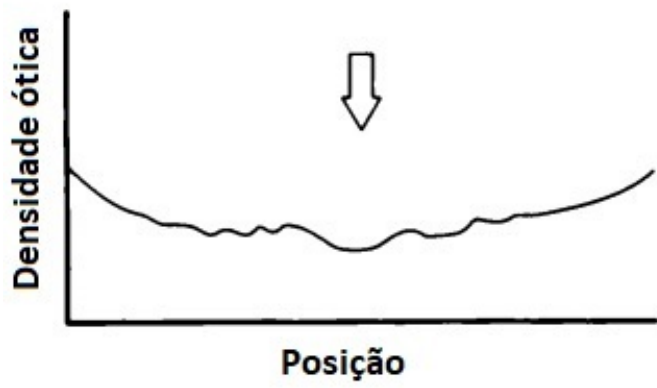

Receptor de imagem

Imagem radiográfica

Figura 2.5: Esquematização do processo de formação da imagem radiográfica, considerando a radiação transmitida primária e espalhada. Imagem retirada e adaptada de Barnes [2].

\subsubsection{Contraste Objeto}

O contraste objeto, do inglês subject contrast $(S C)$, reflete as diferenças entre as propriedades do objeto e do meio circundante, tais como densidade, composição química e coeficiente de atenuação linear, estando também, relacionado às suas dimensões e as características do espectro de raios X utilizado (material do ânodo, filtração, potencial do tubo e camada semi-redutora) e com a eficiência do receptor 
da imagem $[67,68]$.

A figura 2.6 ilustra a definição de $S C$, considerando um corpo com espessura $L$ e um objeto de espessura $t$.
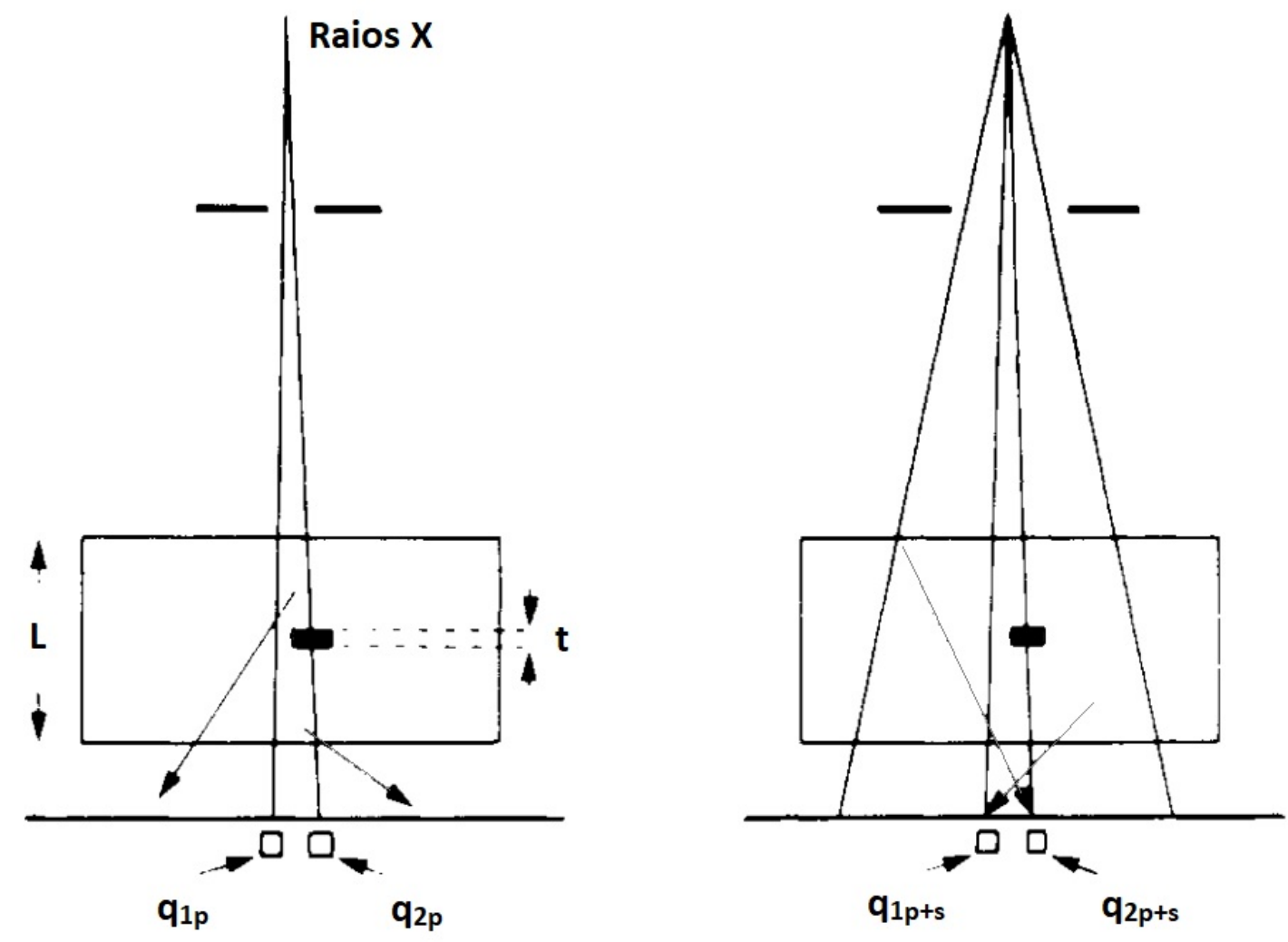

Figura 2.6: Definição de $S C$ em imagens radiográficas, considerando: (a) somente as contribuições de partículas primárias, relacionadas com o tecido circundante $e$ o objeto contrastante, $q_{1_{p}}$ e $q_{2_{p}}$, respectivamente; $e$ (b) a contribuição das radiações primária e espalhada, $q_{1_{p+s}}$ e $q_{2_{p+s}}$. Imagem retirada e adaptada de Carlson et al. [3].

A figura 2.6(a) representa um caso ideal, onde apenas os fótons primários são considerados ao atingirem o receptor, enquanto a figura 2.6(b) mostra um caso real, onde ambos os feixes primário e espalhado são considerados.

Considerando a figura 2.6, $S C$ pode ser definido a partir das seguintes relações: 


$$
\begin{gathered}
S C=\ln \left(\frac{q_{1}}{q_{2}}\right) \\
S C=2 \cdot \frac{\left|q_{1}-q_{2}\right|}{q_{1}+q_{2}}
\end{gathered}
$$

As grandezas $q_{1}$ e $q_{2}$ representam as fluências de energias absorvidas no receptor de imagem, relacionadas ao tecido circundante e ao objeto contrastante, respectivamente [3], incluindo as contribuições dos fótons primários e espalhados. Com isso, pode-se dizer que a eficiência do receptor da imagem influencia no contraste objeto.

Embora as equações 2.12 e 2.13 forneçam resultados similares, a primeira é comumente utilizada para descrever o contraste em um sistema tela-filme, enquanto a segunda é empregada em receptores digitais [3].

Caso os valores de $q_{1}$ e $q_{2}$ sejam próximos, a equação 2.13 pode ser aproximada por:

$$
S C=\frac{\left|q_{1}-q_{2}\right|}{q_{1}}
$$

Segundo Carlsson et al. [3], a grandeza física mais apropriada para $q$ é a fluência de energia absorvida no receptor de imagem, embora existam outras definições apresentadas na literatura $[2,51,69,70,71]$.

Para um caso ideal, mostrado na figura 2.6(a), considerando a grandeza $q$ como a fluência de fótons transmitidos e correlacionando as equações 2.14 e 2.11, o contraste objeto pode ser reescrito de acordo com as propriedades físicas do material como $[51,68]$ :

$$
S C=1-e^{\Delta \mu \cdot t}
$$

sendo $\Delta \mu$ a diferença entre os coeficientes de atenuação do tecido circundante e do objeto contrastante. Esta relacão mostra que o contraste objeto depende estritamente de $\Delta \mu$ e da espessura do objeto contrastante. Para pequenas dimensões, a equação 2.15 pode ser aproximada para $S C \approx \Delta \mu . t$, a qual mostra uma relação linear entre os valores de $S C$ e suas dependências [51]. 


\subsubsection{Degradação do Contraste por Espalhamento}

Em uma situação real, como mostrada na figura 2.6(b), a fluência de fótons chegando ao receptor de imagem contém contribuições de fótons primários $q_{p}$ e espalhados $q_{s}$. Considerando que $q_{2}=q$ e $q_{1}=q+\Delta q$, sendo $q=q_{p}$ e assumindo que a radiação é uniforme no receptor da imagem $\left(q_{1 s}=q_{2 s}=q_{s}\right)$, o contraste do objeto, apresentado na equação 2.12 pode ser reescrito como:

$$
S C=\ln \left(1+\frac{\Delta q_{p}}{q_{p}+q_{s}}\right)=\ln \left(1+C D F \cdot \frac{\Delta q_{p}}{q_{p}}\right)
$$

onde $C D F$ é o fator de degradação do contraste, sendo escrito como:

$$
C D F=\left(1+\frac{q_{s}}{q_{p}}\right)^{-1}
$$

Para valores muito pequenos, o $S C$ pode ser calculado considerando a contribuição dos fótons espalhados através da equação:

$$
S C=C D F \cdot \frac{\Delta q_{p}}{q_{p}}
$$

O mesmo resultado pode ser deduzido usando a equação 2.14.

Os valores de $q_{s} / q_{p}=S / P$ podem ser utilizados para quantificar o efeito do espalhamento no contraste do objeto em exames mamográficos [72, 73]. Este termo é chamado de razão espalhado-primário. A intensidade relativa da radiação espalhada varia com a espessura e composição da mama, tamanho de campo, atenuação e a energia da radiação incidente. Valores típicos na mamografia encontram-se no intervalo de 0,33 a $1,5[74]$.

\subsubsection{Razão Contraste-Ruído}

Após a obtenção da imagem por um sistema de detecção digital, ela é pré-processada automaticamente pelo software de aquisição através de uma série de etapas. Assim, uma vez que o contraste na imagem pode ser fortemente alterado, ele não é considerado o parâmetro de qualidade mais significativo para a descrição de uma imagem digital.

O parâmetro de qualidade de imagem mais utilizado em aquisições digitais é a razão contraste-ruído $(C N R)$, descrita na equação a seguir: 


$$
C N R=\frac{\left|q_{1}-q_{2}\right|}{\sqrt{\left(\sigma_{q_{1}}^{2}+\sigma_{q_{2}}^{2}\right) / 2}}
$$

sendo os termos $\sigma_{q_{1}}$ e $\sigma_{q_{2}}$, as incertezas do sinais mensurados do tecido circundante e do objeto contrastante, respectivamente.

A $C N R$ não é afetada por processamentos da imagem, sendo portanto, uma grandeza mais relevante para descrever a visualização de diferentes estruturas em uma imagem digital [51]. De forma análoga ao contraste, a $C N R$ depende das propriedades do objeto e da vizinhança, das características do feixe incidente e do receptor de imagem utilizado [51, 71].

\subsection{Receptores de Imagem}

\subsubsection{Tipos dos detectores}

Os detectores mais utilizados em mamografia são os tela-filme, CR e os detectores digitais. O primeiro consiste em uma tela de fósforo que absorve fração dos raios $\mathrm{X}$ incidentes. A energia absorvida é então convertida em luz, a qual é recebida por um filme fotográfico dentro do cassete do receptor. A imagem é produzida através de processamentos químicos para gerar um padrão de densidade ótica no filme $[4,75]$.

O segundo tipo de detector consiste em um componente capaz de converter o sinal de raios X em sinal eletrônico, o qual é digitalizado. Este processo pode ocorrer de modo indireto ou direto. No modo indireto, um material cintilante converte a energia de fótons absorvidos em luz, a qual é recebida por fotodiodos e convertido em sinal elétrico. Já no modo direto, uma material semicondutor converte a energia de raios $\mathrm{X}$ absorvidos em cargas elétricas [75, 76].

\subsubsection{Resposta dos detectores}

A curva característica do receptor de imagem descreve o seu comportamento quando exposto à radiação, representando a conversão da energia cedida ao receptor no sinal de saída da imagem visível. A figura 2.7 mostra o perfil das curvas 
características de um receptor tela-filme e de um receptor digital em um determinado intervalo de exposições relativas.

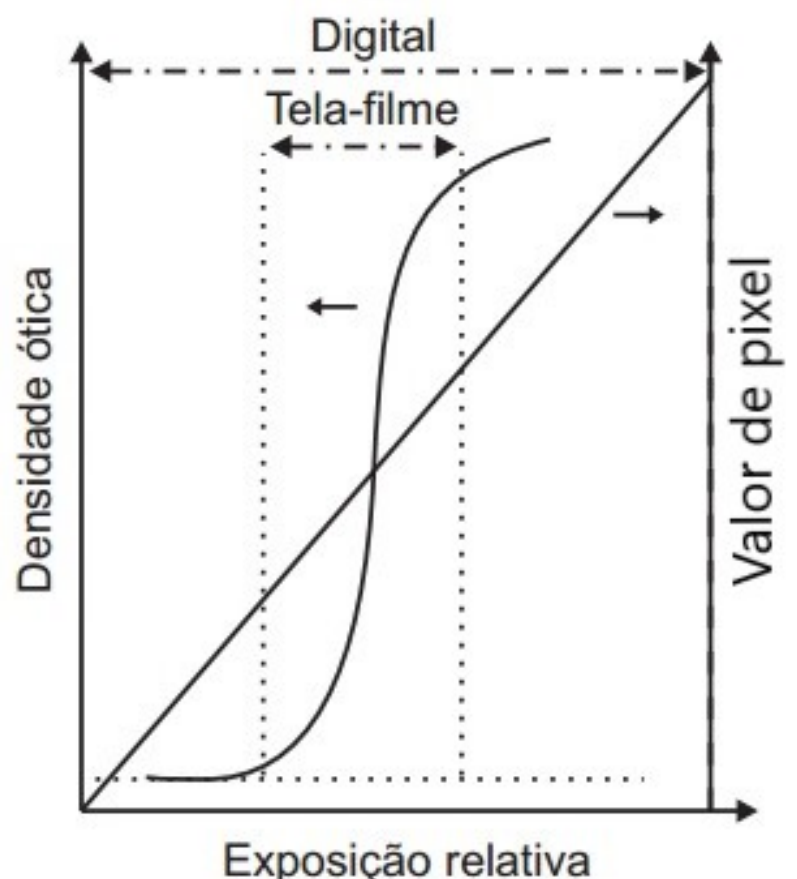

Figura 2.7: Curvas características de um receptor tela-filme e de um receptor digital. Imagem retirada de Mahesh [4].

A curva característica de um receptor tela-filme mostra uma relação não-linear entre a exposição relativa no detector e a densidade óptica no filme. Já a curva característica do receptor digital apresenta uma relação linear entre a exposição relativa e os valores de pixel.

As diferentes respostas à exposições relativas estão diretamente relacionadas à capacidade de diferenciação de características presentes na imagem, o que justifica as formas distintas de se calcular o contraste objeto para os receptores tela-filme e digital, mostrados nas equações 2.12 e 2.13 .

O contraste do receptor é representado pela inclinação da curva característica no intervalo de exposição considerado e descreve o fator de amplificação do contraste do objeto pela resposta do receptor da imagem [51, 67]. Para detectores não-lineares, tais como o sistema tela-filme, o contraste do receptor depende do nível de exposição. Este comportamento indica que uma exposição ótima é necessária para alcançar o máximo de contraste, devido à limitada extensão dinâmica destes receptores. Para 
detectores digitais, os quais apresentam respostas lineares, o contraste do receptor é constante, de forma que este possui uma maior extensão dinâmica $[4,51]$.

Em um sistema de imagens, flutuações nos sinais são esperadas em formas de ruídos. Estes ruídos podem ser provenientes de imperfeições estruturais do receptor, ou intrínsecas à própria formação da imagem, diretamente relacionada à exposição relativa. Este ultimo é conhecido como ruído quântico, o qual segue uma distribuição de Poisson. Em um caso ideal, esta é única fonte de ruído presente na formação de imagens, podendo ser reduzida com uma maior exposição relativa, ou pelo aumento da eficiência quântica do receptor de imagens [76].

\subsubsection{Eficiência quântica}

A capacidade de um detector em absorver a radiação e convertê-la em sinal é conhecida como eficiência quântica. Esta grandeza está relacionada às características do detector, como seu coeficiente de atenuação $\mu_{a t}$ e à sua espessura $\left(t_{d}\right)$, da seguinte forma $[51,55]$ :

$$
E f f=1-e^{\left(\mu \cdot \frac{t_{d}}{\cos (\theta)}\right)}
$$

sendo $\theta$, o ângulo de incidência do fóton sobre o detector.

A figura 2.8 mostra a eficiência quântica de dois detectores utilizados em sistemas de mamografia digital e considerados neste trabalho, selênio amorfo (aSe) e iodêto de césio (CsI).

Regiões onde há uma queda repentina de eficiência, demarcadas na figura 2.8, estão associadas às bandas de absorção da camada $\mathrm{K}$ dos materiais que compões os detectores. Para o aSe, a a energia de absorção da camada K é aproximadamente 12,67 keV, já para o CsI, esta energia está em 33,17 e 35,97 keV [77]. Detectores excitados nas energias equivalentes à suas bandas de absorção sofrem relaxação por fluorescência logo em seguida, emitindo raios X em todas as direções. Assim, grande parte da energia do fóton absorvido pelo detector é perdida, diminuindo assim, sua eficiência. 

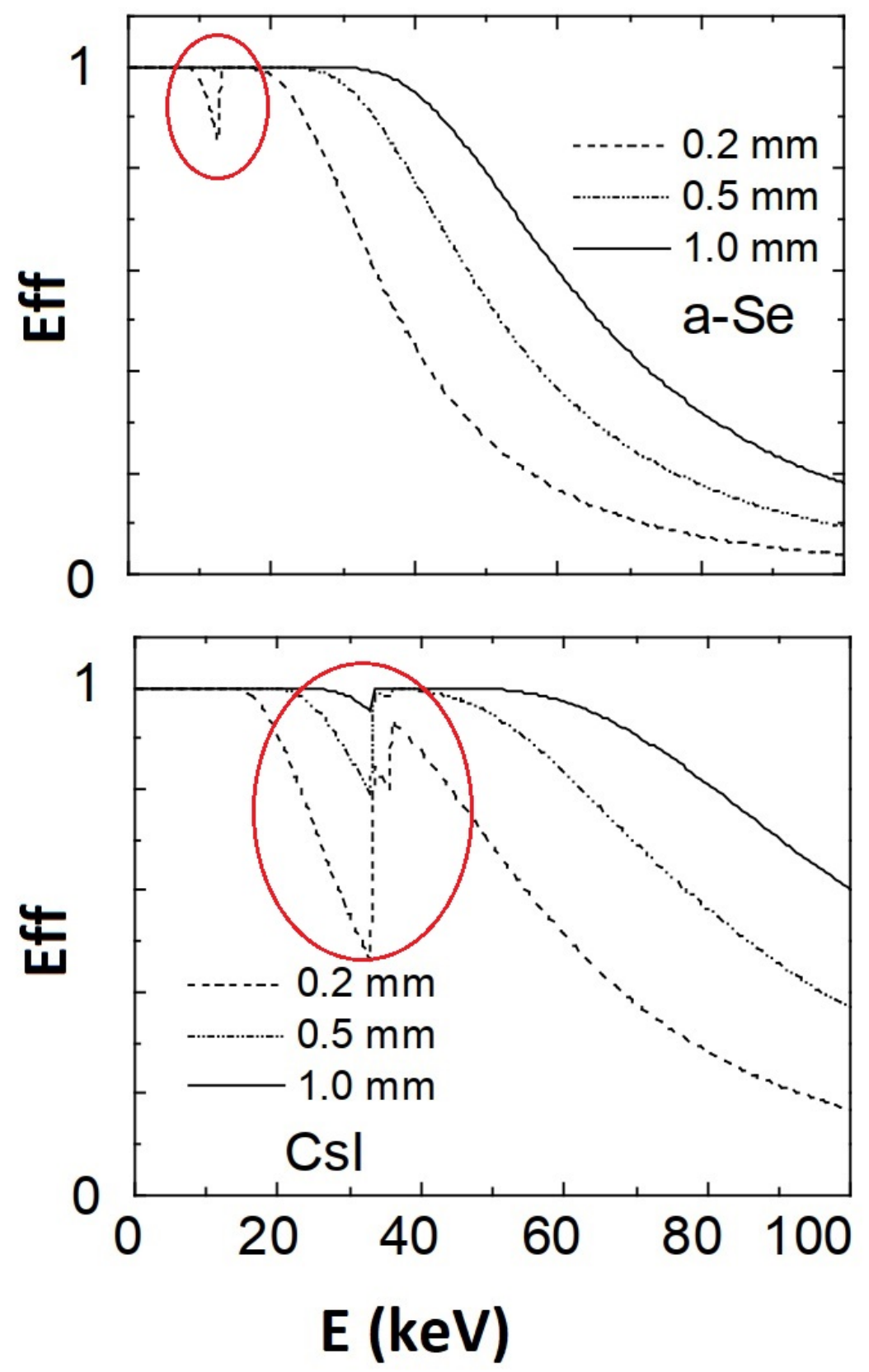

Figura 2.8: Eficiências quânticas dos detectores de aSe e CsI. Imagem retirada e adaptada de Dance et al. [5].

\subsection{Grandezas Dosimétricas}

Para descrever a interação da radiação com a matéria, torna-se útil definir grandezas não-estocásticas, chamadas de grandezas dosimétricas. Estas representam as medidas dos processos pelos quais a energia de uma partícula é convertida 
ou depositada na matéria. Nesta seção são descritas as principais grandezas dosimétricas de interesse em mamografia.

\subsubsection{Kerma}

A grandeza dosimetrica chamada Kerma (do inglês - kinect energy released per unit mass) é definida em termos do valor esperado da energia transferida de uma partícula não carregada para partículas carregadas, por unidade de massa, em um ponto de interesse, incluindo a energia de perdas radioativas e excluindo a energia transferida de uma partícula carregada para outra [57]. O kerma $(K)$ é definido como [57]:

$$
K=\frac{d \bar{E}_{t r}}{d m} \quad\left[\text { unidade }: \frac{J}{K g}=G y\right]
$$

onde $d \bar{E}_{t r}$ é o valor médio da energia transferida por partículas não-carregadas, para partículas carregadas, em um volume infinitesimal de massa $d m$.

Para um feixe polienergetico incidindo em um ponto $\mathrm{P}$, o kerma pode ser definido como mostrado na equação a seguir [51]:

$$
K=\int_{E=0}^{E_{\max }} E \times \Phi_{E}(E) \times\left(\frac{\mu_{t r}}{\rho}(E)\right) d E
$$

sendo $\mu_{t r} / \rho$, o coeficiente de transferência de energia e $\Phi_{E}(E)$ a fluência incidente entre $E$ e $E+d E$.

\subsubsection{Exposição}

A exposição $(X)$ descreve um campo de raios-X com base em sua capacidade de ionizar o ar. Esta grandeza é definida de acordo com a equação a seguir:

$$
X=\frac{d Q}{d m} \quad\left[\text { unidade }: \frac{C}{k g}\right]
$$

onde $d Q$ representa o valor, em coulomb, carga total de íons de mesmo sinal produzidos no ar quando todos os elétrons liberados por fótons em uma massa $d m$ de ar, são completamente freados neste meio [51, 57].

A exposição em um ponto $P$ pode ser relacionada ao kerma no ar neste mesmo ponto de acordo com a seguinte equação: 


$$
X=(1-g)\left(\frac{e}{\bar{W}}\right) K_{a r}
$$

sendo $g$ a fração da energia perdida pelo elétron na produção de raio-X, $\bar{W}$ é a energia média gasta em um gás para se produzir um par de íons e por fim, e é a carga do elétron. Para o ar, $\bar{W} / e=33,97 \mathrm{~J} / \mathrm{C}[57]$.

A equação 2.24 pode ser simplificada, considerando um meio de interação onde as perdas radiativas de energia dos elétrons são desprezíveis $(g \approx 0)$.

\subsubsection{Dose Absorvida}

A dose absorvida é uma grandeza dosimétrica de grande interesse na física radiológica e se relaciona com a energia absorvida no meio $\left(E_{a b}\right)$. Em um ponto $P$, a dose absorvida é definida como:

$$
D_{a b}=\frac{d \bar{E}_{a b}}{d m} \quad[\text { unidade }: G y]
$$

A dose absorvida está relacionada diretamente com as partículas carregadas secundárias geradas no meio irradiado [57]. Em um caso geral, não é possível descrever a dose com uma relação simples em função da fluência de energia. Somente na condição de equilibrio de partículas carregadas, a dose absorvida em um meio se aproxima do kerma colisional no ar e pode ser descrito a partir de parâmetros relacionados ao feixe incidente e ao meio irradiado [57].

Para um material de uma determinada espessura, a dose absorvida depende da profundidade do material analisado, uma vez que o feixe incidente é atenuado pelo meio de forma que alguns fótons podem ser absorvidos ou espalhados e as partículas carregadas podem transferir energia em diferentes profundidades [57]. Assim, a dose média absorvida no material é obtida ao se integrar toda sua espessura $L$.

$$
\overline{D_{a b}}=\frac{1}{L} \int_{z=0}^{z=L} D_{a b}(z) d z
$$

sendo $D_{a b}(z)$ a dose absorvida em uma camada na profundidade $z$. Este termo depende da fluência de fótons naquela camada, na condição de EPC. Lembrando que a fluência de fótons em qualquer profundidade é composta tanto de fótons primários como secundários (espalhados). 


\subsubsection{Dose Glandular Média}

A dose glandular média $\left(\bar{D}_{g}\right)$ é considerada a grandeza dosimétrica mais adequada para descrever o risco de carcinogênese associado ao exame mamográfico, uma vez que o tecido glandular é mais radiossensível [78, 79, 80]. Como a medida direta desta grandeza é impossível [80], diversos modelos para sua determinação foram propostos, buscando relacionar fatores de conversão com a medida do kerma (ou exposição) no ar na entrada da mama [44, 79, 80, 81].

O modelo mais simples para a determinação da $\bar{D}_{g}$ em mamografia relaciona esta grandeza com a medida do kerma de entrada na mama, utilizando apenas um parâmetro, conforme mostrado na equação a seguir [79, 81, 82, 83]:

$$
\bar{D}_{g}=K_{a r} \cdot \bar{D}_{g} N
$$

sendo $\bar{D}_{g} N$ um fator chamado de dose glandular normalizada, que representa a razão entre a dose média absorvida no tecido glandular e o kerma no ar de entrada na mama, sem retroespalhamento. Este modelo de determinação de $\bar{D}_{g}$ foi proposto por Stanton et al. [79] e Wu et al. [81, 84], sendo recomendado pelo Protocolo Americano de Dosimetria [85]. Entretanto, os autores utilizaram um fator de conversão para a medida de exposição na entrada da mama.

A dose glandular normalizada depende das características físicas da mama (espessura e glandularidade) e da radiação incidente (combinação ânodo/filtro, potencial do tubo e $C S R)$.

Um modelo alternativo para a determinação $\bar{D} g$ foi proposto por Dance [44] e modificado em trabalhos posteriores [80, 86], sendo recomendado no Protocolo Europeu de Dosimetria [87, 88]. Neste modelo, a $\bar{D}_{g N}$ é fatorizada em três diferentes grandezas: $g, c$ e $s$, utilizadas para descrever as dependências com a espessura da mama e $C S R$, composição da mama e combinação ânodo/fitro, respectivamente. Assim, a $\bar{D}_{g}$ pode ser determinada a partir da seguinte relação;

$$
\bar{D}_{g}=K_{a r} . g . c . s
$$

De forma geral, a determinação de $\bar{D}_{g}$, de acordo com as equações 2.27 e 2.28 , é baseada somente na determinação dos fatores de dose glandular normalizada, uma 
vez que o kerma no ar de entrada na pele pode ser determinado ao se utilizar uma câmara de ionização [89, 90].

Apesar da normalização através do Kerma no ar ser a mais utilizada, alguns autores consideram a normalização da dose através da exposição na entrada da pele $\left(X_{e}\right)$ como a mais prática para se computar a dose em uma mamografia [51, 91].

Estudos recentes mostraram que componentes do mamógrafo posicionados logo abaixo da mama podem contribuir com a dose glandular total recebida pela mama, através de fótons retroespalhados, ou provenientes de fluorescência [5].

\subsection{Técnica de Radiografia por Dupla-Energia}

A mamografia digital por dupla-energia é uma técnica que explora a diferença entre os coeficientes de atenuação de diferentes componentes da mama, a partir da combinação entre duas aquisições mamográficas digitais obtidas em baixa e alta energias, considerando apenas a contribuição de fótons transmitidos (primários) [20, 23, 92, 93], podendo ser aplicada através de diversas formas demonstradas nos tópicos a seguir:

\subsubsection{Decomposição de $\mu$}

Esta técnica, criada por Alvarez e Macovski [23], propõe que, para uma determinada energia, o coeficiente de atenuação linear de um material pode ser descrito como a combinação linear de duas funções dependentes da energia e dois fatores de ponderação, específicos do material analisado. Lehmann et al. [24] propuseram que o coeficiente de atenuação linear de um material qualquer pode ser decomposto em dois coeficientes de atenuação de dois materiais base (como por exemplo, lucite e alumínio), multiplicados por suas respectivas espessuras. Com isso, a partir de aquisições de imagens em energias diferentes, é possível se determinar o coeficiente de atenuação de qualquer material, possibilitando a obtenção de imagens radiográficas que destaquem algum determinado tecido de interesse. 


\subsubsection{Realce por subtração}

Esta técnica consiste no realce de um tecido de interesse, através da subtração ponderada entre imagens mamográficas digitais, ao suprimir o sinal do background de seu entorno. Estudos mostraram que a mamografia por dupla-energia é capaz de detectar tecidos tumorais com maior eficiência do que o método convencional $[6,92,94,95]$.

O formalismo de subtração por dupla-energia, proposto por Ergun et al. [27], pode ser utilizado para se destacar microcalcificações ao suprimir o sinal dos demais tecidos mamários [6], como mostrado na equação a seguir:

$$
D E=\ln S_{h}-R \cdot \ln S_{l}+k
$$

onde, $R=\frac{\mu_{h}}{\mu_{l}}$ e $k=\ln \frac{\left(S_{0 l}\right)^{R}}{S_{0 h}}$

sendo DE a imagem resultante, $S_{h}$ e $S_{l}$, os sinais devidos aos fótons absorvidos pelo detector, em alta e baixa energias, respectivamente. $S_{0 h}$ e $S_{0 l}$ são sinais de fótons não atenuados de alta e baixa energias, respectivamente e por fim, $\mu_{h}$ e $\mu_{l}$ são os coeficientes de atenuação da mama, para alta e baixa energias.

O formalismo mostrado acima é descrito para feixes monoenergéticos. Na consideração de feixes polienergéticos, devem ser utilizados os valores médios dos coeficientes de atenuação $\overline{\mu_{h}}$ e $\overline{\mu_{l}}$, calculados a partir da seguinte relação [6]:

$$
\overline{\mu_{j}}=\frac{\int_{0}^{E \max } \mu_{j}(E) \cdot I_{0}(E) \cdot d E}{\int_{0}^{E m a x} I_{0}(E) \cdot d E} \quad j=l, h
$$

onde $I_{0}(E)$ é a distribuição de intensidade do espectro de raios X e Emax, a energia máxima deste espectro.

Considerando que o sinal das imagens combinadas possuem um perfil de ruído coerente com uma distribuição de Poisson, a incerteza de $D E$ pode ser expressa de acordo com a seguinte equação [6, 30, 31]:

$$
\sigma_{D E}^{2}=\frac{1}{S_{h}}+\frac{1}{S_{0 h}}+R^{2} \cdot\left(\frac{1}{S_{l}}+\frac{1}{S_{0 l}}\right)
$$


A figura 2.9 ilustra a aplicação desta técnica de combinação utilizando feixes monoenergéticos.

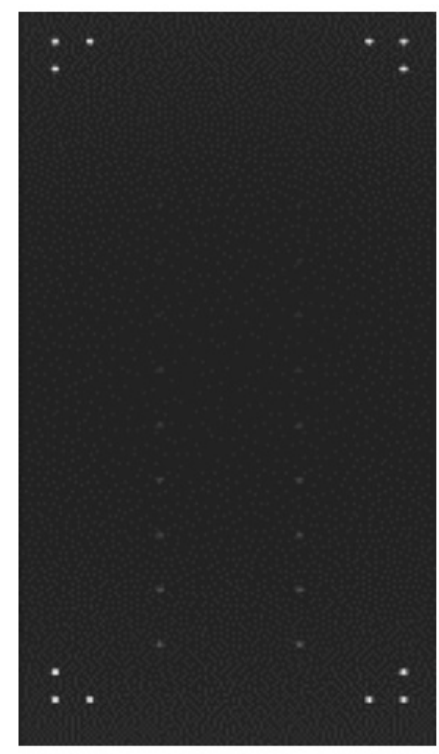

(a)

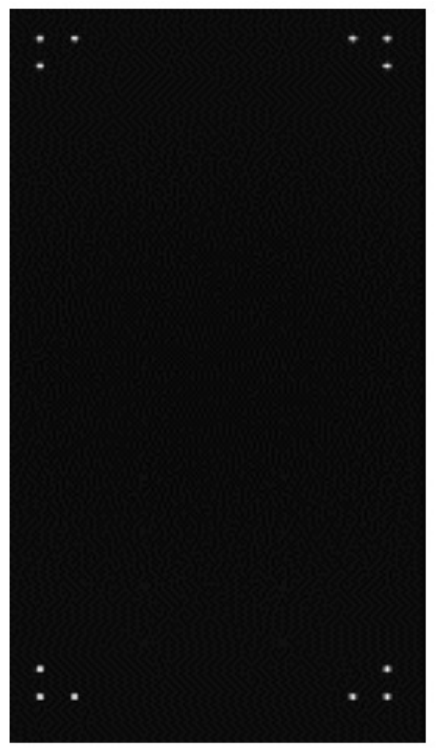

(b)

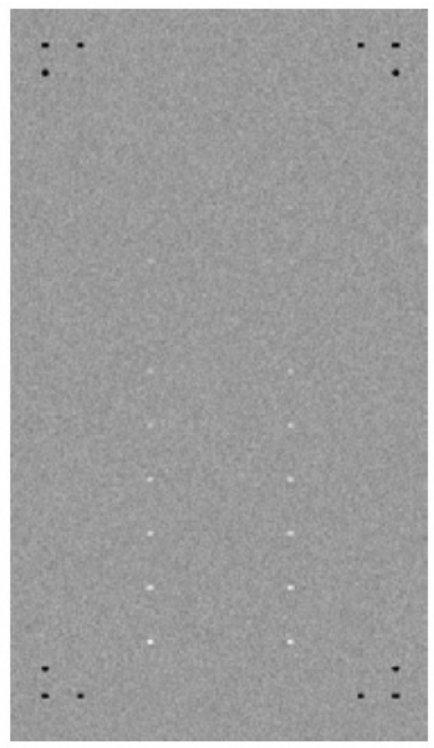

(c)

Figura 2.9: Imagens simuladas em (a) baixa energia (18 keV), (b)alta energia( 47 $\mathrm{keV}$ ) e (c) imagem subtraída. Figura retirada de Bliznakova et al [6].

É possível observar que os detalhes em 2.9(c) são mais contrastantes com seus entornos, em comparação às figuras 2.9(a) e 2.9(b). A técnica de subtração também foi capaz de ampliar a capacidade de identificação de objetos menores, os quais não são detectáveis nas imagens adquiridas por modo convencional.

A técnica de realce por subtração também é amplamente estudada e aplicada em aquisições de imagens por agente de contraste [93, 96].

\subsubsection{Geração de Imagens Quantitativas}

A técnica de dupla energia para a geração de imagens quantitativas foi proposta por Lemacks et al. [7], buscando realçar e quantificar tecidos de interesse, como microcalcificações e fração glandular [7, 18, 35].

Com base no modelo mostrado na figura 2.10, a espessura total da mama $T$ pode ser descrita por:

$$
T=t_{a}+t_{b}+t_{c}
$$




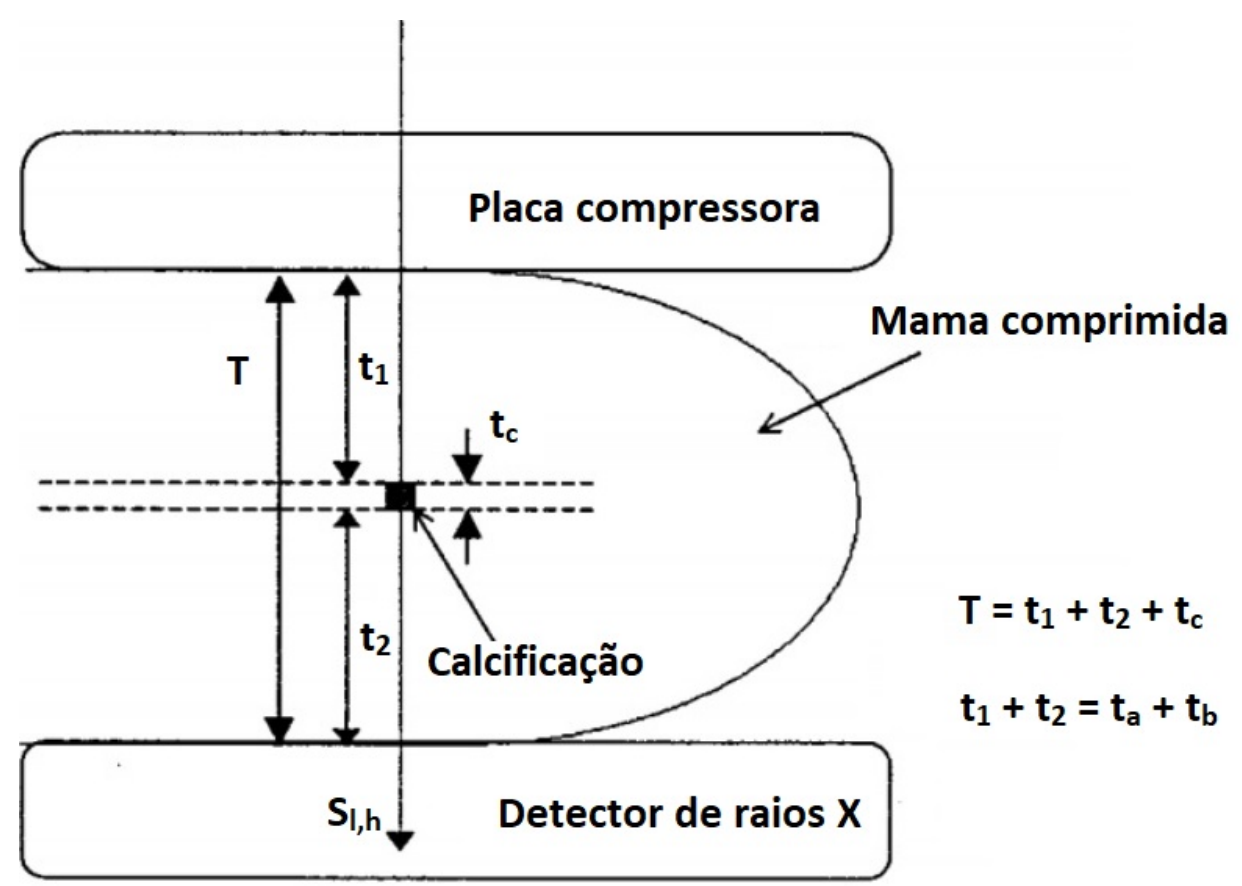

Figura 2.10: Modelo geométrico de uma mama comprimida de espessura T, com calcificações de tamanho $t_{c}$, e tecidos adiposo e glandular de espessuras $t_{a} e t_{b}$, respectivamente, onde $t_{1}+t_{2}=t_{a}+t_{b}$. Imagem retirada e adaptada de Lemacks et al [7].

Considerando um feixe monoenergético com energia $E$ e uma fluência de partículas $\Phi_{0}$, que atravessa a região contendo a calcificação e atinge um detector com eficiência $E f f$, o sinal pode ser representado pela seguinte equação:

$$
S=\Phi_{0} \cdot e^{-\mu_{a} \cdot t_{a}} \cdot e^{-\mu_{b} \cdot t_{b}} \cdot e^{-\mu_{c} \cdot t_{c}} \cdot E f f
$$

sendo, $\mu_{a}, \mu_{b}$ e $\mu_{c}$, os coeficientes de atenuação lineares dos tecidos adiposo, glandular e de calcificação, respectivamente. Isolando o termo $t_{a}$ da equação 2.32 e aplicando em 2.33, obtém-se a seguinte relação:

$$
S=\Phi_{0} \cdot e^{-\mu_{a} \cdot T} \cdot e^{-\Delta \mu_{b} \cdot t_{b}} \cdot e^{-\Delta \mu_{c} \cdot t_{c}} \cdot E f f
$$

sendo $\Delta \mu_{b} \equiv \mu_{b}-\mu_{a}$ e $\Delta \mu_{c} \equiv \mu_{c}-\mu_{a}$.

Definindo um termo $D=F\left(t_{b}, t_{c}\right)$ como uma relação logarítmica e análoga à densidade ótica, entre o sinal da equação 2.34 e um sinal de referência $S_{r e f}$, não atenuado pela mama, sendo escrito como: 


$$
D\left(t_{b}, t_{c}\right) \equiv \ln \left(\frac{S_{r e f}}{S}\right)=\ln \left(\frac{\Phi_{0} \cdot E f f}{\Phi_{0} \cdot e^{-\mu_{a} \cdot T} \cdot e^{-\Delta \mu_{b} \cdot t_{b}} \cdot e^{-\Delta \mu_{c} \cdot t_{c}} \cdot E f f}\right)
$$

O sinal de referência, também pode ser adquirido com a utilização de um corpo atenuante, composto de tecido adiposo e de mesma espessura da mama, cancelando a contribuição deste tecido no sistema [7, 16, 97].

O termo $D$ pode ser definido para duas energias distintas, descritas pelos índices $l$ e $h$, representando aquisições de baixa e alta energias, respectivamente. Assim, as seguintes relações podem ser definidas: $t_{b}=f_{b}\left(D_{l}, D_{h}\right)$ e $t_{c}=f_{c}\left(D_{l}, D_{h}\right)$, onde $f_{b}$ e $f_{c}$ são funções de mapeamento de espessuras do tecido glandular e de microcalcificações, respectivamente.

Para um feixe monoenergético, o termo $D$ possui uma relação linear com as características da mama. Assim, $t_{b}$ e $t_{c}$ podem ser facilmente resolvidos a partir de um sistema linear [7].

Utilizando um feixe polienergético, o termo $D$ pode ser redefinido como:

$$
D\left(t_{b}, t_{c}\right)=\ln \left(\frac{\int \Phi_{0}(E) \cdot E f f(E) \cdot d E}{\int \Phi_{0}(E) \cdot e^{-\mu_{a}(E) \cdot T} \cdot e^{-\Delta \mu_{b}(E) \cdot t_{b}} \cdot e^{-\Delta \mu_{c}(E) \cdot t_{c}} \cdot E f f(E) \cdot d E}\right)
$$

Diferentemente da quantificação utilizando um feixe monoenergético, $t_{b}\left(D_{l}, D_{h}\right)$ e $t_{c}\left(D_{l}, D_{h}\right)$ não podem ser determinados através de um sistema linear. Diversos estudos buscaram correlacionar estes termos à funções polinomiais, como uma maneira de resolvê-los [16, 18, 35, 41, 97, 98]. Kappadath et al. [18] mostraram que uma função polinomial de ordem cúbica, descrita pela equação 2.37, é capaz de estimar de maneira otimizada, espessuras de microcalcificações.

$$
t_{c}=c_{0}+c_{1} \cdot D_{l}+c_{2} \cdot D_{h}+c_{3} \cdot\left(D_{l}\right)^{2}+c_{4} \cdot\left(D_{h}\right)^{2}+c_{5} \cdot D_{l} \cdot D_{h}+c_{6} \cdot\left(D_{l}\right)^{3}+c_{7} \cdot\left(D_{h}\right)^{3}
$$

Os termos $c_{j}$, para $j=1,7$, são constantes, as quais são obtidas através de uma calibração. Para isso, são construídos mapas de $D c_{l}$ e $D c_{h}$, análogos aos termos $D_{l}$ e $D_{h}$, a partir de imagens de fantomas com espessuras conhecidas dos tecidos a serem estudados.

Kappadath et al. [18] estimaram que a incerteza propagada para a imagem quantitativa em espessuras de microcalcificações $\left(\sigma_{t_{c}}^{2}\right)$ pode ser descrita, de forma aproximada, pelas seguintes relações: 


$$
\sigma_{t_{c}}^{2}=\frac{\left(\bar{\mu}_{f_{g}}^{h}\right)^{2} \cdot \sigma_{D_{l}}^{2}+\left(\bar{\mu}_{f_{g}}^{l}\right)^{2} \cdot \sigma_{D_{h}}^{2}}{\left(\bar{\mu}_{f_{g}}^{l} \cdot \bar{\mu}_{t_{c}}^{h}-\bar{\mu}_{f_{g}}^{h} \cdot \bar{\mu}_{t_{c}}^{l}\right)^{2}}
$$

sendo $\sigma_{D_{l}}^{2}$ e $\sigma_{D_{h}}^{2}$, as variâncias dos mapas de $D_{l}$ e $D_{h}$, respectivamente, descritas pela seguinte relação: $\sigma_{D_{j}}^{2}=\left(\sigma_{S} / S\right)_{j}^{2}+\left(\sigma_{S_{r e f}} / S_{r e f}\right)_{j}^{2}, \quad j=l, h$. Onde $\sigma_{S}$ e $\sigma_{S_{r e f}}$ são incertezas de $S$ e $S_{r e f}$, respectivamente.

Já para a quantificação da glandularidade, Ducote \& Molloi [19] propuseram uma relação análoga à da equação 2.36 Porém, apenas com a presença de tecido adiposo e glandular. A estimativa da espessura do tecido glandular se dá pelo seguinte polinômio:

$$
t_{b}=\frac{b_{0}+b_{1} \cdot D_{l}+b_{2} \cdot D_{h}+b_{3} \cdot\left(D_{l}\right)^{2}+b_{4} \cdot\left(D_{h}\right)^{2}+b_{5} \cdot D_{l} \cdot D_{h}}{\sqrt{1+b_{6} \cdot D_{l}+b_{7} \cdot D_{h}}}
$$

Assim como para a quantificação de microcalcificações, as constantes $b_{j}$ também são estimadas através do processo calibração.

A partir desta quantificação, a fração glandular $\left(f_{g}\right)$ pode ser estimada através da seguinte relação [33]:

$$
f_{g}=\frac{t_{b} \rho_{b}}{T \rho_{a}+t_{b}\left(\rho_{b}-\rho_{a}\right)}
$$

sendo $\rho_{a}$ e $\rho_{b}$, as densidades dos tecidos adiposo e glandular, respectivamente. 


\section{Capítulo 3}

\section{Materiais e Metodologia}

\subsection{Construção do Modelo Geométrico}

\subsubsection{Ambiente de aquisição (simulação) de imagens}

A figura 3.1 ilustra o modelo geométrico utilizado para a simulação de imagens mamográficas.

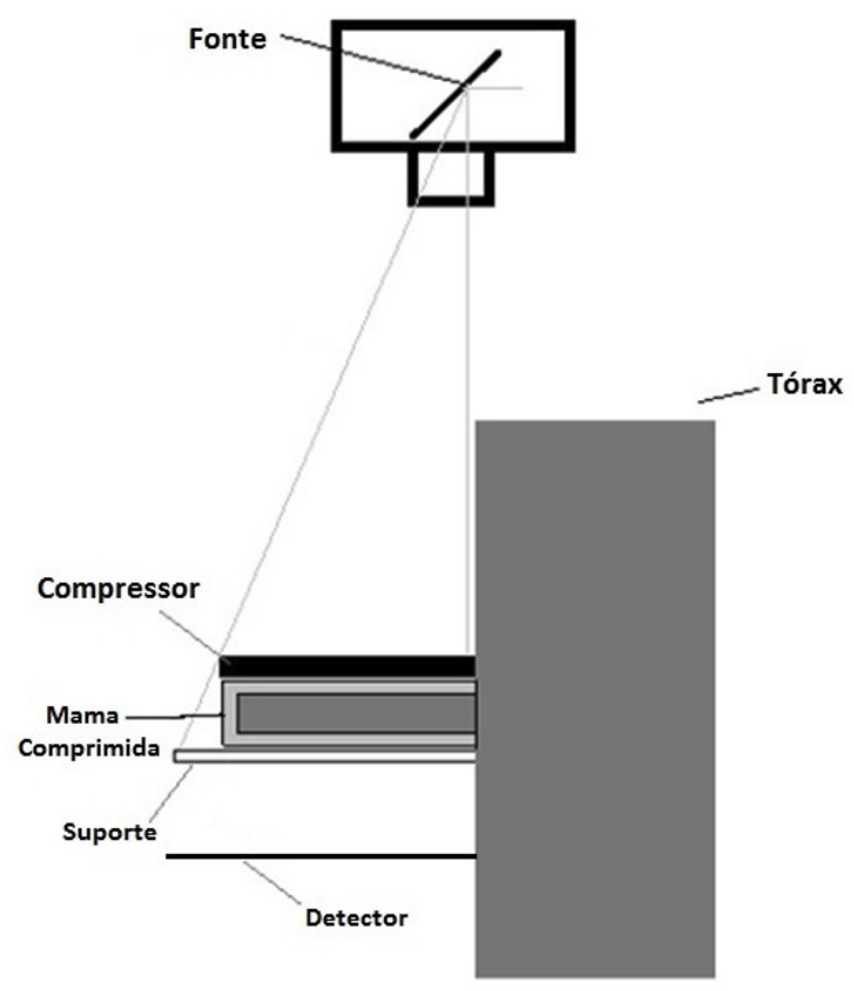

Figura 3.1: Modelo geométrico do ambiente de simulação de imagens 
As simulações computacionais foram realizadas a partir de um modelo geométrico previamente implementado e validado [33, 40]. Foi utilizada uma fonte polienergética gerada a partir de um ponto focal com $0,3 \mathrm{~mm}$ à uma distância de $65 \mathrm{~cm}$ de um detector contendo 201x201 pixels. Foram considerados detectores de iodeto de césio (CsI) e selênio amorfo (aSe), com espessuras de 150 e $250 \mu \mathrm{m}$, respectivamente. Para fins comparativos, o tamanho do pixel de ambos os detectores foi definido em $75 \mu \mathrm{m}$, representando a resolução espacial aproximada do detector de aSe [76]. O compressor foi composto de acrílico com $3 \mathrm{~mm}$ de espessura. Logo abaixo da mama foi posicionado um suporte de carbono de 2,1 $\mathrm{mm}$ de espessura, a uma distância de $2,2 \mathrm{~cm}$ do detector. O tórax foi composto de água e possui dimensões de 40x15x50 cm.

\subsubsection{Modelos geométricos da mama}

A figura 3.2 mostra os modelos geométricos construídos da mama para a simulação de imagens contendo diferentes microcalcificações e frações glandulares $(f g)$.
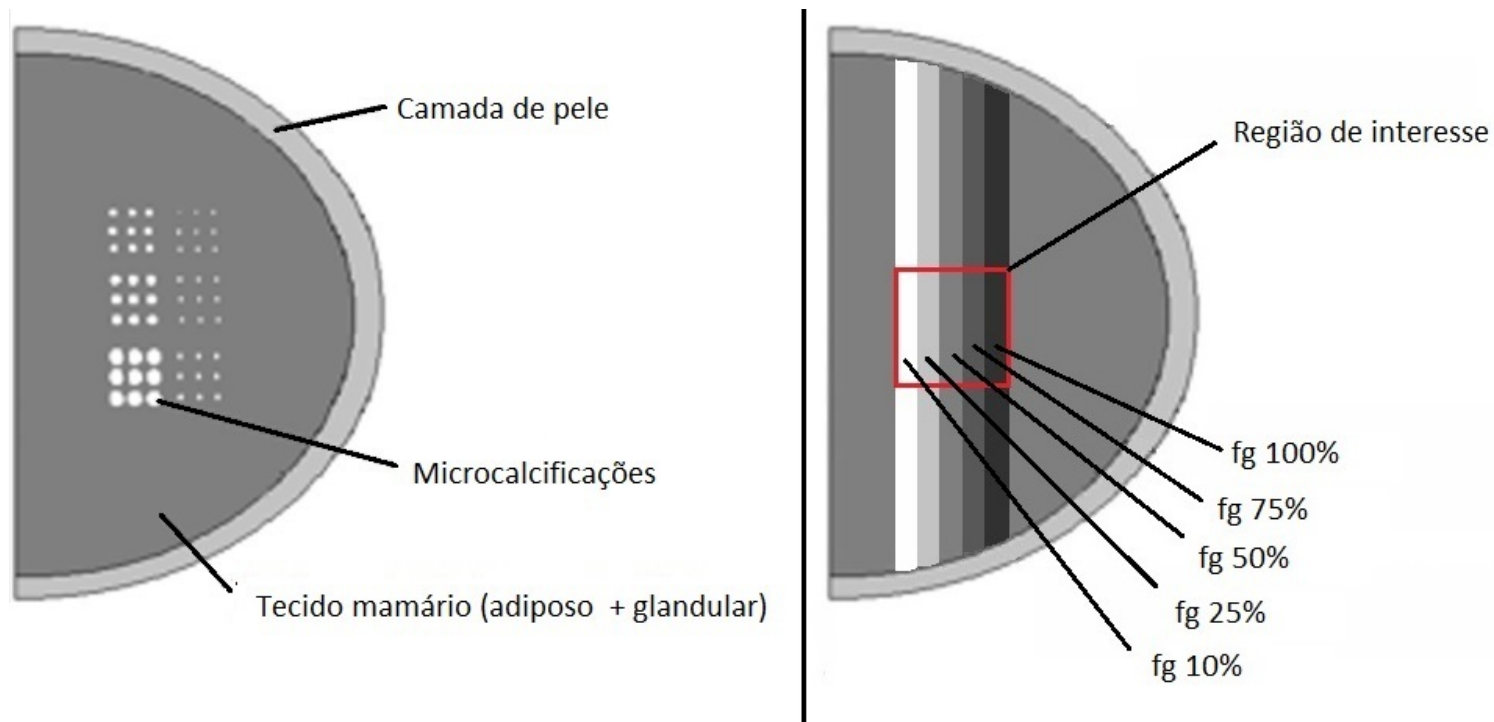

Figura 3.2: $\quad$ Modelo geométrico da mama para a geração de imagens de microcalcificações (esquerda) e frações glandulares (direita).

Foram consideradas mamas semicirculares com raio de $8 \mathrm{~cm}$ e espessuras de 2, 4 e $6 \mathrm{~cm}$, com uma camada externa de pele de 1,45 $\mathrm{mm}$ de espessura e uma camada interna, composta por uma mistura homogênea entre tecidos adiposo 
e glandular. A pele foi simulada com base na composição elementar reportada pelo ICRU [99], já o tecido mamário foi simulado com base nas frações de peso e densidades das componentes elementares dos tecidos adiposo e glandular propostos por Hammerstein et al. [78], mostradas na tabela 3.1.

Tabela 3.1: Composição elementar dos tecidos adiposo e mamário e pele.

\begin{tabular}{|c|c|c|c|c|c|c|}
\hline \hline \multicolumn{7}{|c|}{ Composição Elementar } \\
\hline Tecido & $\rho\left(\mathrm{g} / \mathrm{cm}^{3}\right)$ & $\mathrm{H}(\%)$ & $\mathrm{C}(\%)$ & $\mathrm{N}(\%)$ & $\mathrm{O}(\%)$ & $\mathrm{P}(\%)$ \\
\hline Pele & 1,1 & 10,1 & 22,8 & 4,6 & 61,9 & 0,6 \\
\hline Adiposo & 0,93 & 11,2 & 61,9 & 1,7 & 25,1 & 0,1 \\
\hline Glandular & 1,04 & 10,2 & 10,2 & 3,2 & 67,7 & 0,5 \\
\hline
\end{tabular}

Para simulação de imagens de microcalficicações, foram inseridos na mama, discos de CaCO3, com diâmetros e espessuras variados entre 100 e $600 \mu \mathrm{m}$, organizadas em grupos de 9 componentes de mesmas dimensões. O formato cilíndrico foi escolhido para minimizar o efeito de borda na visualização das calcificações. Observações anteriores mostraram que a variação da fração glandular não influencia na quantificação do tamanho de microcalcificações [40]. Portanto para estes casos, a glandularidade foi fixada em $50 \%$.

Já para a simulação de imagens com diferentes glandularidades, a mama foi seccionada em camadas homogêneas com frações glandulares entre 10 e 100\%, sem a presença de microcalcificações.

As simulações foram feitas para mamas com espessuras entre 2 a $6 \mathrm{~cm}$.

\subsection{Adaptação e Validação do Código PENELOPE}

Foi utilizado um código PENELOPE previamente adaptado para o cálculo de grandezas dosimétricas e simulação de imagens [40]. Porém, estas adaptações foram revisadas e complementadas, a fim de se obter resultados mais acurados, próximos de um ambiente experimental. A validação destas novas adaptações foram realizadas através de um extenso estudo, envolvendo os parâmetros descritos a seguir. 


\subsubsection{Grandezas dosimétricas}

A dose total absorvida pela mama (excluindo a pele), Dm, foi calculada ao dividir a energia absorvida pelo volume interno da mama, $E m$, por sua massa, $M$, e multiplicada por um fator de conversão de unidades, $f c$, (de $e V / g$ para $m G y$ ), como mostrado na equação a seguir:

$$
D m=\frac{E m}{M} \cdot f c
$$

sendo $f c=1,602 \cdot 10^{13}$.

A dose glandular média, $D g$, foi obtida através da seguinte equação:

$$
D g=\frac{E m}{f g} \cdot G(E)
$$

sendo $f g$ a fração glandular correspondente do tecido interno da mama e $G$, um fator de ponderação proposto por Boone [82], dependente da energia $E$ do fóton incidente e dado pela equação a seguir:

$$
G(E)=\frac{f g \cdot\left(\frac{\mu_{e n}(E)}{\rho}\right)_{g}}{f g \cdot\left(\frac{\mu_{e n}(E)}{\rho}\right)_{g}+(1-f g) \cdot\left(\frac{\mu_{e n}(E)}{\rho}\right)_{a}}
$$

sendo, $\left(\mu_{e n} / \rho\right)_{g}$ e $\left(\mu_{e n} / \rho\right)_{a}$, os coeficientes mássicos de absorção de energia dos tecidos glandular e adiposo, respectivamente. Estes coeficientes foram retirados da base de dados do NIST [100] e suas densidades são mostrados na tabela 3.1. Para cada interação sofrida pelo fóton no tecido mamário, o fator G era recalculado de acordo com sua nova energia $E[101]$.

Os cálculos de Dm e Dg consideram os fótons provenientes do retroespalhamento e fluorescência do bucky (suporte da mama e detector), os quais podem incidir na mama [73, 102].

A estimativa das grandezas dosimétricas foi validada a partir do cálculo dos valores de dose glandular normalizada $(D g N)$, estimado de acordo com a equação $3.4[82,83,84]$.

$$
D g N=\frac{D g}{K_{a r}}
$$


onde $K_{a r}$ refere-se ao kerma no ar na entrada da pele, desconsiderando retroespalhamento. O kerma no ar foi obtido analiticamente, calculado pelo código PENELOPE durante as simulações de forma análoga a apresentada na equação 2.21, como:

$$
K_{a r}=\sum_{i} E_{i} \cdot \frac{N\left(E_{i}\right)}{A_{m}} \cdot\left(\frac{\mu_{t r}}{\rho}\left(E_{i}\right)\right)_{a r}
$$

sendo $\mu_{t r} / \rho$ o coeficiente de transferência de energia mássico do ar e $N\left(E_{i}\right)$, o número de fótons incidentes com energia $E_{i}$ sobre a superfície da mama de área $A_{m}$. Os valores de $\mu_{t r} / \rho$ do ar $\left(\mathrm{cm}^{2} / \mathrm{g}\right)$ foram calculados através do ajuste de uma equação exponencial baseada nos valores adquiridos por Higgins et al. [103], demonstrado a seguir:

$$
\mu_{t r}(E)=14,96 \times 10^{\frac{-E}{4872,99}}+1,19 \times 10^{\frac{-E}{11758,92}}+197,38 \times 10^{\frac{-E}{2213,84}}+0,023
$$

É importante ressaltar que para a faixa de energia considerada neste trabalho, a fração de perdas radiativas pelos elétrons no ar, $g_{a r}$, é desprezível, sendo menor do que $10^{-4}$ para energias de até $100 \mathrm{keV}$ [103]. Assim, os valores de $\mu_{t r}$ e $\mu_{a b}$ são semelhantes e o $K_{a r}$ pode ser diretamente correlacionado com a exposição $X$, descrito pela equação 2.24 .

A $D g N$ foi escolhida para a validação do código, por servir como parâmetro de referência e controle de qualidade para cálculos de dose glandular em mamografia clínica [82, 88], além de não depender da fluência de partículas primárias incidentes na mama.

O primeiro teste de validação foi realizado com a comparação entre os valores de $D g N$ em função da energia de feixes monoenergéticos, adquiridos por este trabalho e por Fedon et al. [8]. O modelo geométrico dos autores foi reproduzido, utilizando uma mama semicircular com raio de $8,5 \mathrm{~cm}, 4 \mathrm{~cm}$ de espessura e $50 \%$ de glandularidade, envolta por uma camada de pele com $0,4 \mathrm{~cm}$ de espessura. Fedon et al. calcularam a $D g N$ a partir da exposição, $X$, portanto, foram realizadas as devidas conversões.

O segundo teste de validação foi realizado para feixes polienergéticos ao reproduzir o modelo geométrico de Dance [44] e comparar valores de DgN em 
função da camada semi-redutora (do inglês, $H V L$ ), obtidos por este trabalho e pelo autor. Foi considerada uma mama semicircular com $8 \mathrm{~cm}$ de raio, $2 \mathrm{~cm}$ de espessura e 50\% de glandularidade, envolta de uma camada de 0,5 cm de tecido adiposo, simulando a pele. O autor posicionou um receptor de imagens abaixo da mama, porém, não considerou sua influência para as estimativas de $D g N$. Um teste adicional foi realizado, ao se adquirir valores de $D g N$ com a presença de um bucky completo (suporte da mama, grade anti-espalhamento e detector) logo abaixo da mama neste modelo geométrico. Esta etapa foi utilizada para se avaliar a possível influência de fótons retroespalhados pelo bucky sobre os valores de $D g N$.

\subsubsection{Aplicação de detectores de CsI e aSe para a simulação de imagens}

O código PENELOPE foi previamente adaptado para simular imagens com e sem a contribuição do feixe espalhado pela mama, utilizando um detector ideal [40]. Neste trabalho, o código foi readaptado para simular imagens a partir dos detectores de iodeto de césio (CsI) e selênio amorfo $(a S e)$, com espessuras de 150 e $250 \mu \mathrm{m}$, respectivamente.

Diversos trabalhos na literatura utilizam equações analíticas para se determinar a eficiência quântica dos detectores [6, 29, 31]. Porém, estes cálculos consideram apenas a interação primária entre o fóton e o detector, excluindo possíveis eventos que considerem o escape ou reabsorção de fótons espalhados [104].

Neste trabalho, a eficiência dos detectores foi estimada através de simulações computacionais, onde cada detector foi irradiado por feixes estreitos e monoenergéticos, com energias entre 1 e $80 \mathrm{keV}$ e ângulos $(\theta)$ em relação ao eixo de incidência Z, entre 0 e $88^{\circ}$, como ilustrado na figura 3.3.

Através de um detector de impacto, fornecido pelo código PENELOPE, foi obtida uma função resposta para cada feixe simulado. Esta função resposta era integrada e dividida pela energia total do feixe incidente. Esta razão foi tomada como a eficiência quântica do detector. Para cada energia e ângulo observados, foram simulados $10^{8}$ fótons.

A figura 3.4 mostra os mapas de contorno das eficiências quânticas, em percentual, dos detectores de CsI e aSe, em função da energia e do ângulo de 


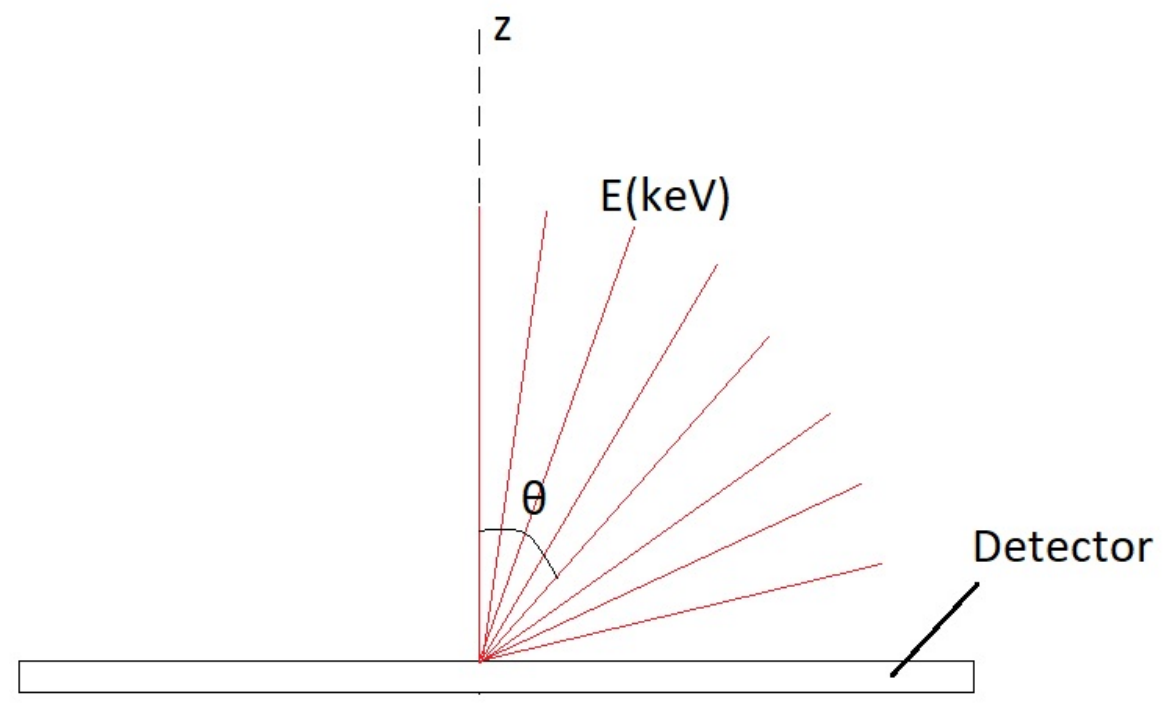

Figura 3.3: $\quad$ Modelo de simulação para a determinação da eficiência dos detectores de CsI e aSe.

incidência dos fótons.

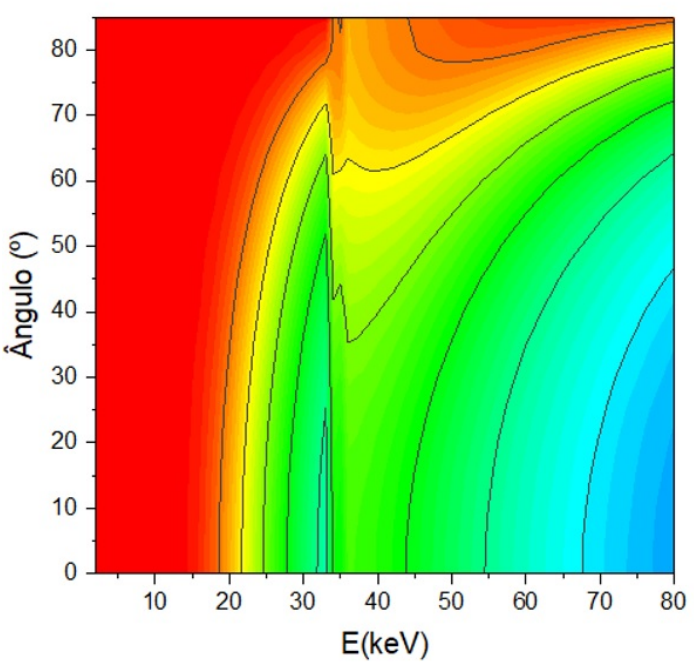

(a)

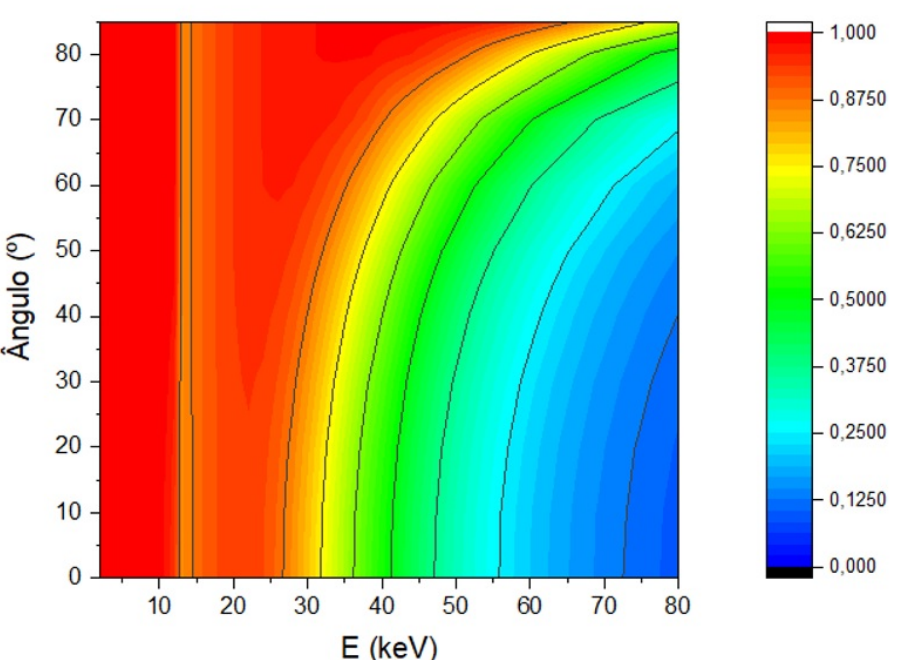

(b)

Figura 3.4: Mapas de eficiência quântica dos detectores de (a) iodeto de césio e (b) selênio amorfo.

Na figura, é possível observar a alta queda da eficiência nas regiões das bordas de absorção da camada $\mathrm{K}$ em ambos os casos $\left(\mathrm{K}_{C s}=35,98 \mathrm{keV}, \mathrm{K}_{I}=33,17 \mathrm{keV}\right.$ e 
$\left.\mathrm{K}_{S e}=12,66 \mathrm{keV}\right)$ [105]. Nota-se também a eficiência do detector de aSe, na região da borda de absorção, é praticamente constante para quaisquer ângulos de incidência dos fótons. Isso ocorre pois grande parte dos fótons originados da fluorescência da camada K não são reabsorvidos pelo detector, independentemente do ângulo entre o feixe primário e a superfície de detecção.

Era esperado que, para energias muito baixas, a eficiência quântica fosse próxima de $100 \%$ devido ao alto coeficiente de absorção do dos materiais componentes dos detectores para estas energias [106].

A validação das adaptações realizadas nesta etapa foi realizada através do estudo da capacidade de visualização de características presentes na mama, utilizando os dois detectores simulados. A primeira validação foi realizada através da comparação dos valores da razão contraste-ruído $(C N R)$ de um objeto presente em um fantoma, em função da energia de feixes polienergéticos, obtidos por este trabalho e por Baldelli et al. [107] e Jakubiak et al [108]. Os modelos geométricos de ambos os autores foram reproduzidos. Os valores de CNR foram obtidos para discos de alumínio com $200 \mu \mathrm{m}$, presentes em um fantoma de acrílico com $4 \mathrm{~cm}$ de espessura. Baldelli et al. utilizaram em seu experimento, um mamógrafo GE Seno DS ${ }^{\circledR}$, o qual possui um detector de CsI. Já Jakubiak et al. utilizaram um equipamento de tomossíntese, Siemens Mammomat Inspiration ${ }^{\circledR}$, o qual possui um detector de $a S e$.

Os valores de CNR foram calculados de acordo com a equação 2.19.

A segunda validação foi realizada ao comparar valores de figura de mérito (do inglês - FOM) em função da energia de feixes polienergéticos, obtidos por este trabalho e por Baldelli et al [109]. A FOM foi calculada de acordo com a seguinte equação:

$$
F O M=\frac{C N R^{2}}{\overline{D g}}
$$

A geometria utilizada pelos autores, e reproduzida neste trabalho, consiste em um fantoma CIRS (CIRS, Inc., Norfolk, VA) simulando um tecido mamário com $50 \%$ de glandularidade e $4 \mathrm{~cm}$ de espessura. Em seu interior se encontra um disco com $1 \mathrm{~cm}$ de espessura, composto de um fantoma CIRS, simulando um tecido $100 \%$ adiposo. A CNR foi calculada entre este disco de alumínio e seu entorno e a 
dose glandular média, $\overline{D g}$, foi fixada de acordo com as especificações do autor. Foi utilizado um detector de aSe para aquisição das imagens.

A tabela a 3.2 descreve a composição elementar dos fantomas CIRS, simuladores de tecidos adiposo, glandular e uma mistura homogênea com 50\% de glandularidade $[110,111]$, os quais são utilizados nesta etapa e outras a serem apresentadas:

Tabela 3.2: Composição elementar dos fantomas CIRS, simuladores de tecidos glandular, adiposo e mistura homogênea com $50 \%$ de glandularidade.

\begin{tabular}{|c|c|c|c|c|c|c|c|c|c|}
\hline \hline \multicolumn{10}{|c|}{ Composição Elementar - Fantoma CIRS } \\
\hline Tecido & $\rho\left(\mathrm{g} / \mathrm{cm}^{3}\right)$ & $\mathrm{H}(\%)$ & $\mathrm{C}(\%)$ & $\mathrm{N}(\%)$ & $\mathrm{O}(\%)$ & $\mathrm{Cl}(\%)$ & $\mathrm{Ca}(\%)$ & $\mathrm{P}(\%)$ & $\mathrm{Al}(\%)$ \\
\hline Adiposo & 0,924 & 11,8 & 76,0 & 1,2 & 9,8 & 1,2 & - & - & - \\
\hline Glandular & 1,04 & 10,9 & 70,2 & 1,2 & 12,5 & 1,1 & 0,6 & - & 3,5 \\
\hline $50 \%$ Adiposo + 50\% Glandular & 0,98 & 11,1 & 72,74 & 1,04 & 14,82 & - & 0,3 & - & - \\
\hline
\end{tabular}

\subsection{Simulação de Imagens Mamográficas}

\subsubsection{Determinação da dose glandular média}

As imagens deste trabalho foram simuladas a partir de uma dose glandular média $D g$ fixa, de acordo com a espessura da mama. Os valores de $D g$ foram determinados, respeitando os limites propostos no Protocolo Europeu de Controle de Qualidade em Mamografia [88]. Para as imagens com diferentes frações glandulares, a camada com $50 \%$ de glandularidade foi tomada como referência para se limitar os valores de $D g$. Para a mama com $2 \mathrm{~cm}$ de espessura, a Dg foi fixada em 0,6 mGy. Já para as mamas de 4 e 6 cm de espessura, este valor foi fixado em 1,0 e 1,2 mGy, respectivamente.

O código PENELOPE foi adaptado para que em cada simulação fossem geradas (simuladas) imagens com frações da $D g$ máxima estabelecida (entre 10 e 100\%). Este fracionamento é importante para se avaliar a influência das varias ponderações de dose entre as escolhas de baixa e alta energias no processo de combinação. 


\subsubsection{Escolha dos feixes de raios $\mathrm{X}$}

As imagens foram adquiridas para feixes polienergéticos entre 20 e $80 \mathrm{kVp}$, para diversas combinações ânodo/filtro. De acordo com a literatura, imagens combinadas por técnicas de dupla energia tendem a sofrer uma redução no ruído propagado com o aumento da separação entre as energias médias dos feixes utilizados [18, 20, 31, 40]. A tabela 3.3 descreve e classifica os feixes polienergéticos utilizados neste trabalho.

Tabela 3.3: Feixes polienergéticos utilizados para a aquisição das imagens.

\begin{tabular}{|c|c|c|c|c|}
\hline \hline \multicolumn{5}{|c|}{ Baixa Energia } \\
\hline Ânodo & Filtro & $\mathrm{kVp}$ & E média $(\mathrm{keV})$ & Nomenclatura \\
\hline Mo & $\mathrm{Mo}(30 \mu \mathrm{m})$ & $18-35$ & $13,37-17,93$ & $\mathrm{Mo} / \mathrm{Mo}$ \\
\hline $\mathrm{Rh}$ & $\mathrm{Rh}(25 \mu \mathrm{m})$ & $18-35$ & $13,77-19,55$ & $\mathrm{Rh} / \mathrm{Rh}$ \\
\hline \multicolumn{5}{|c|}{ Alta Energia } \\
\hline Ânodo & Filtro & $\mathrm{kVp}$ & E média $(\mathrm{keV})$ & Nomenclatura \\
\hline $\mathrm{W}$ & $\mathrm{Cu}(0,32 \mathrm{~mm})$ & $37-50$ & $31,49-38,75$ & $\mathrm{~W} / \mathrm{Cu}$ \\
\hline $\mathrm{Rh}$ & $\mathrm{Cu}(0,32 \mathrm{~mm})$ & $37-50$ & $31,20-38,42$ & $\mathrm{Rh} / \mathrm{Cu}$ \\
\hline $\mathrm{W}$ & $\mathrm{Al}(1,6 \mathrm{~mm})+\mathrm{Cu}(0,32 \mathrm{~mm})$ & $52-80$ & $39,84-52,55$ & $\mathrm{~W} / \mathrm{Al}+\mathrm{Cu}$ \\
\hline
\end{tabular}

A maioria dos feixes descritos na tabela 3.3 foram retirados de Boone et al. [53] e Boone \& Seibert [112]. Porém, os feixes com potênciais entre 40 e 50 kVp, sem a presença de uma filtração intrínseca de alumínio, não estão disponíveis na literatura. Estes feixes são importantes, pois caracterizam espectros de raios X presentes em sistemas mais modernos de mamografia que utilizam técnicas não-convencionais para aquisição de imagem, como realce por contraste ou dupla energia. Portanto, simulações foram realizadas a fim de se gerar estes feixes, além de outros que possam ser pertinentes em trabalhos futuros. Com o objetivo de validar estas simulações, alguns feixes foram simulados com mesma energia e combinação ânodo/filtro das encontradas na literatura $[53,112]$.

A figura 3.5 compara característica de dois feixes simulados neste trabalho e aqueles encontrados na literatura [53, 112], como a distribuição em energia da 
fluência de fótons $\left(\phi_{E}\right)$, energia média e camada semi-redutora.

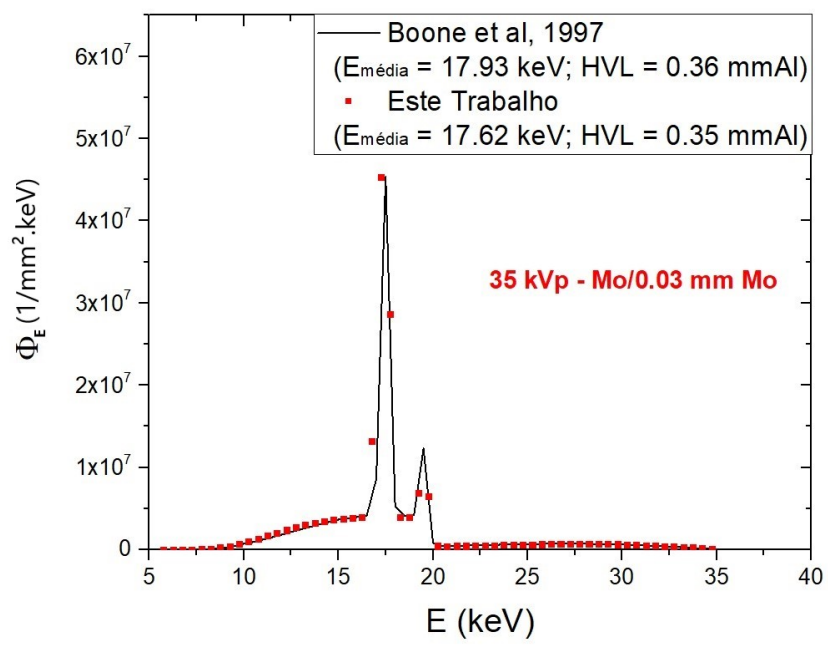

(a)

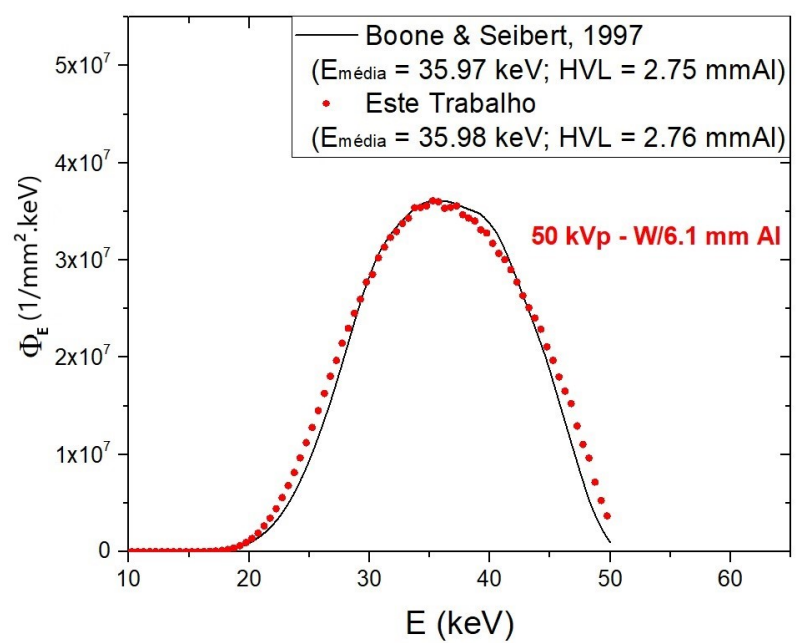

(b)

Figura 3.5: Comparativos entre feixes de (a) $35 \mathrm{kVp}$ e (b) $50 \mathrm{kVp}$, simulados neste trabalho, com aqueles fornecidos pela literatura.

De acordo com a figura, é observada uma boa concordância entre as características dos feixes simulados neste trabalho os obtidos na literatura. Assim, a metodologia empregada neste trabalho para a simulação de feixes polienergéticos foi devidamente validada.

\subsubsection{Avaliação das imagens simuladas}

As imagens simuladas foram avaliadas através comparativo do contraste $(S C)$, ruído e $C N R$ de calcificações, utilizando ambos os detectores considerados neste trabalho. O contraste e a $C N R$ foram calculados entre as calcificações de 600 $\mu \mathrm{m}$ e seu entorno, de acordo com as equações 2.6 e 2.19. O ruído foi obtido através do desvio padrão obtido dos sinais observados.

Além disso, um breve estudo foi realizado, a partir da observação dos sinais obtidos do background das imagens simuladas com todos os feixes polienergéticos e detectores considerados. Os padrões observados nestes estudos foram devidamente avaliados de acordo com princípios físicos e observações da literatura [31, 40, 113] 


\subsection{Formação de Imagens Quantitativas}

A geração de imagens quantitativas para avaliação da morfologia de microcalcificações e da fração glandular, foi fundamentado de acordo com os princípios descritos na seção 2.6.3. A figura 3.6 esquematiza os passos tomados para a geração das imagens quantitativas.

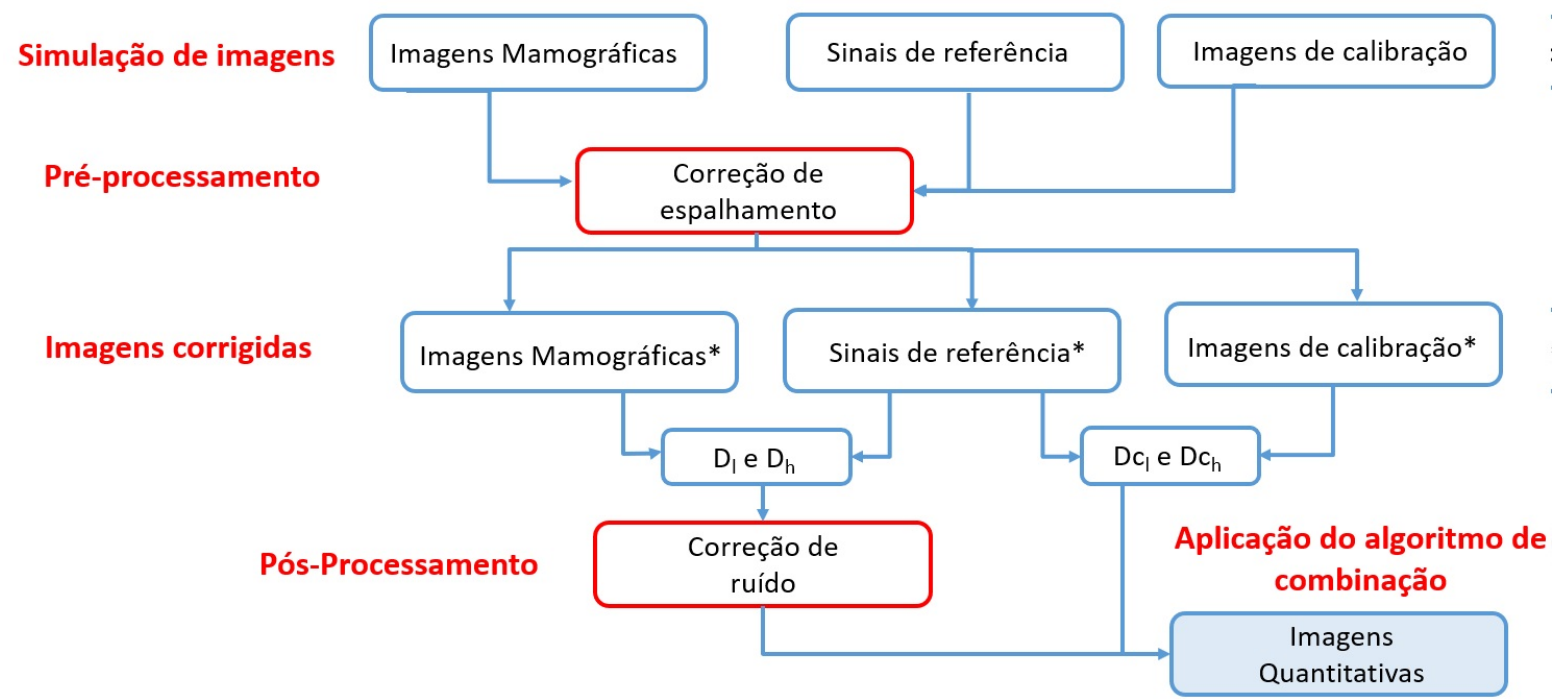

Figura 3.6: Esquematização para o processo de formação de imagens quantitativas.

A simulação e análise das imagens mamográficas foram descritas de acordo com a seção 3.3. Já os demais procedimentos para a construção das imagens quantitativas são descritos a seguir.

\subsubsection{Pré-Processamento: Algoritmo de Correção de Espalhamento}

Como pode ser notado nas explicações da seção 2.6, as técnicas de combinação por dupla energia são aplicáveis apenas para imagens simuladas a partir de feixes primários. Assim, as imagens a serem combinadas devem passar por um processo de eliminação da componente espalhada. Caso a metodologia para eliminar o espalhamento seja eficaz, a imagem resultante teria apenas da contribuição do feixe primário, o qual independe do campo de radiação utilizado. Assim, o algoritmo aplicado não só prepara as imagens para o processo de combinação, mas valida a 
utilização de um campo reduzido para a realização mais rápida das simulações.

Neste trabalho, o método de pinhole $[114,115]$ foi adotado para a estimativa e eliminação da componente espalhada das imagens. Este método consiste em posicionar uma placa colimadora de chumbo com $1 \mathrm{~mm}$ de espessura, logo acima do detector de imagens, cobrindo toda sua superfície. A placa possui pequenos orifícios com $1 \mathrm{~mm}$ de diâmetro igualmente espaçados em intervalos de $1 \mathrm{~cm}$, pelos quais, apenas fótons com ângulos muito baixos em relação ao eixo de incidência conseguem atravessar. Com isso, foi possível criar uma "máscara"capaz de estimar o número de fótons primários que passam por cada orifício. Então, esta máscara é subtraída da imagem total (adquirida sem a presença da placa de chumbo). Os sinais resultantes obtidos nas localizações de cada orifício foram utilizados para se estimar a contribuição do espalhamento na imagem. Esta estimativa foi realizada ao se ajustar uma função quadrática superficial ao longo de todo plano espacial (x,y), dada a seguir:

$$
S(x, y)=\left(c_{0}+c_{1} \cdot x+c_{2} \cdot x^{2}\right)\left(c_{3}+c_{4} \cdot y+c_{5} \cdot y^{2}\right)
$$

A superfície de espalhamento estimada é então subtraída da imagem total, resultando em uma imagem que considera apenas a contribuição do feixe primário. Este algoritmo foi aplicado através do Matlab ${ }^{\circledR}$.

A figura 3.7 ilustra o processo de estimativa do perfil da componente de espalhamento de uma imagem. Neste exemplo, foi utilizado um feixe de $24 \mathrm{kVp}$ (Mo/Mo) irradiando toda a área do detector. Foi considerada uma mama com $4 \mathrm{~cm}$ de espessura.

A eficiência da correção de espalhamento foi avaliada através do cálculo da porcentagem de erro do valor quadrático médio ( $R M S p e)$, descrita pela equação 3.9. Esta grandeza calcula a diferença entre os valores absolutos de pixel adquiridos para duas imagens [116].

$$
R M S_{p e}=\frac{100}{\sqrt{n}} \sqrt{\sum_{i=1}^{n}\left(\frac{I_{p c}-I_{p s}}{I_{p s}}\right)^{2}}
$$

onde, $n$ é o número de pixels da imagem e $I_{p c}$ e $I_{p s}$, são os sinais dos pixels (dados 


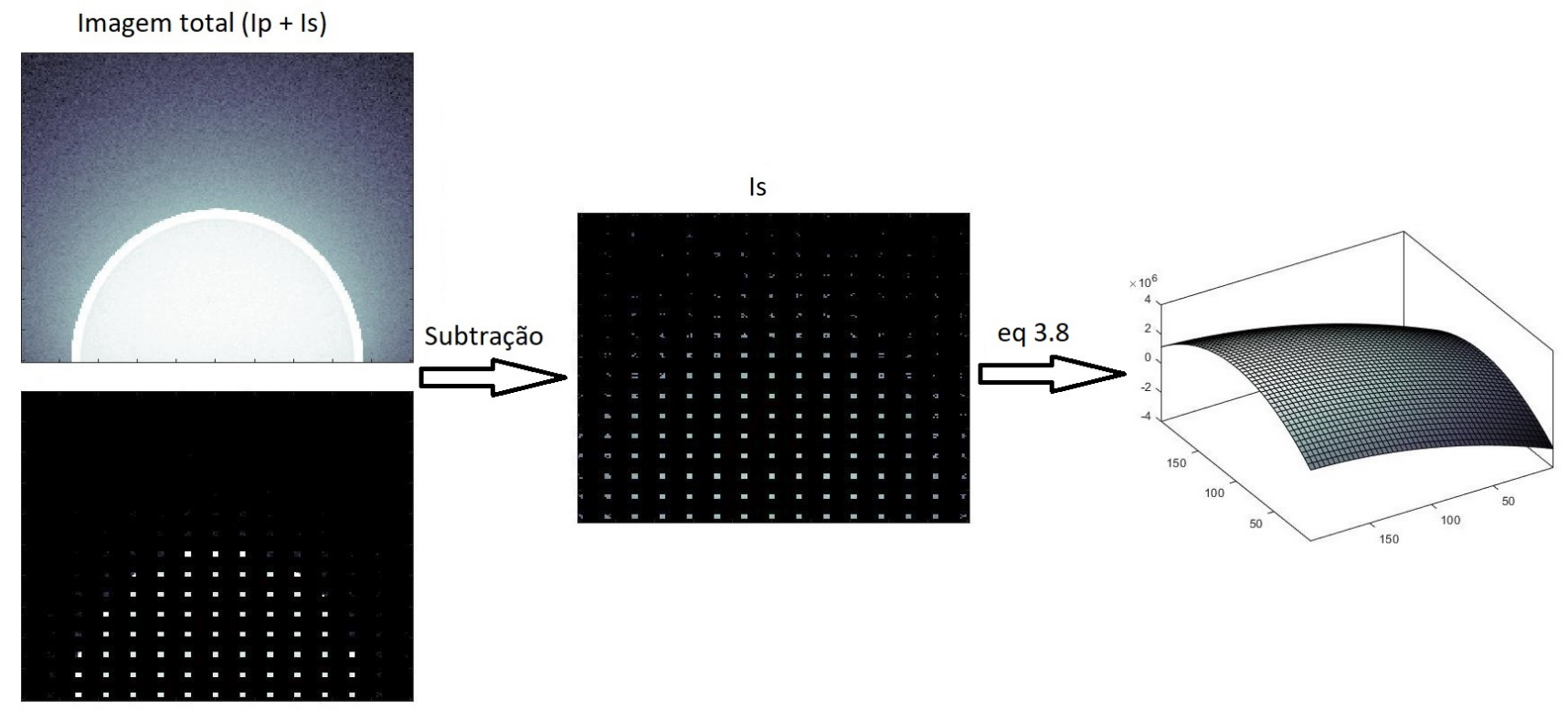

Imagem com grade (Ip)

Figura 3.7: Esquema de aplicação do método de pinhole para a estimativa do perfil de espalhamento da imagem.

em energia absorvida) das imagens corrigida pelo algoritmo e simulada apenas com a componente primária, respectivamente.

Para fins comparativos, imagens considerando a componente primária foram simuladas. Os valores de RMSpe foram calculados entre estas imagens e as aquelas corrigidas pelo processo de pinhole. Um estudo adicional foi realizado, calculando o RMSpe entre as imagens simuladas apenas com a componente primária e as imagens não-processadas, contendo ambas as componentes primária e espalhada. Os resultados obtidos neste trabalho foram comparados com os de Kappadath et al [115].

Para diminuir o tempo de simulação, foi utilizada neste trabalho uma área de radiação reduzida, englobando apenas a região de interesse da mama [117]. Porém, a distribuição da radiação espalhada é dependente do tamanho da área de radiação [118]. Com base nisso, a eficiência do algoritmo de algoritmo de pré-processamento foi também analisada para estas condições. 


\subsubsection{Sinais de referência e mapas de $\mathbf{D}_{l}$ e $\mathbf{D}_{h}$}

Para a construção dos mapas de $\mathrm{D}_{l}$ e $\mathrm{D}_{h}$, de acordo com a seção 2.6.3, foram simulados dois tipos sinais de referência encontrados na literatura $[6,7,18,33,38$, 119]. O primeiro, considerando uma incidência direta do feixe de radiação sobre o detector, sem a presença da mama. Este modelo foi chamado neste trabalho como "referência I0", por conter apenas a informação do feixe não atenuado pela mama. O segundo modelo consiste na aquisição de imagens de um fantoma, composto de tecido $100 \%$ adiposo. Este modelo foi adotado de duas formas possíveis, considerando a composição elementar do tecido adiposo real, mostrado na tabela 3.1 e através da utilização de um fantoma CIRS (simulador de tecido adiposo), descrito na tabela 3.2 .

Os mapas de $\mathrm{D}_{l}$ e $\mathrm{D}_{h}$ tiveram seus comportamentos estudados, avaliando suas dependências com a energia do feixe utilizado e comparando as influências exercidas por cada tipo de imagem de referência utilizada.

\subsubsection{Fantoma de calibração e mapas de $\mathrm{DC}_{l}$ e $\mathrm{DC}_{h}$}

Como foi observado na seção 2.6.3, um fantoma de calibração é necessário para a realização do processo de combinação das imagens.

A figura 3.8 mostra o fantoma de calibração construído para este trabalho.
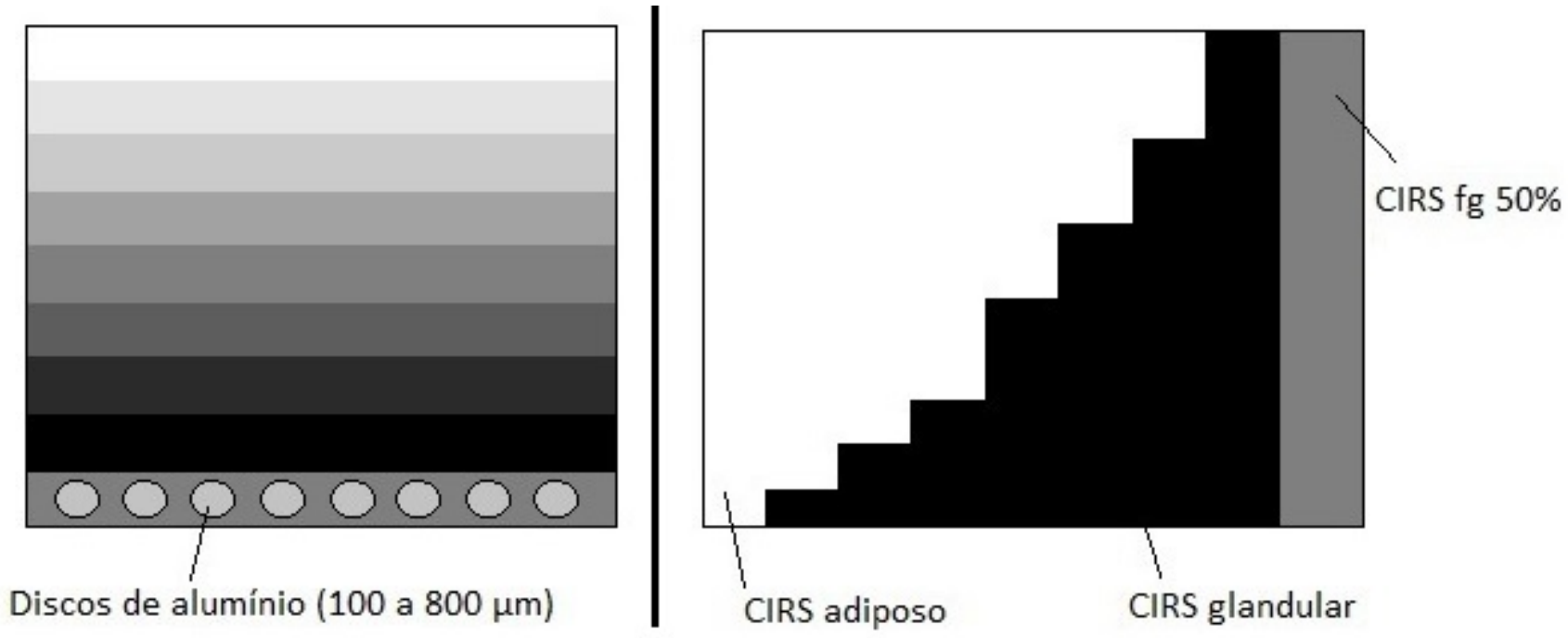

Figura 3.8: Vistas superior (esquerda) e lateral (direita) do fantoma de calibração utilizado neste trabalho 
Para a calibração de imagens quantitativas em morfologia de microcalcifiações, foi utilizada uma região do fantoma composta por um material CIRS, simulando um tecido homogêneo com 50\% de glandularidade. Nesta região, foram inseridos discos de alumínio com espessuras entre 100 e $800 \mu \mathrm{m}$.

Na quantificação da fração glandular foram utilizadas regiões do fantoma de calibração compostas por diferentes espessuras de materiais CIRS, simuladores de tecidos adiposo e glandular.

As composições elementares dos fantomas CIRS utilizados na calibração foram extraídos da tabela 3.2. Os mapas de $D c_{l}$ e $D c_{h}$ foram construídos de forma análoga às definições de $D_{l}$ e $D_{h}$. Foram feitas análises qualitativas e quantitativas de suas dependências com a energia do feixe de radiação e dose glandular absorvida na mama.

Um estudo adicional foi realizado, onde o fantoma de calibração foi modificado, substituindo os discos de alumínio por carbonado de cálcio $\left(\mathrm{CaCO}_{3}\right)$. Já as camadas de materiais CIRS simuladores de tecido adiposo e glandular foram substituídos por seus equivalentes de composição realista, descritos na tabela 3.1. Os valores de $D c_{l}$ e $D c_{h}$, adquiridos para as configurações de fantomas $A l+C I R S$ e $\mathrm{CaCO}_{3}+$ Tecidos, foram comparados em diferentes energias para uma espessura fixa. Este estudo serviu como um comparativo de como os materiais utilizados para a calibração se diferenciam dos tecidos reais, indicando possíveis fatores de correções para se evitar discrepâncias nas quantificações.

\subsubsection{Determinação dos coeficientes de calibração}

Com os valores de $\mathrm{Dc}_{l}$ e $\mathrm{Dc}_{h}$ estabelecidos, os coeficientes de calibração, descritos nas equações 2.37 e 2.39, puderam ser determinados. Diversos autores determinam numericamente estes coeficientes, através do método de mínimos-quadrados [18, 41, 120, 121]. Porém, incertezas podem ser propagadas pela utilização deste método, gerando flutuações indesejadas nas quantificações de microcalcificações e frações glandulares [18].

Além do método utilizado pela literatura, este trabalho também utilizou a regressão linear com regularização de Tikhonov [122]. Este método é utilizado para resolver problemas mal-postos, os quais, são classificados por equações que não 
possuam uma solução única [123, 124].

Seguindo a lógica proposta por Bazán [125] e considerando um problema linear de acordo com a seguinte equação, temos:

$$
X . a=Y, \quad X \in \mathbb{R}^{m x n}
$$

onde $X$ e $Y$ são, respectivamente, uma matriz e um vetor conhecidos, utilizados para se resolver o vetor $a$, contendo os coeficientes de calibração. Caso o sistema seja mal-posto, a matriz $X$ se torna muito sensível à perturbações, gerando soluções para $a$ com um alto grau de imprecisão.

De forma resumida, a regularização de Tikhonov procura estimar a solução do vetor $a$, através da seguinte relação:

$$
a_{\xi}=\underset{a \in \mathbb{R}^{n}}{\arg \min }\left(\|\tilde{X} \cdot a-\tilde{Y}\|_{2}^{2}+\xi^{2} \cdot\|\kappa \cdot a\|_{2}^{2}\right)
$$

onde $\xi>0$ é o parâmetro de regularização, $\kappa \in \mathbb{R}^{m x n}$, a matriz de regularização, $\|.\|_{2}$, a norma Euclidiana e por fim, $\tilde{X}$ e $\tilde{Y}$ são considerações ruidosas da matriz $X$ e do vetor $Y$, sendo correlacionados por:

$$
\|\tilde{X}-X\|_{2} \leq \delta_{X} \quad e \quad\|\tilde{Y}-Y\|_{2} \leq \delta_{Y}
$$

onde $\delta_{X}$ e $\delta_{Y}$ são os níveis de ruído da matrix $\tilde{X}$ e do vetor $\tilde{Y}$, respectivamente.

O parâmetro $\xi$ regula o problema proposto de modo que sejam encontradas soluções aceitáveis, dentro de um determinado viés, correlacionado com a variância deste sistema [126]. Nota-se que para $\xi=0$, a equação 3.11 se aproxima de uma relação de mínimos-quadrados. A matriz de regularização $\kappa$ depende estritamente do problema proposto.

Este algoritmo foi implementado em Matlab ${ }^{\circledR}$ através de pacotes pré-instalados, onde os parâmetros ótimos de $\xi$ e da matriz $\kappa$ são encontrados computacionalmente.

As imagens combinadas através da aquisição dos coeficientes de calibração por ambos os métodos utilizados foram comparadas de acordo com o ruído propagado em cada processo de combinação, descrito pelo coeficiente de variação (CV) [127]: 


$$
C V=\frac{\sigma_{S}}{\bar{S}}
$$

onde $\sigma_{S}$ é o desvio padrão dos sinais dos pixels da região de interesse e $\bar{S}$, o sinal médio destes pixels.

Os coeficientes de calibração encontrados pelo método de mínimos-quadrados e pela regularização Tikhonov foram comparados, a fim de se compreender as características de cada técnica. Aquela que apresentou a melhor relação com o $C V$, e com a determinação dos coeficientes de calibração, foi utilizada para os seguintes processos de combinação e otimização do algoritmo de dupla-energia utilizada neste trabalho.

\subsubsection{Análise da Propagação de Ruído e Sua Correção}

Um estudo foi realizado procurando relacionar a variância dos sinais de um determinado grupo de calcificações presentes em uma imagem combinada com a contribuição (percentual) da escolha de baixa energia na dose glandular $(D g)$ média absorvida pela mama. Este estudo procura encontrar a proporção de dose glandular cedida por cada escolha de baixa e alta energias que minimize o ruído das imagens combinadas.

A dependência do ruído propagado também foi avaliado através de sua dependência com a espessura da mama e com a separação de kVps entre as escolhas de baixa e alta energias. Os resultados encontrados foram devidamente explicados a partir de princípios físicos e observações da literatura [7, 18, 20, 29, 39, 128].

Para eliminar parte do ruído propagado nas imagens combinadas foi aplicado um filtro mediana nos mapas de $\mathrm{D}_{h}$, como proposto na literatura [25, 129]. Este filtro tende a suavizar o sinal ruidoso, preservando as bordas de detalhes presentes nas imagens [130, 131, 132].

O algoritmo, aplicado através do Matlab ${ }^{\circledR}$, é descrito a seguir:

$$
\begin{gathered}
\left(D_{h}\right)_{i, j}^{\prime}=\left[\text { mediana },\left(D_{h}, \text { kernel }\right)_{i, j}\right] \\
\left(t_{c}\right)_{i, j}^{\prime}=t_{c}\left(\left(D_{l}\right)_{i, j},\left(D_{h}^{\prime}\right)_{i, j}\right)
\end{gathered}
$$




$$
(g r)_{i, j}^{\prime}=\operatorname{gr}\left(\left(D_{l}\right)_{i, j},\left(D_{h}^{\prime}\right)_{i, j}\right)
$$

Para a aplicação deste algoritmo foi adotado um kernel de 3 x 3 pixels. Tamanhos maiores de kernels foram avaliados e suas influências sobre as imagens resultantes do processo de combinação foram brevemente discutidas.

A eficiência deste processamento foi avaliado, de forma qualitativa e quantitativa, ao comparar imagens com e sem o tratamento de ruído, além de mensurar o ganho de CNR das calcificações presentes em imagens combinadas após sua aplicação, de acordo com a equação 2.19.

\subsection{Análises e Critérios de Otimização das Imagens Combinadas}

\subsubsection{Identificação e estimativa da morfologia de microcalcificações}

\subsubsection{Comparação de técnicas de combinação por dupla energia}

Foram analisados também mapas de $C N R$ construídos para diversas combinações de baixa e alta energias, utilizando ambas metodologias. Este estudo tem como objetivo avaliar como a propagação de ruído e regiões de otimização podem se diferenciar, dependendo das finalidades pelas quais, as imagens combinadas por dupla-energia são geradas.

\subsubsection{Análise e otimização do realce de microcalcificações em imagens quantitativas}

A avaliação do realce de microcalcificações foi realizada através da criação de mapas de $C N R$, calculados a partir da equação 2.19, em função das combinações de alta e baixa energias. Inicialmente, foram verificados os mapas de CNR para as diferentes espessuras de mama simuladas. Ainda neste caso, para fins de padronização, as demais condições de simulação respeitaram a tabela 3.4.

Após isso, os demais parâmetros como o tamanho das microcalcificações, os tipos de detectores, a qualidade dos feixes e as imagens de referência adotadas foram analisados, verificando suas infuências sobre os mapas de $C N R$. 
Tabela 3.4: Modelo padrão utilizado para as análises e otimizações da geração de imagens quantitativas.

\begin{tabular}{|c|c|}
\hline \hline \multicolumn{2}{c}{ Modelo padrão de teste (MPT) } \\
\hline Espessura & $2 \mathrm{a} 6 \mathrm{~cm}$ \\
\hline Sinal de referência & CIRS (Adiposo) \\
\hline Feixes de Baixa Energia & $\mathrm{Mo} / \mathrm{Mo}$ \\
\hline Feixes de Alta Energia & $\mathrm{W} / \mathrm{Cu}$ e W/Al+Cu \\
\hline Detector & $\mathrm{aSe}$ \\
\hline
\end{tabular}

Por fim, foram analisadas regiões de escolhas de energia em comum para todos os testes realizados, com os quais são obtidos os melhores realces de microcalcificações.

\subsubsection{Otimização da estimativa da morfologia de microcalcificações}

Os mesmos passos da etapa 3.5.1.2 foram realizados para o estudo da acurácia da quantificação das microcalcificações.

Dois critérios foram utilizados nesta etapa. O primeiro é a precisão (Prec), com o qual se verifica a flutuação nas estimativas da espessura de microcalcificações de um mesmo grupo. A precisão foi calculada de acordo com a seguinte equação:

$$
\operatorname{Prec}(\%)=100 .\left(1-\frac{\sigma t_{c m}}{\overline{t_{c m}}}\right)
$$

sendo $\sigma t_{c m}$, o desvio padrão das estimativas de espessura para um determinado grupo de microcalcificações e $\overline{t_{c m}}$, a espessura média estimada.

O segundo critério adotado foi a exatidão (Exat), o qual verifica a diferença entre a espessura média de um grupo de microcalcificações e sua espessura real (simulada). A exatidão é definida pela seguinte equação:

$$
\operatorname{Exat}(\%)=100 .\left(1-\left|\frac{\overline{t_{c m}}-t_{c s}}{t_{c s}}\right|\right)
$$

sendo $t_{c s}$, a espessura real das microcalcificações.

Os mapas de contorno de precisão e exatidão foram analisados em conjunto. As regiões de escolhas de energia com as quais eram obtidas as melhores relações de 
precisão e exatidão, foram classificadas como ótimas.

Escolhas de energias com as quais são obtidos uma precisão e exatidão igual ou superiores à 85\%, são classificadas como aceitáveis.

\subsubsection{Estimativa e otimização da quantificação de frações glandulares}

Para esta etapa, foi calculada a exatidão das estimativas de frações glandulares, de forma análoga à descrita pela equação 3.18. Valores acima de $85 \%$ foram classificados como aceitáveis. Assim como nas etapas de estudo e otimização da estimativa de microcalcificação, diversos testes foram realizados, criando mapas de contorno de exatidão, variando os parâmetros de simulação, como descrito na etapa 3.5.1.2 e respeitando a tabela 3.4.

Em conjunto, foi analisado o ruído propagado nas imagens quantitativas em fração glandular, para determinadas configurações de simulação. Este estudo foi realizado através do cálculo de coeficiente de variação $(C V)$, descrito pela equação 3.13 . 


\section{Capítulo 4}

\section{Resultados}

\subsection{Validações das Modificações no Código PENELOPE e da Construção do Modelo Geométrico}

A adaptação básica do código PENELOPE para cálculos de grandezas dosimétricas e geração de imagens foram devidamente validados em trabalhos anteriores [33, 40]. Porém, neste trabalho foram aplicadas novas modificações, visando aproximar as simulações de um ambiente clínico, como a implementação de detectores de CsI e aSe e a construção de um modelo geométrico completo mais detalhado. Nesta seção, são apresentados, descritos e discutidos os resultados que validam as modificações realizadas no código PENELOPE, empregados para a execução deste trabalho. Esta validação foi feita através da comparação entre os dados da literatura $[8,44,107,108,109]$ e os encontrados neste trabalho.

As comparações foram divididas em duas subseções: A primeira subseção apresenta a validação do cálculo de dose glandular normalizada (DgN). A segunda subseção apresenta a validação da visualização de objetos presentes na mama, através do cálculo de CNR.

\subsubsection{Grandezas dosimétricas}

A figura 4.1 mostra os valores de $\mathrm{DgN}$ em função da energia de um feixe monoenergético, irradiando em uma mama $4 \mathrm{~cm}$, juntamente com os valores obtidos por Fedon et al [8]. 


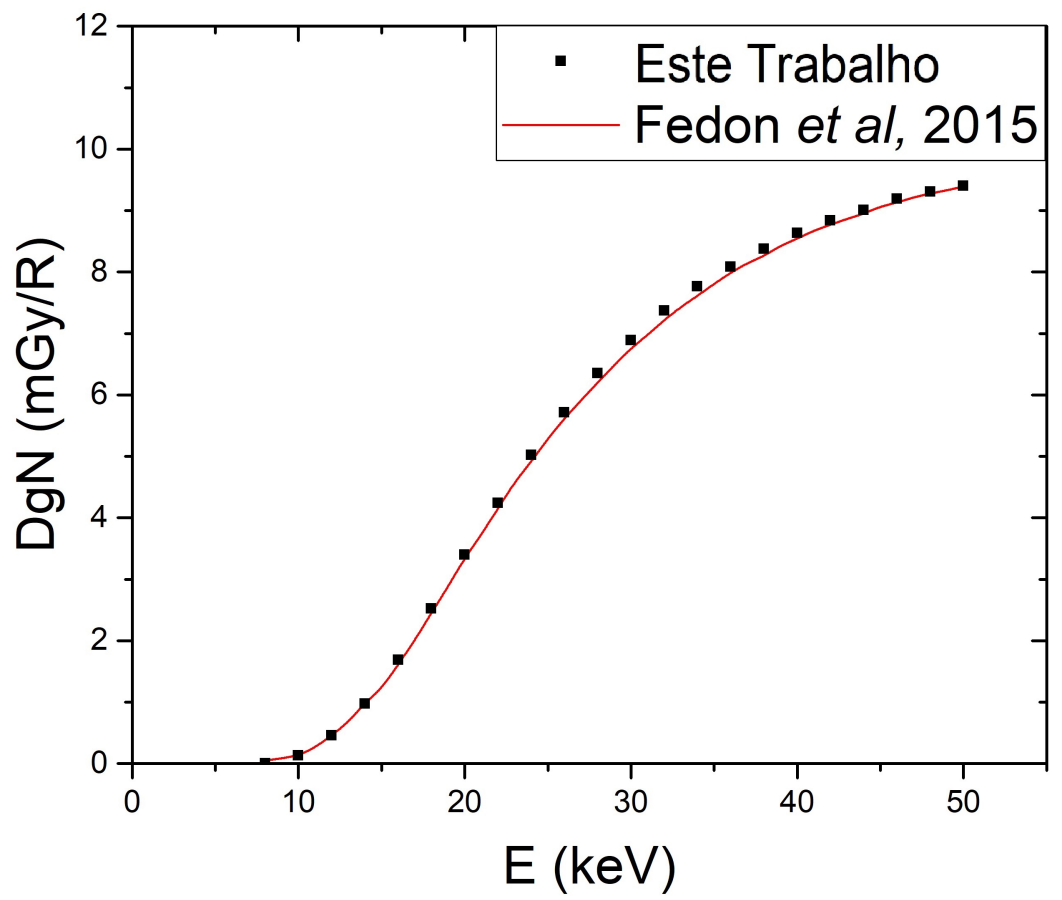

Figura 4.1: $D g N$ em função da energia de feixes monoenergéticos. Comparação entre os valores obtidos neste trabalho e os adquiridos por Fedon et al. [8], utilizando uma mama com $4 \mathrm{~cm}$ de espessura e $50 \%$ de glandularidade.

A figura mostra uma boa concordância entre os resultados, com uma variação média de $1.2 \%$ entre os valores deste trabalho e os da literatura [8]. A alta acurácia observada pode ser explicada pela utilização da mesma base de dados por ambos os trabalhos [133].

A figura 4.2 mostra os valores de $\mathrm{DgN}$ em função do HVL de feixes polienergéticos, para uma mama de $2 \mathrm{~cm}$ de espessura e $50 \%$ de glandularidade. São mostrados os dados adquiridos por este trabalho utilizando o modelo geométrico da literatura, com e sem a inclusão de um bucky, juntamente com os dados de Dance $[44]$.

A figura mostra uma boa concordância entre os resultados deste trabalho e os da literatura, com uma diferença média de 1.7\%. Dance [44] utilizou a base de dados de Storm \& Israel [134] para os cálculos de seção de choque total, diferentemente deste trabalho. Porém, para os fatores de forma coerente e funções de espalhamento incoerente, foram retirados dos trabalhos de Hubbell et al. [63] e Hubbel \& Øverbø 


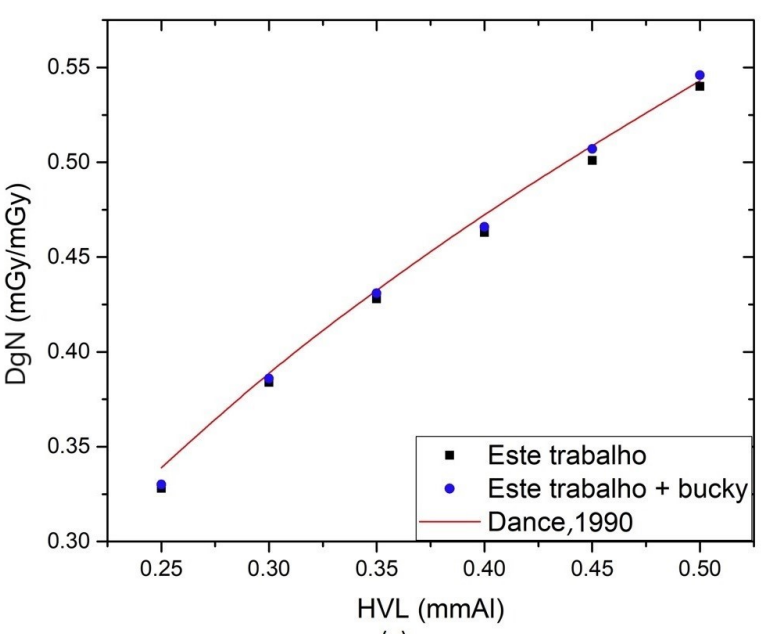

(a)

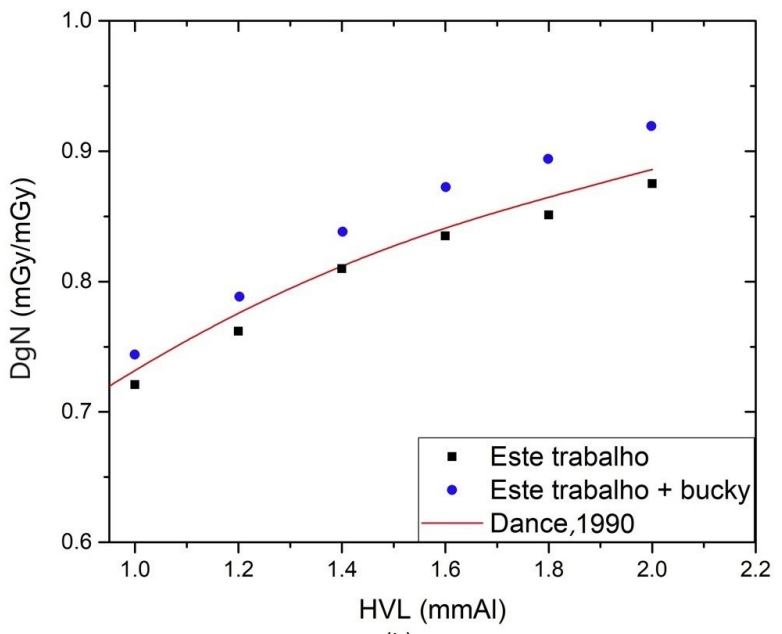

(b)

Figura 4.2: Valores de DgN em função do HVL para feixes de (a) baixa energia e (b) alta energia, utilizando uma mama de $2 \mathrm{~cm}$ de espessura e 50\% de glandularidade.

[135], os quais originaram a base de dados EPDL97 [133], utilizada pelo código PENELOPE.

A figura 4.2a mostra que a inclusão do bucky influenciou minimamente os resultados, causando um acréscimo menor do que $1 \%$ nos valores de DgN. Já na figura $4.2 \mathrm{~b}$, é visto que a inclusão do bucky causou um acréscimo considerável dos valores de $\operatorname{DgN}$ com o aumento do $H V L$, chegando à $5 \%$. Isto ocorre devido ao aumento de fótons transmitidos pela mama e retroespalhados pelas componentes do bucky $[5,73]$. Um trabalho foi realizado com o objetivo de investigar este fenômeno e foi concluído que o retroespalhamento gerado no bucky causa um acréscimo considerável nos valores de DgN ao simular mamas mais finas (abaixo de $4 \mathrm{~cm}$ ) e feixes de raios $\mathrm{X}$ mais energéticos. Este trabalho foi apresentado no $14^{\circ}$ Simpósio Internacional de Física das Radiações em Córdoba, Argentina (ISRP 2018) e submetido para publicação.

Vale ressaltar que este trabalho utilizou espectros de raios $\mathrm{X}$ baseados em cálculos de Boone et al. [53], enquanto Dance [44] se baseou em dados tabelados por Birch et al. [136]. Com base no que foi observado nas figuras 4.1 e 4.2 , pode se dizer que os cálculos de DgN se mostraram pouco sensíveis às diferentes resoluções de energia e fontes para a construção dos espectros. 


\subsubsection{Geração de imagens}

A tabela 4.1 mostra os valores de CNR para a visualização de discos de alumínio de $200 \mu \mathrm{m}$ inseridos em placas de PMMA de diferentes espessuras, irradiadas por feixes polienergéticos.

Tabela 4.1: Comparação dos valores de CNR adquiridos neste trabalho com aqueles encontrados na literatura, para a visualização de discos de aluminio de $200 \mu \mathrm{m}$ de espessura presentes em diferentes condições de simulação.

\begin{tabular}{|c|c|c|c|c|c|}
\hline \hline \multicolumn{7}{|c|}{ Validação: CNR } \\
\hline Autor & Sistema & Espessura $(\mathbf{c m})$ & $\mathbf{k V p}$ & $\mathbf{C N R}$ & CNR (Este trabalho) \\
\hline \multirow{3}{*}{ Baldelli et al. } & \multirow{2}{*}{ GE Seno DS } & 2 & $25(\mathrm{Mo} / \mathrm{Mo})$ & 13,9 & 15,1 \\
& & 4 & $27(\mathrm{Mo} / \mathrm{Rh})$ & 8,7 & 9,6 \\
& & 6 & $29(\mathrm{Rh} / \mathrm{Rh})$ & 6,6 & 7,1 \\
\hline \multirow{3}{*}{ Jakubiak et al. } & Siemens Mammomat Inspiration & 2 & $24(\mathrm{~W} / \mathrm{Rh})$ & 14,6 & 15,3 \\
& & 4 & $27(\mathrm{~W} / \mathrm{Rh})$ & 11,2 & 12,1 \\
& & 6 & $29(\mathrm{~W} / \mathrm{Rh})$ & 9,6 & 10,1 \\
\hline
\end{tabular}

De acordo com a tabela, as diferenças médias entre os valores de CNR encontrados neste trabalho e os retirados de Baldelli et al. [107] e Jakubiak et al. [108], foram de 6,2\% e 6\%, respectivamente. Os resultados adquiridos neste trabalho mostraram uma boa concordância com a literatura. A discrepância observada pode ser explicada pela aplicação de metodologias computacionais deste trabalho, a qual desconsidera detalhes estruturais dos detectores e certas fontes de ruídos além do ruído quântico, como os ruídos eletrônico e estrutural [76, 137, 138].

A figura 4.3 mostra os valores de FOM adquiridos por este trabalho e pela literatura [109], para a visualização de um disco de $1 \mathrm{~cm}$ de espessura, representando um tecido 100\% adiposo, inserido em uma mama de $4 \mathrm{~cm}$ de espessura com $50 \%$ de glandularidade.

É observada na figura uma boa correlação entre os resultados deste trabalho e a literatura [109], apresentando uma diferença máxima de 8,3\%. Assim como relatado na análise dos dados da tabela 4.1, esta diferença pode ser justificada pelas diferentes metodologias aplicadas entre os trabalhos.

De acordo com Poon \& Verhaegen [139], é esperada uma diferença de até $5 \%$ entre valores produzidos por simulações que se utilizam das mesmas bases de dados. Já para simulações que se utilizam de diferentes modelos físicos e fótons com 


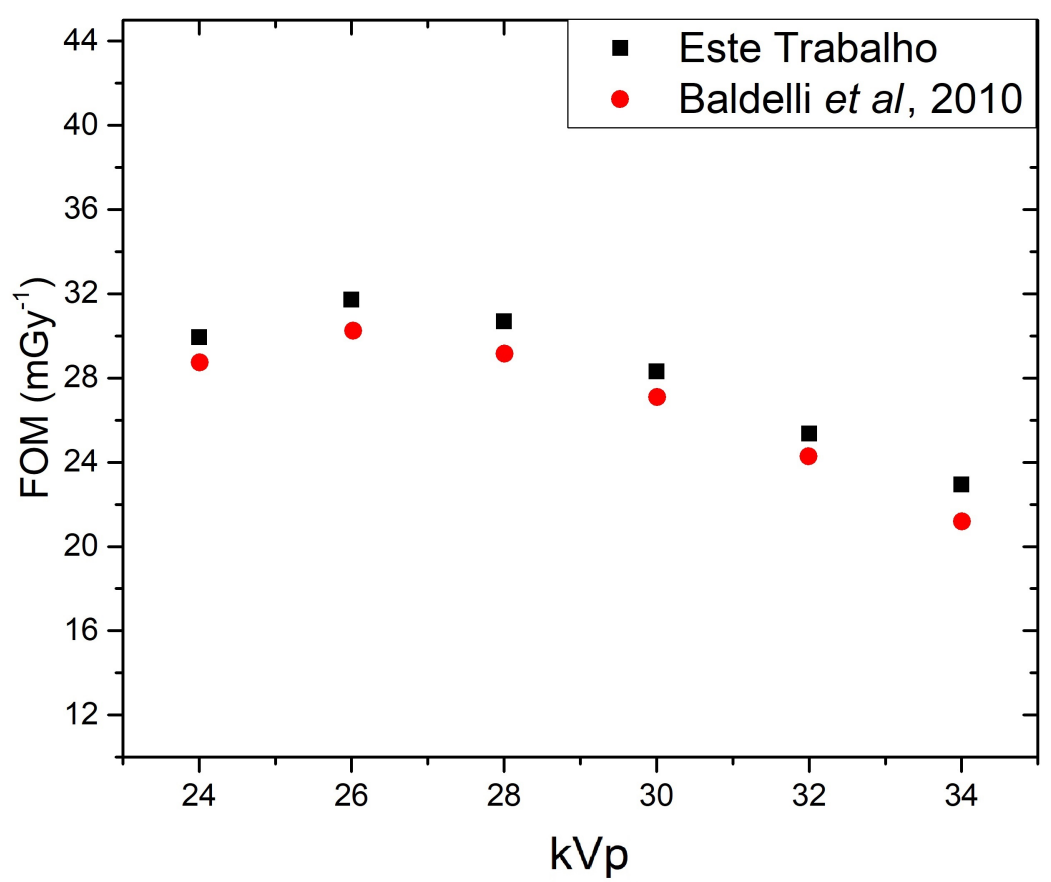

Figura 4.3: Valores de FOM em função do $k V p$, utilizando um fantoma CIRS simulando uma mama com $4 \mathrm{~cm}$ e $50 \%$ de glandularidade.

energia inferior à $1 \mathrm{MeV}$, é esperada uma diferença de até $15 \%$. Assim, os desvios encontrados nos resultados apresentados nesta seção estão de acordo com o previsto pela literatura, o que valida as modificações realizadas no código PENELOPE e a construção do modelo geométrico.

\subsection{Análise das Imagens Simuladas}

Nesta seção são realizados estudos qualitativos e quantitativos das imagens geradas (simuladas) neste trabalho. Uma comparação foi realizada para imagens simuladas a partir de mamas com 2 e $4 \mathrm{~cm}$ de espessura considerando diferentes detectores e qualidades de feixes de raio $\mathrm{X}$.

\subsubsection{Estudos da influência dos tipos de detectores}

A figura 4.4 mostra as influências do $\mathrm{kVp}$ e da escolha do tipo de detector, sobre o contraste, ruído quântico e CNR de calcificações com $600 \mu \mathrm{m}$ de espessura. 
Considerando uma mama $2 \mathrm{~cm}$ de espessura, $50 \%$ de glandularidade e dose absorvida de 0,6 mGy. Foram utilizados feixes com $\mathrm{kVp}$ entre 28 (Mo/Mo) e $80 \mathrm{kVp}$ $(\mathrm{W} / \mathrm{Al}+\mathrm{Cu})$.

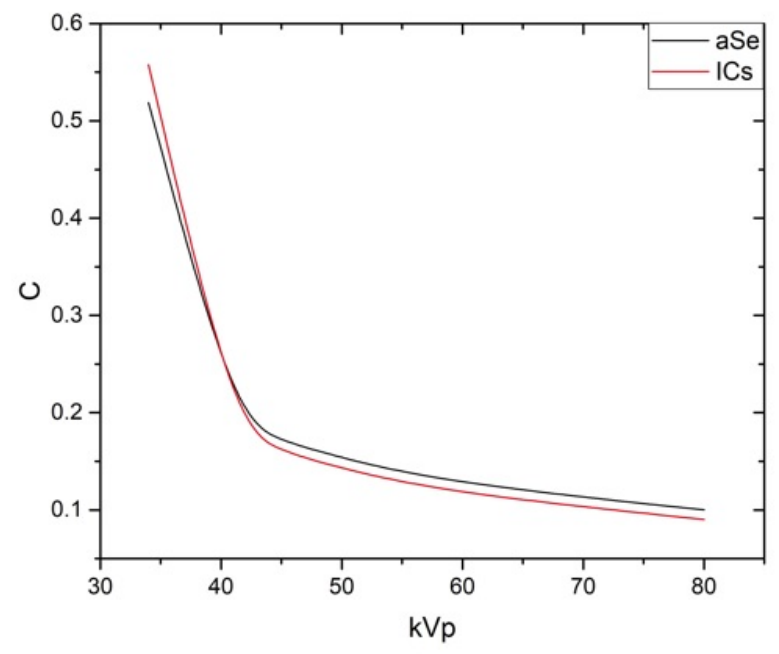

(a)

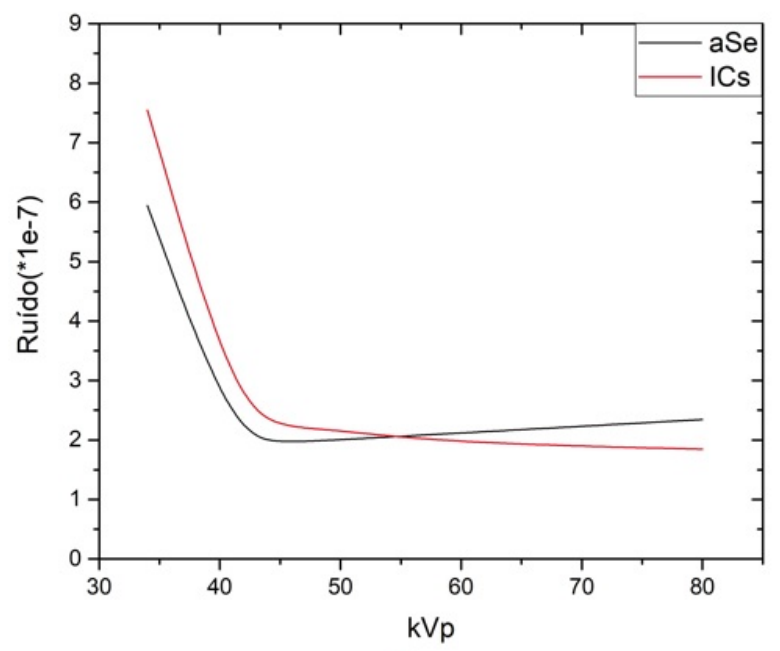

(b)

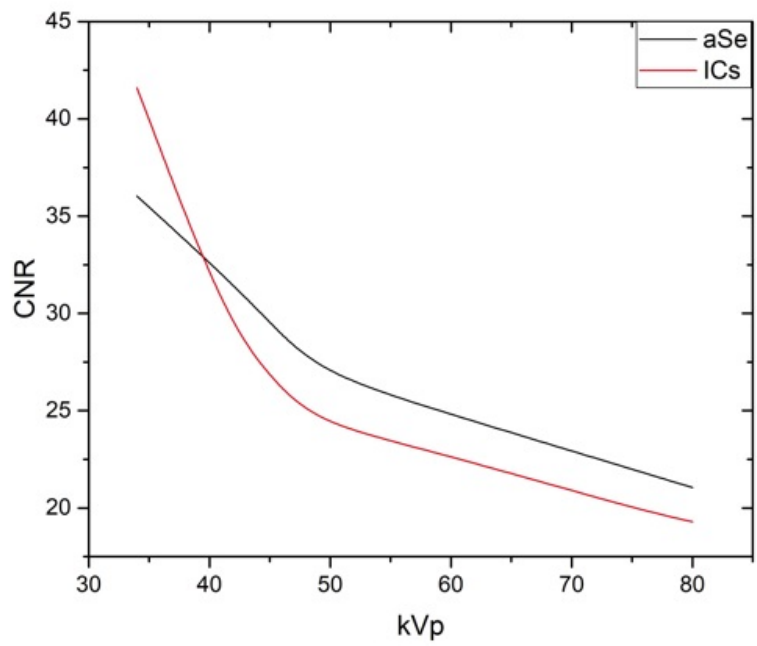

(c)

Figura 4.4: Análises de (a) contraste, (b) ruído e (c) CNR de calcificação com $600 \mu \mathrm{m}$ de espessura inseridas em uma mama com $2 \mathrm{~cm}$ de espessura e $50 \%$ de glandularidade. Imagens foram geradas para feixes de diferentes $k V p s$, utilizando detectores de CsI e aSe.

A figura 4.4(a) mostra o decréscimo do contraste com o aumento do $\mathrm{kVp}$ utilizado. Isso ocorre devido à diminuição da diferença entre os coeficientes de atenuação das calcificações e do background com o aumento da energia média dos fótons incidentes. Como o contraste depende apenas desta diferença e da espessura 
do objeto [113], é esperado que haja o decréscimo em seus valores com o aumento da energia do feixe de raios X. Foi observado também, que apesar da eficiência do CsI ser superior à do aSe em energias acima de $40 \mathrm{keV}$, de acordo com figura 3.4, seu contraste é inferior em maiores kVps. Isto ocorre, pois, a energia média dos fótons que são transmitidos pela calcificação é maior do que a dos fótons que transmitem em sua vizinhança, causando assim, uma maior diferenciação entre os sinais, graças à uma menor eficiência de absorção na região do objeto.

Na figura 4.4(b), é possível observar a queda do ruído com o aumento do $\mathrm{kVp}$. Isso ocorre devido ao aumento do número de fótons transmitidos pela mama com o aumento da energia média dos fótons incidentes. Também é observado que o ruído quântico do detector de aSe ultrapassa o do detector de $C s I$ em maiores kVps. Isto era previsto, pois como dito na análise da figura 4.4(a), a menor eficiência do $a S e$ em relação ao CsI em altas energias, faz com que uma menor quantidade de energia seja depositada no detector, causando assim, um aumento na incerteza do sinal observado. Este fato será de grande auxilio na aplicação do algoritmo de dupla energia para geração de imagens quantitativas, pois é visto que a imagem combinada recebe o ruído de ambas as contribuições de baixa e alta energias [31, 40]. Então, se uma imagem for muito ruidosa por sua baixa eficiência, ela pode prejudicar a imagem resultante do processo de combinação.

Por fim, a figura 4.4(c) mostra que a visibilidade das calcificações é melhor para o CsI em energias menores que $40 \mathrm{kVp}$. Esta observação influencia diretamente a aplicação computacional do algoritmo de dupla energia para a quantificação das microcalcificações. Como foi observado na literatura, a escolha de baixa-energia na combinação das imagens pode ter grande influência sobre contraste dos objetos [40].

A figura 4.5 mostra o sinal do detector em função de imagens geradas para uma mama com $4 \mathrm{~cm}$ de espessura e $50 \%$ de glandularidade, irradiada com diversos feixes polienergéticos. A dose glandular foi fixada em $1 \mathrm{mGy}$. Os valores de pixel foram coletados em regiões sem a presença de microcalcificações. A fim de eliminar a dependência da qualidade dos feixes, os dados foram levantados em função de suas energias médias.

É observada na figura a discrepância entre os sinais adquiridos em imagens geradas com feixes classificados neste trabalho como baixas e altas energias. Como 


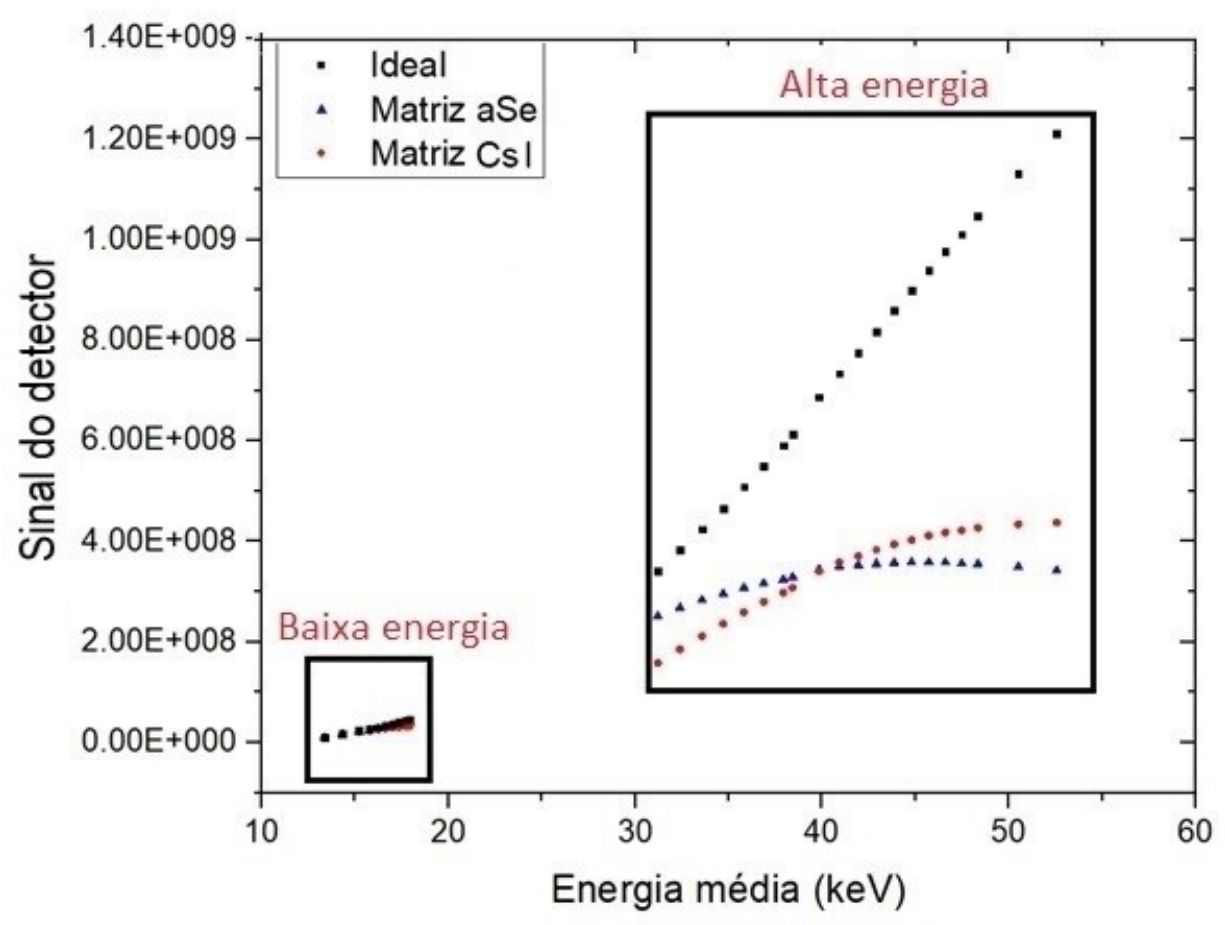

Figura 4.5: Sinal médio do detector em função da energia média do feixe de raios $X$ utilizado. Foi considerada uma mama com $4 \mathrm{~cm}$ de espessura e $50 \%$ de glandularidade.

explicado na seção 3.3.2, esta separação foi proposital, uma vez que já foi estabelecido na literatura $[6,18,20,29,31,40]$ que uma maior separação entre as escolhas de baixa e alta energias é recomendada para a minimização da propagação de ruído nas imagens, resultantes do processo de combinação. Na figura, também é possível observar a diferença entre os valores médios de pixel de imagens geradas pelos diferentes detectores. Os valores de pixel das imagens geradas com o detector de $a S e$ são ultrapassados pelos valores das imagens geradas por CsI na região próxima dos $40 \mathrm{keV}$, como previsto nos valores de eficiência mostrados na figura 4.4. De acordo com a literatura que se utiliza da técnica de dupla energia para o realce de microcalcificações [6, 31], as escolhas ótimas de energias combinadas são diretamente afetadas pela escolha do detector. Este fato será melhor analisado posteriormente, na seção de otimização das imagens combinadas, onde serão comparados valores de CNR coletados para imagens combinadas para o realce e para a quantificação das microcalcificações. 


\subsubsection{Verificação qualitativa das imagens geradas}

A figura 4.6 mostra a imagens geradas que foram utilizadas como base para a quantificação da morfologia de microcalcificações. São mostradas imagens geradas a partir da utilização de feixes de $49 \mathrm{kVp}(\mathrm{W} / \mathrm{Cu})$ e $60 \mathrm{kVp}(\mathrm{W} / \mathrm{Al}+\mathrm{Cu})$ e detectores de selênio amorfo $(a S e)$ e iodeto de césio $(C s I)$. A dose glandular recebida pela mama foi de $1 \mathrm{mGy}$.

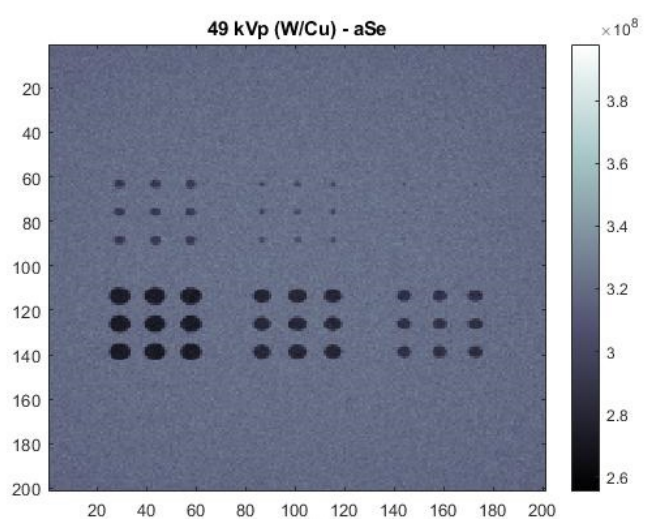

(a)

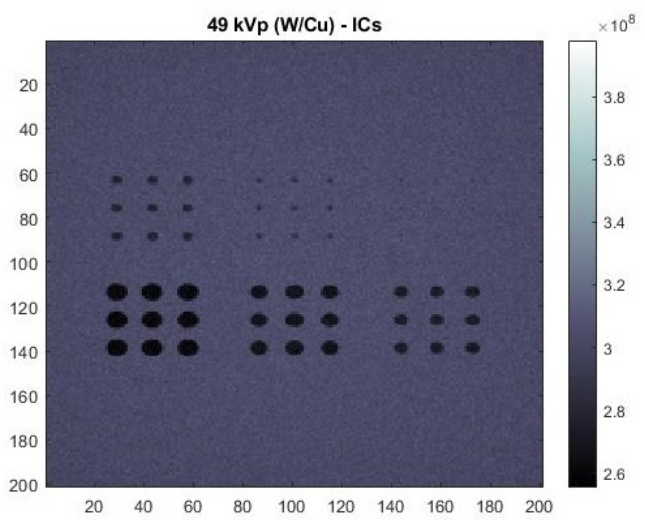

(c)

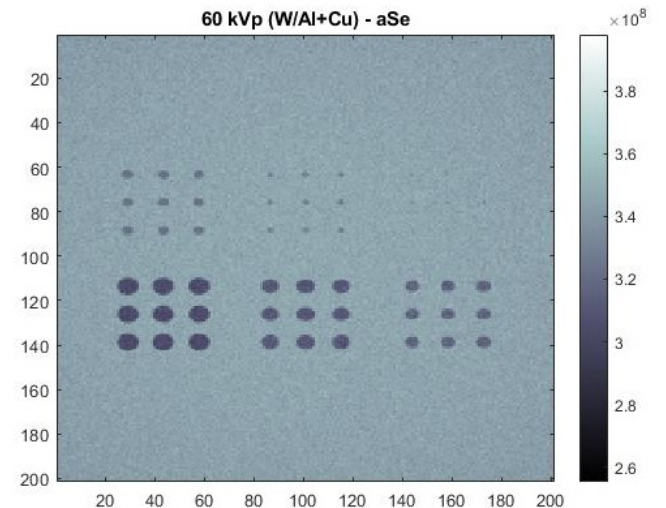

(b)

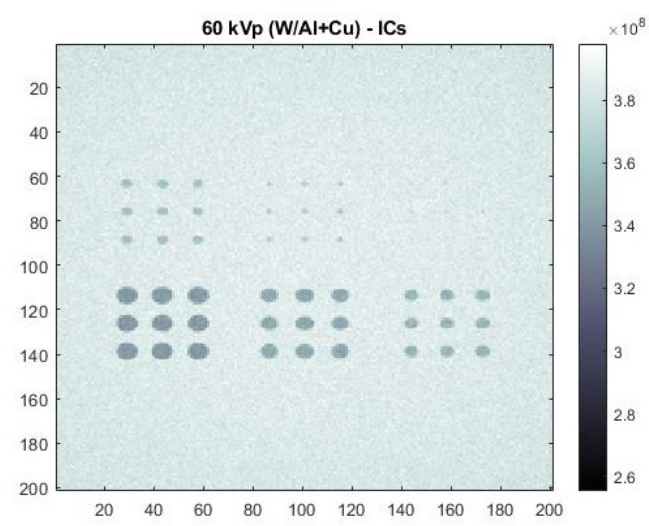

(d)

Figura 4.6: Imagens geradas para uma mama de $4 \mathrm{~cm}$ de espessura e glandularidade de 50\%, com presença de microcalcificações de diferentes morfologias, utilizando: (a) feixe de $49 \mathrm{kVp}$ e detector de aSe; (b) feixe de 60 $k \mathrm{Vp}$ e detector de aSe; (c) feixe de $49 \mathrm{kVp}$ e detector de CsI; (d) feixe de $60 \mathrm{kVp}$ e detector de CsI.

De acordo com a figura 4.6, há uma degradação na visibilidade das calcificações com o aumento da energia do feixe utilizado. Observando o grupo de calcificações com $600 \mu \mathrm{m}$ de espessura, foi calculado um valor de CNR para a figura 4.6(a) 14,6\% maior do que a calculada para a figura 4.6(b). Comparando as 
figuras 4.6(c) e 4.6(d), o decréscimo foi de 15,3\%. Esta diminuição na visibilidade ocorre devido a perda de contraste proporcionada pelo aumento da energia do feixe, como já observado na análise da figura 4.4(a). Observando os diferentes detectores, é possível notar a maior capacidade de visualização das calcificações na utilização do detector de $a S e$, em relação ao detector de CsI. Esta observação está coerente com as análises realizadas para a figura 4.4(c), onde é observado maiores valores de CNR na utilização do detector de $a S e$, energias maiores que $40 \mathrm{kVp}$.

É notado em todas as imagens apresentadas na figura 4.6, que as calcificações de $100 \mu \mathrm{m}$ de espessura são praticamente impercetíveis. Isto pode ser explicado a partir de dois fatores: primeiramente, como dito na seção 3.1, as calcificações possuem seus diâmetros equivalente às suas espessura. De acordo com o teorema de Nyquist [140], a resolução espacial de um sistema de imagem é aproximadamente o dobro do tamanho do pixel [141]. Assim, como os detectores utilizados neste trabalho possuem um tamanho de pixel de $75 \mu \mathrm{m}$, a máxima resolução espacial observável é de aproximadamente $150 \mu \mathrm{m}$. Outra explicação seria a limitação da dose cedida na mama para a geração das imagens. Diversos autores [6, 29, 129] determinaram que o diâmetro mínimo de uma calcificação detectável está entre 150 e $250 \mu \mathrm{m}$. Esta limitação se dá principalmente pela propagação do ruído quântico [115]. Tanto este trabalho quanto os autores citados, utilizaram limites de dose glandular aceitos pelo Protocolo Europeu de Controle de Qualidade em Mamografia [88], portanto, possuem limitações semelhantes na visualização de microcalcificações.

A figura 4.7 mostra a imagens geradas que foram utilizadas como base para as quantificações de fração glandular e componentes do tecido mamário (lipídio, proteína e água). São mostradas imagens geradas a partir da utilização de feixes de $49 \mathrm{kVp}(\mathrm{W} / \mathrm{Cu})$ e $60 \mathrm{kVp}(\mathrm{W} / \mathrm{Al}+\mathrm{Cu})$ e detectores de selênio amorfo $(a S e)$ e iodeto de césio $(C s I)$. A dose glandular foi referenciada a partir da camada com $50 \%$ de glandularidade, sendo definida em 1 mGy.

De acordo com a figura 4.7, as dependências dos valores de CNR com as energias do feixe e tipos de detectores utilizados, se assemelham às observadas na figura 4.6. Porém, a distinção entre as camadas homogêneas de tecidos adiposo e glandular são observadas sem limitações de frequência espacial. Os números atômicos efetivos dos tecidos adiposo e glandular são 6,33 e 6,93 [142] e de acordo 


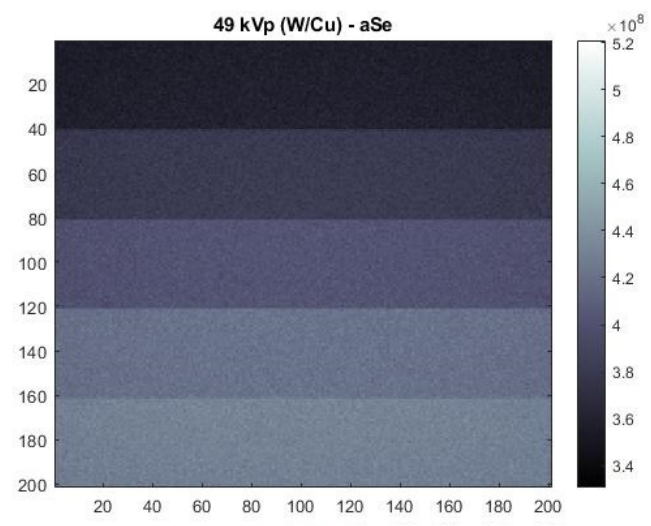

(a)

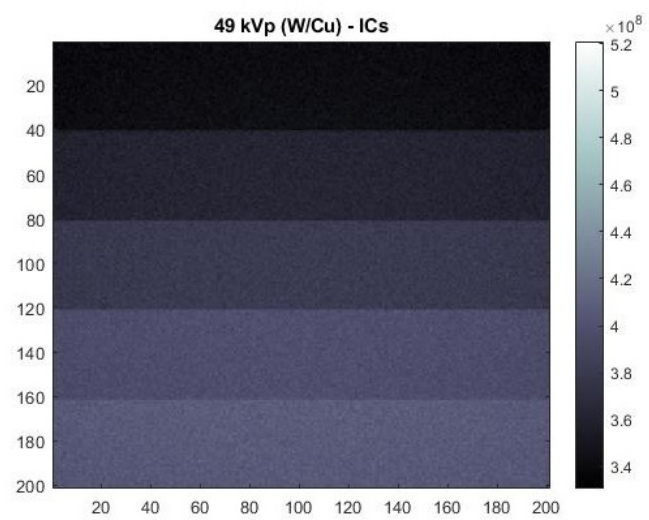

(c)

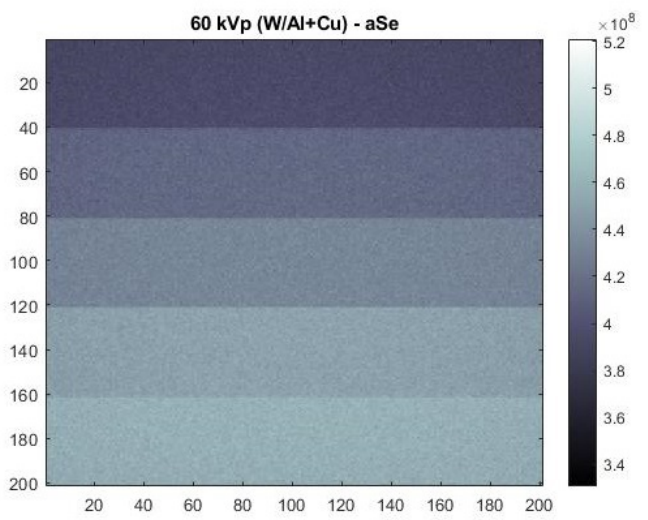

(b)

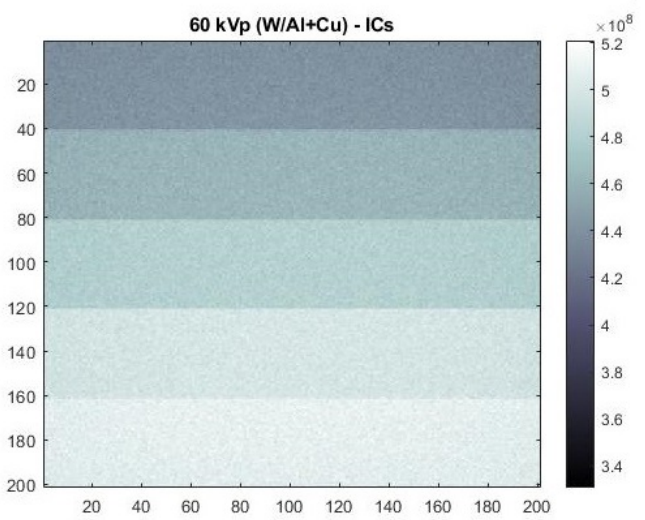

(d)

Figura 4.7: Imagens geradas para uma mama de $4 \mathrm{~cm}$ de espessura, seccionada em camadas homogêneas de diferentes frações glandulares, utilizando: (a) feixe de $49 \mathrm{kVp}$ e detector de aSe; (b) feixe de $60 \mathrm{kVp}$ e detector de aSe; (c) feixe de $49 \mathrm{kVp}$ e detector de CsI; (d) feixe de $60 \mathrm{kVp}$ e detector de CsI.

com Ducote \& Molloi [143], esta diferença pode ser explorada para se quantificar estes tecidos através da técnica de dupla energia.

Foi visto através das análises realizadas, que o CNR mínimo de um objeto observável nas figuras deste trabalho, se encontra entre 2,5 e 3. Em 1948, Rose [144] determinou de forma qualitativa, que um objeto seria identificável em uma imagem, caso possuísse uma razão sinal-ruído $(S N R)$ entre 3 e 5 . Estudos posteriores [145, 146] ampliaram os resultados de Rose e concluíram que um objeto é observável, caso apresente um SNR ou CNR no intervalo entre 2 e 5 . Assim, o limiar encontrado para este trabalho esta de acordo com previsto pela literatura. 


\subsection{Formação de Imagens Quantitativas}

\subsubsection{Pré-Processamento: Algoritmo de Correção de Espalhamento}

Nesta etapa são mostrados os resultados da aplicação do algoritmo correção de espalhamento, proposto por Kappadath et al. [115], nas imagens simuladas para este trabalho.

A tabela 4.2 mostra os valores de RMSpe de aquisição em diversas energias, entre imagens geradas apenas com o contribuição primária e as imagens com e sem a correção de espalhamento. Foi considerada uma mama com $4 \mathrm{~cm}$ de espessura e $50 \%$ de glandularidade. A dose glandular absorvida pela mama foi de $1 \mathrm{mGy}$ e os resultados foram observados considerando os detectores de aSe e CsI.

Tabela 4.2: Valores de RMSpe entre imagens geradas apenas com a contribuição da componente primária e imagens antes e depois da aplicação do algoritmo de correção de espalhamento. Foram comparadas imagens geradas para os detectores de aSe e CsI.

\begin{tabular}{|c|cc|cc|}
\hline \multicolumn{5}{c}{ RMSpe (\%) } \\
\hline $\mathrm{E}(\mathrm{kVp})$ & Sem correção (aSe) & Com correção (aSe) & Sem correção (CsI) & Com correção (CsI) \\
\hline $18(\mathrm{Mo} / \mathrm{Mo})$ & 12,18 & 1,31 & 12,32 & 1,32 \\
$24(\mathrm{Mo} / \mathrm{Mo})$ & 13,26 & 1,32 & 13,51 & 1,34 \\
$30(\mathrm{Mo} / \mathrm{Mo})$ & 11,84 & 1,08 & 12,36 & 1,13 \\
$49(\mathrm{~W} / \mathrm{Cu})$ & 8,14 & 0,61 & 7,71 & 0,58 \\
$50(\mathrm{~W} / \mathrm{Cu})$ & 8,68 & 0,70 & 8,41 & 0,63 \\
$60(\mathrm{~W} / \mathrm{Al}+\mathrm{Cu})$ & 7,74 & 0,57 & 7,27 & 0,55 \\
\hline Média & 10,31 & 0,93 & 10,26 & 0,92 \\
\hline
\end{tabular}

A eficácia do algoritmo de espalhamento da imagem fica clara na análise dos dados apresentados na tabela. Em média, o algoritmo eliminou $95 \%$ da componente espalhada, para ambos os detectores considerados. Kappadath et al. [115] observaram uma incerteza de 3 a $7 \%$ em suas estimativas. Assim, a eficiência na correção do espalhamento obtido por este trabalho é coerente com os resultados obtidos pelos autores. É importante notar que os autores utilizaram de um campo total de radiação, englobando toda a mama, enquanto neste trabalho, foi utilizado 
um campo reduzido. Isto mostra que o algoritmo é eficaz para quaisquer tamanhos de campo de radiação. Para as demais espessuras de mama consideradas neste trabalho, foi obtida uma eficácia semelhante na correção do espalhamento.

A figura 4.8 exemplifica o processo de eliminação do espalhamento de uma imagem gerada neste trabalho. Foi considerada uma mama com $4 \mathrm{~cm}$ de espessura e $50 \%$ de glandularidade, irradiada com um feixe de $24 \mathrm{kVp}$ (Mo/Mo). Foi utilizado um detector de $a S e$ e a dose glandular absorvida pela mama foi de $1 \mathrm{mGy}$.

Analisando qualitativamente, é possível observar a semelhança entre as figuras 4.8(a) e 4.8(d), indicando uma boa eficácia do algoritmo na eliminação da contribuição espalhada. Para este caso, o algoritmo eliminou $94 \%$ do espalhamento. A figura 4.8(c) mostra que a estimativa da componente espalhada respeitou o perfil quadrático esperado, de acordo com a literatura [73, 115, 118, 143]. Ao se analisar a visibilidade das calcificações de $600 \mu \mathrm{m}$ das imagens apresentadas nas figuras 4.8(a) e 4.8(d), foi visto que a imagem corrigida possui um CNR $8 \%$ menor em relação à imagem gerada apenas com a componente primária. Isto indica uma propagação de ruído por parte do algoritmo aplicado, estando coerente com as observações de Kappadath et al. [115], os quais constataram uma perda na visibilidade das calcificações.

Com base no que foi analisado, é evidente que o algoritmo foi eficaz na correção do espalhamento das imagens, preparando-as de forma aceitável para o processo de combinação. Todas as imagens deste trabalho passaram pelo processo de correção de espalhamento.

\subsubsection{Mapas de $\mathrm{D}_{l}$ e $\mathrm{D}_{h}$}

Nesta etapa são mostradas características dos mapas de $\mathrm{D}_{l}$ e $\mathrm{D}_{h}$, a partir da análise das influências exercidas em seus valores, pela energia do feixe de radiação e pelo sinal de referência considerada. Os resultados foram obtidos considerando uma mama com $4 \mathrm{~cm}$ de espessura e 50\% de glandularidade, irradiada por diferentes qualidades de feixes. A dose glandular absorvida foi de $1 \mathrm{mGy}$ e foi utilizado um detector de $a S e$.

A figura 4.9 mostra os valores de $\mathrm{D}_{l}$ e $\mathrm{D}_{h}$, em função da espessura das microcalcificações, utilizando diversos feixes de radiação. Foram consideradas os 


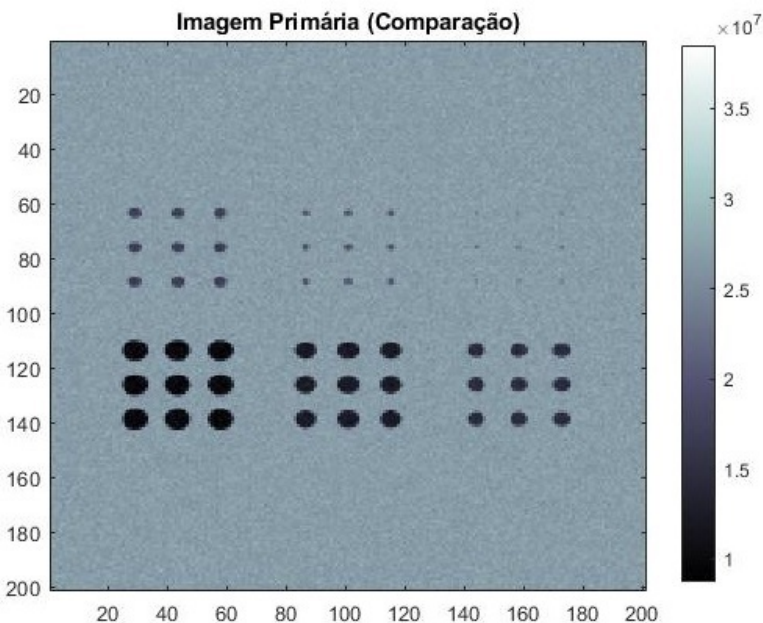

(a)

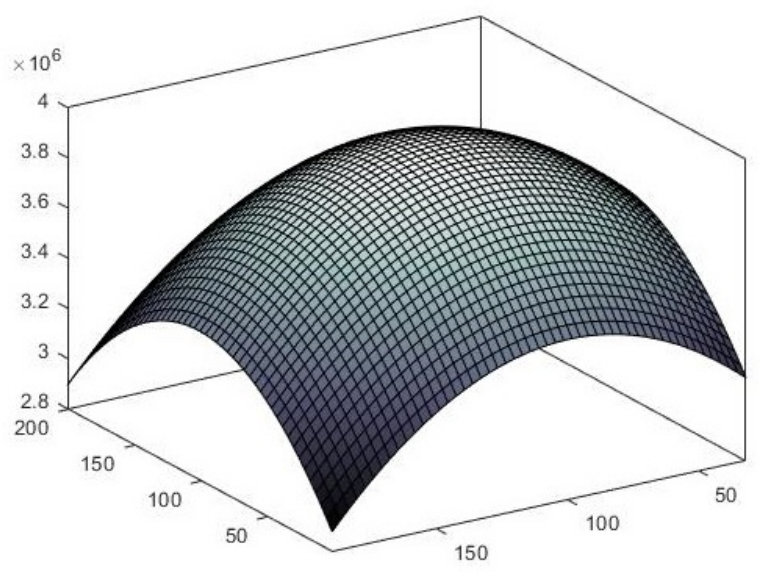

(c)

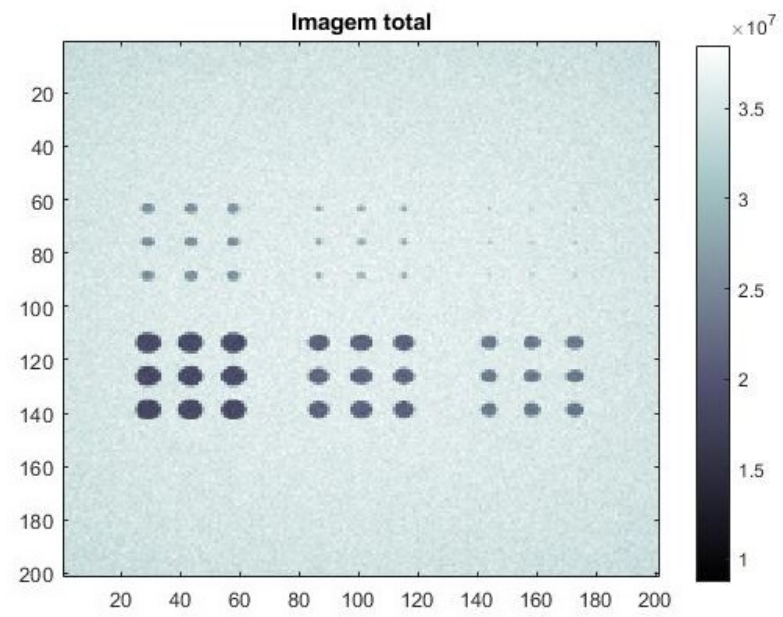

(b)

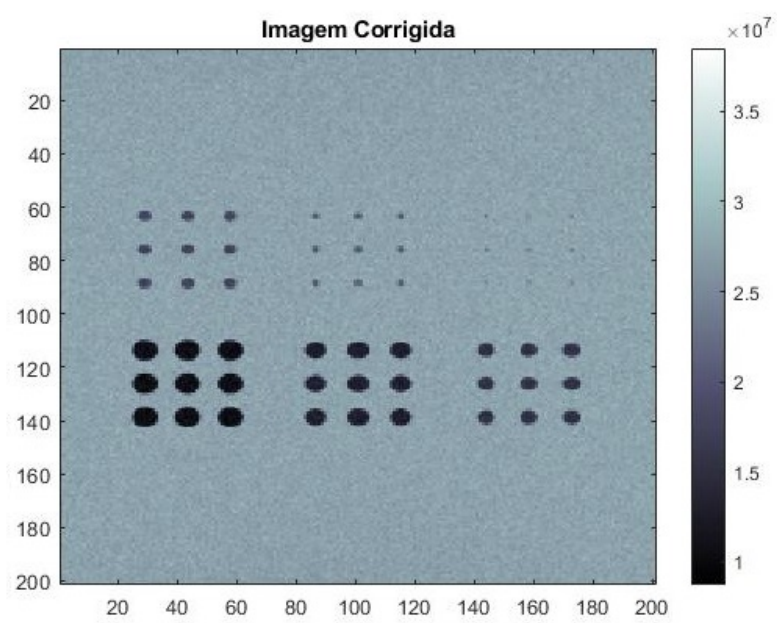

(d)

Figura 4.8: Processo de correção de espalhamento de uma imagem gerada utilizando um detector de aSe e uma mama de $4 \mathrm{~cm}$ e $50 \%$ de glandularidade, irradiada por um feixe de $24 \mathrm{kVp}$. São mostradas na figura: (a) A imagem gerada apenas com a componente primária; (b) a imagem total com componentes primária e espalhada; (c) o perfil estimado da componente de espalhamento; (d) a imagem corrigida.

sinais de referência adquiridas utilizando um fantoma CIRS, simulando um tecido $100 \%$ adiposo.

$\mathrm{Na}$ figura, fica clara a relação linear entre os valores de $\mathrm{D}_{l}$ e $\mathrm{D}_{h}$ e a espessura das microcalficicações. É observado também a queda do coeficiente angular das retas, com o aumento da energia do feixe utilizado. Estas observações são coerentes com o previsto na equação 2.35, com a qual, pode ser determinado que 


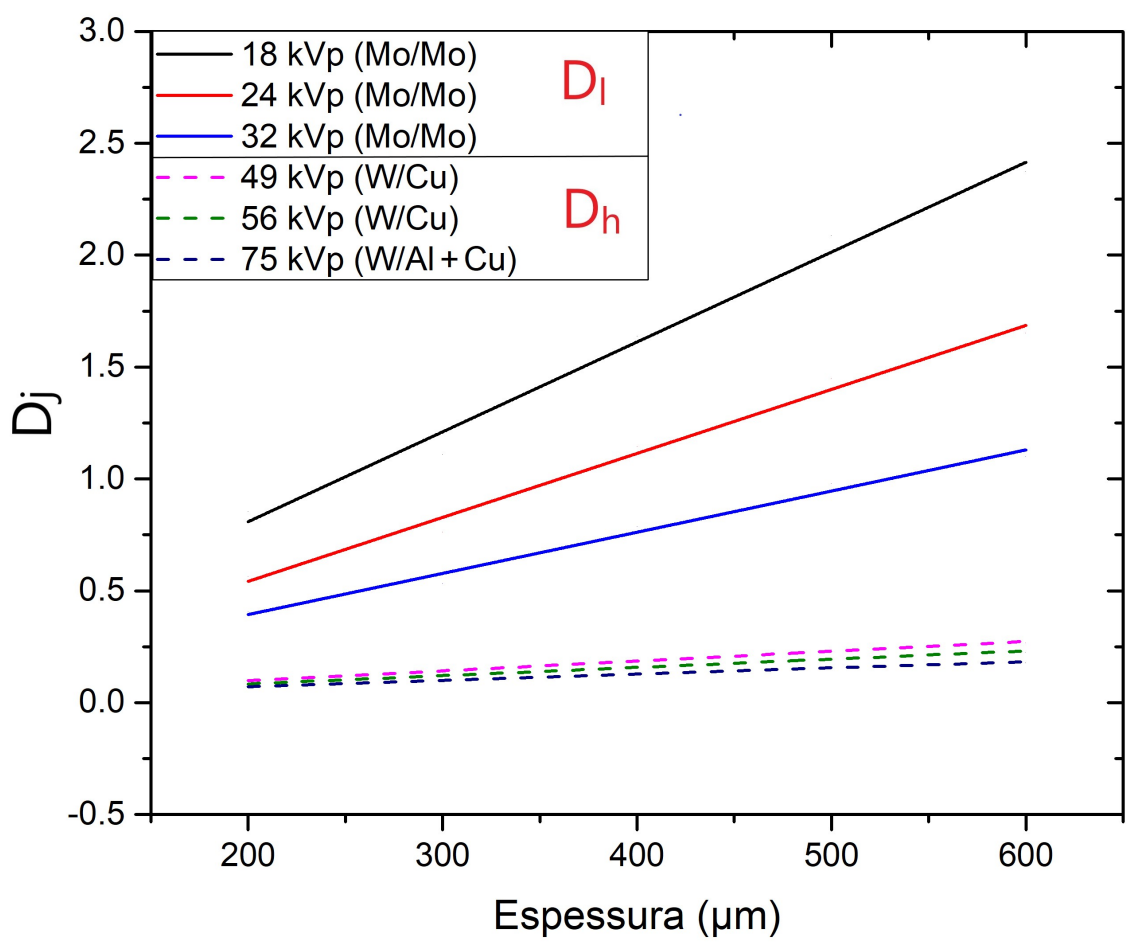

Figura 4.9: Valores de $D_{l}$ (traços contínuos) e $D_{h}$ (traços pontilhados), em função da espessura de microcalcificações. Foram utilizados diversos feixes, irradiando uma mama com $4 \mathrm{~cm}$ de espessura e $50 \%$ de glandularidade. Foram consideradas imagens geradas através de um fantoma CIRS, como referência para a construção das imagens.

o coeficiente angular das retas é igual à diferença entre os coeficientes de atenuação da microcalcificação e da mama. Com o aumento da energia média do feixe, há uma redução desta diferença [106], diminuindo assim, a angulação das retas. Os valores de $\mathrm{D}_{l}$ mostraram possuir uma sensibilidade maior às espessuras de microcalficiações e variações na energia dos feixe. As dependências de $\mathrm{D}_{l}$ e $\mathrm{D}_{h}$ são semelhantes aos do contraste de microcalcificações, o qual, para pequenas dimensões, possui uma relação linear com o tamanho do objeto e com a diferença entre seu coeficiente de atenuação e o de seu entorno $[51,117,147]$. Este fato reforça a ideia de que as contribuições em baixa energia são as maiores responsáveis pelo visibilidade das microcalcificações e dos componentes do tecido mamário nas imagens quantitativas geradas por técnica de dupla energia. 
A figura 4.10 compara características dos mapas de $\mathrm{D}_{l}$ e $\mathrm{D}_{h}$, para diferentes tipos de sinais de referência. Os resultados mostrados na figura 4.10(a) foram adquiridos para um feixe de $24 \mathrm{kVp}$ (Mo/Mo).

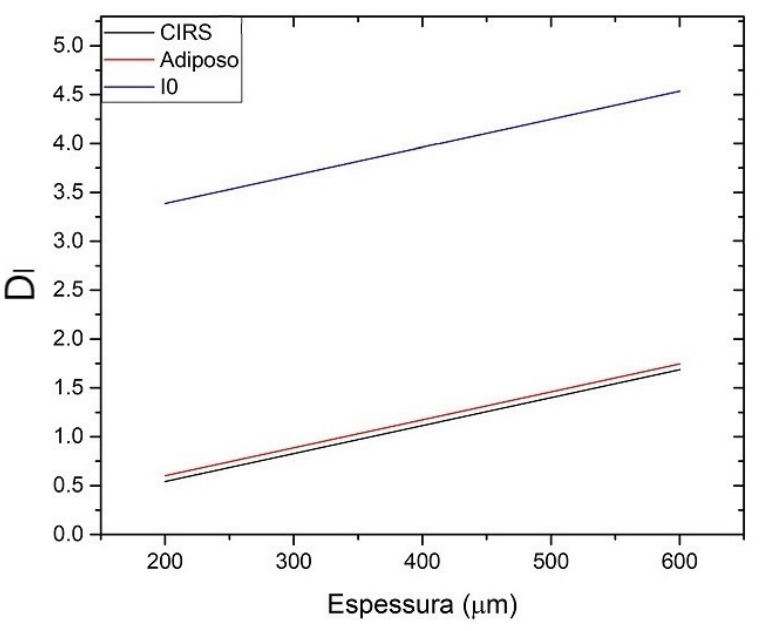

(a)

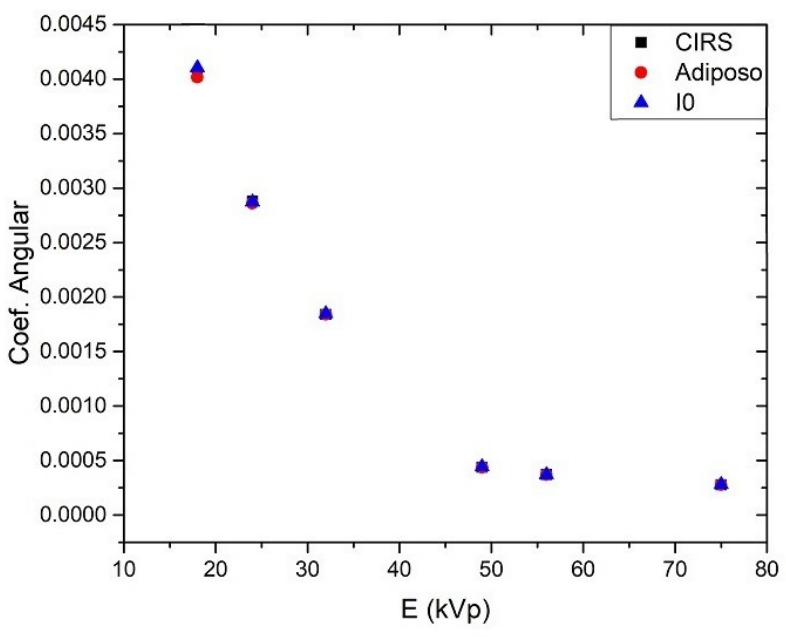

(b)

Figura 4.10: Estudo da influência do tipo de sinal de referência nas características de $D_{l}$ e $D_{h}$. (a) Valores de $D_{l}$, em função da espessura de microcalcificações, gerados com um feixe de $24 \mathrm{kVp}$ e diferentes tipos de sinais de referência. (b) Coeficiente angular das retas construídas em função da energia do feixe utilizado. Foram comparadas imagens de $D_{l}$ e $D_{h}$ geradas a partir da utilização das referências $I_{0}$, tecido mamário $100 \%$ adiposo e fantoma CIRS (100\% adiposo).

A figura 4.10(a) mostra que mapas de $\mathrm{D}_{l}$ construídos a partir de um sinal de referência $I_{0}$, possui valores de pixel maiores dos que os observados nos mapas construídos com as referências de tecido adiposo ou CIRS. Isso ocorre devido ao aumento do número de fótons que são absorvidos pelo detector na obtenção do sinal de referência $I_{0}$.

A proximidade entre as retas construídas com os fantomas 100\% adiposo e CIRS (simulando um tecido $100 \%$ adiposo) era esperada, já que estes fantomas possuem densidades e coeficientes de atenuação semelhantes $[106,110,111]$. Considerando um ambiente experimental, é evidente que para se adquirir os sinais de referência e os coeficiente de calibração, se faz necessária a utilização de um objeto que substitua o tecido adiposo real $[18,32,41]$. Os resultados observados aqui, validam a utilização deste fantoma para estudos clínicos. É observado também que as retas observadas estão paralelas entre si. A figura 4.10(b) ilustra este fato, ao 
comparar os coeficientes angulares das retas obtidas para os três tipos de referência, em função da energia do feixe. É notado que a angulação das retas não dependem do tipo de referência tomada. Isto está de acordo com as análises da figura 4.9, onde é concluído com base na equação 2.35, que a curvatura das retas depende exclusivamente de características da mama e do objeto estudado.

\subsubsection{Mapas de $\mathrm{Dc}_{l}$ e $\mathrm{Dc}_{h}$}

Nesta etapa foram realizados estudos quantitativos e qualitativos dos mapas gerados de $\mathrm{Dc}_{l} \mathrm{e} \mathrm{Dc}_{h}$. Foram feitas análises da influência da dose glandular cedida na mama nas curvas de calibração, além de possíveis discrepâncias entre sinais obtidos dos materiais de calibração e os componentes do tecido mamário. Foram considerados fantomas com $6 \mathrm{~cm}$ de espessura e o detector de $a S e$.

A figura 4.11 compara curvas de $\mathrm{Dc}_{l}$ e $\mathrm{Dc}_{h}$, em função das energias médias dos feixes de radiação, obtidas para doses glandulares de 0,12 mGy e 1,2 mGy. Um filtro mediana, com kernel de 3x3 pixels, foi utilizado nos mapas construídos a partir da dose glandular de 1,2 mGy, a fim de se eliminar o máximo de ruído. Os valores de $\mathrm{Dc}_{l}$ e $\mathrm{Dc}_{h}$ foram coletados para um disco de alumínio de $800 \mu \mathrm{m}$ inseridos no fantoma. O sinal de referência CIRS, simulando um tecido $100 \%$ adiposo foi utilizada na construção dos mapas.

A figura mostra que as curvas de $\mathrm{Dc}_{l}$ e $\mathrm{Dc}_{h}$ são suavizadas com o aumento da dose glandular absorvida. A imprecisão das curvas obtidas para 0,12 mGy ocorre devido à quantidade de ruído propagado para a construção dos mapas. Com o aumento da dose, este ruído tende a diminuir [148], aumentando a precisão nos valores obtidos de $\mathrm{Dc}_{l}$ e $\mathrm{Dc}_{h}$. A utilização do filtro mediana nas aquisição de 1,2 mGy fez com que o ruído fosse reduzido de forma significativa, sem prejudicar as informações da imagem [130]. Foi verificado durante a execução deste trabalho, que valores de $\mathrm{Dc}_{l}$ e $\mathrm{Dc}_{h}$ mal estabelecidos, prejudicam a exatidão da quantificação das características da mama. Com base nisto, pode ser determinado que para uma melhor acuraria das imagens quantitativas, geradas pela técnica de dupla-energia, a calibração deve ser realizada com a menor propagação de ruídos possível.

A figura 4.12 mostra mapas de $\mathrm{Dc}_{l}$, obtidos a partir de fantomas irradiados 


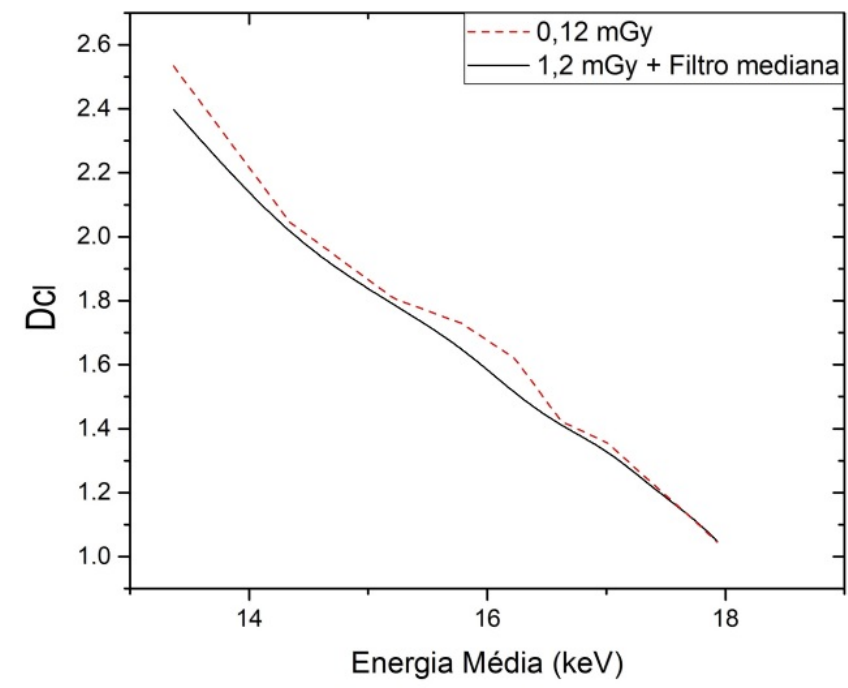

(a)

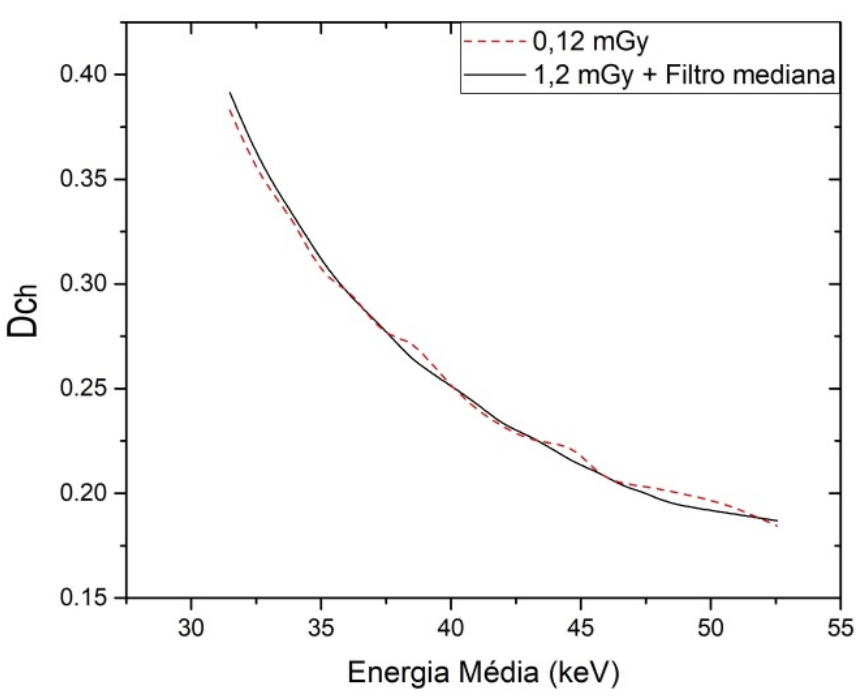

(b)

Figura 4.11: Valores de (a) $D c_{l}$ e (b) $D c_{h}$ obtidos para um disco de alumínio de $800 \mu \mathrm{m}$, em função da energia média do feixe e da dose glandular absorvida. Foi considerado um fantoma de calibração com $6 \mathrm{~cm}$ de espessura.

por um feixe de $34 \mathrm{kVp}$ (Mo/Mo), com doses glandulares fixadas em 0,12 e 1,2 mGy. Assim como para análises anteriores, a imagem de 1,2 mGy recebeu um tratamento de ruído através de um filtro mediana. O perfil dos valores de $\mathrm{Dc}_{l}$ dos discos de alumínio são descritos pelas linha vermelhas. Como no caso anterior, foi considerada para a construção do mapa, o sinal de referência CIRS, simulando um tecido $100 \%$ adiposo.

Comparando qualitativamente as figuras 4.12(a) e 4.12(c), fica claro o aumento da visibilidade e distinção dos discos de alumínio e camadas de tecidos adiposo e glandular (CIRS) com o aumento da dose cedida no fantoma. Os perfis dos discos de alumínio das figuras 4.12(b) e 4.12(d) ilustram melhor o aumento da acurácia nos valores de $\mathrm{Dc}_{l}$ para maiores doses absorvidas. Enquanto uma tendência clara dos sinais não é vista na figura 4.12(b), a figura 4.12(c) mostra a relação linear entre os valores de $\mathrm{Dc}_{l}$ e a espessura do objeto observado. Esta maior distinção beneficia a aplicação da técnica de quantificação por dupla energia, como discutido para a figura 4.11.

A figura 4.13 mostra as comparação entre valores de $\mathrm{Dc}_{l}$ e $\mathrm{Dc}_{h}$, obtidos para dois sistemas distintos, um construído com fantomas CIRS (simulando tecidos adiposo e glandular) e discos de alumínio e outro, construído com composições reais 


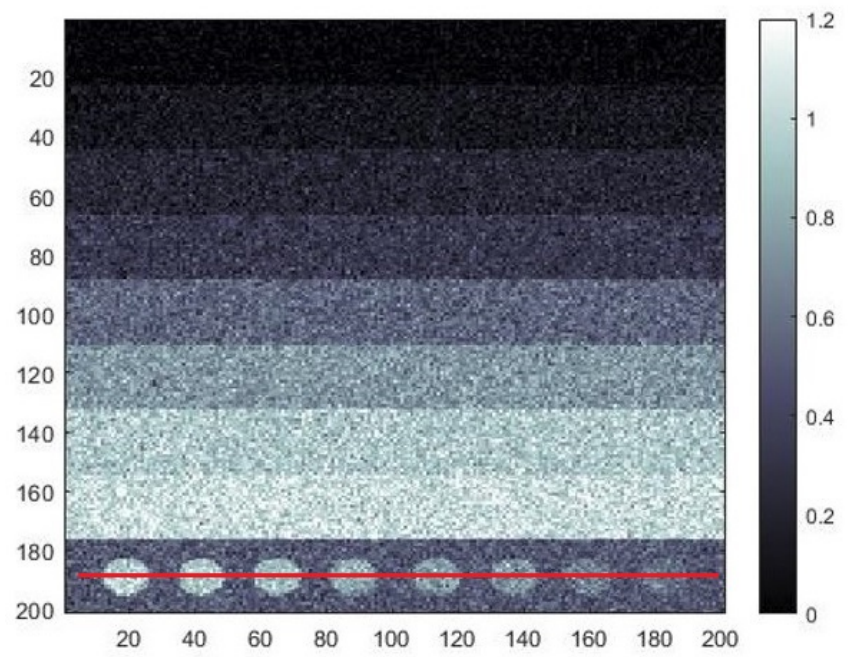

(a)

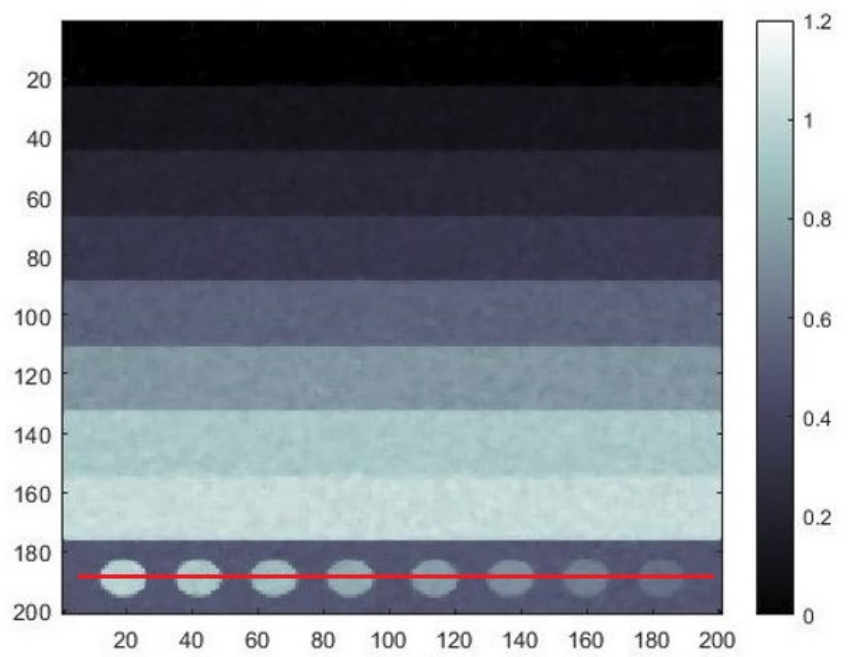

(c)

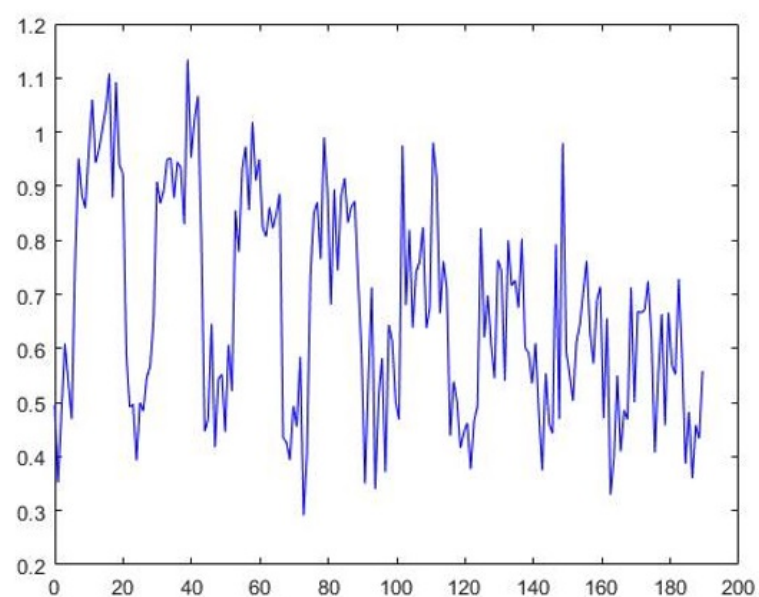

(b)

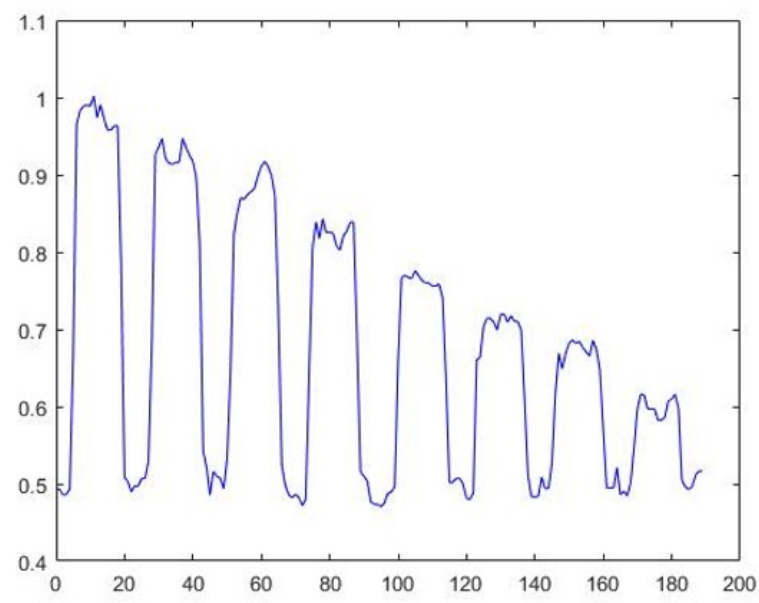

(d)

Figura 4.12: Mapas de $D c_{l}$ construídos a partir de um fantoma de calibração com $6 \mathrm{~cm}$ de espessura, irradiado por um feixe de $34 \mathrm{kVp}$ (Mo/Mo). (a) Mapa construído a partir de uma dose glandular de 0,12 mGy e (b) o perfil dos valores de $D c_{l}$ dos discos de alumínio. (c) Mapa construído a partir de uma dose glandular de 1,2 mGy e (d) o perfil dos valores de $D c_{l}$ dos discos de alumínio.

de tecidos adiposo e glandular e discos de $\mathrm{CaCO}_{3}$.

A figura 4.13(a) mostra que os valores de $\mathrm{Dc}_{l}$ e $\mathrm{Dc}_{h}$ com composições reais de tecidos se assemelham aos valores adquiridos com a consideração dos fantomas CIRS, para os dois feixes testados. Isso valida novamente o uso dos fantomas CIRS na calibração do sistema para a quantificação dos tecidos adiposo e glandular, sem a necessidade da aplicação de um fator de correção. Já a figura 4.13(b) mostra que as 


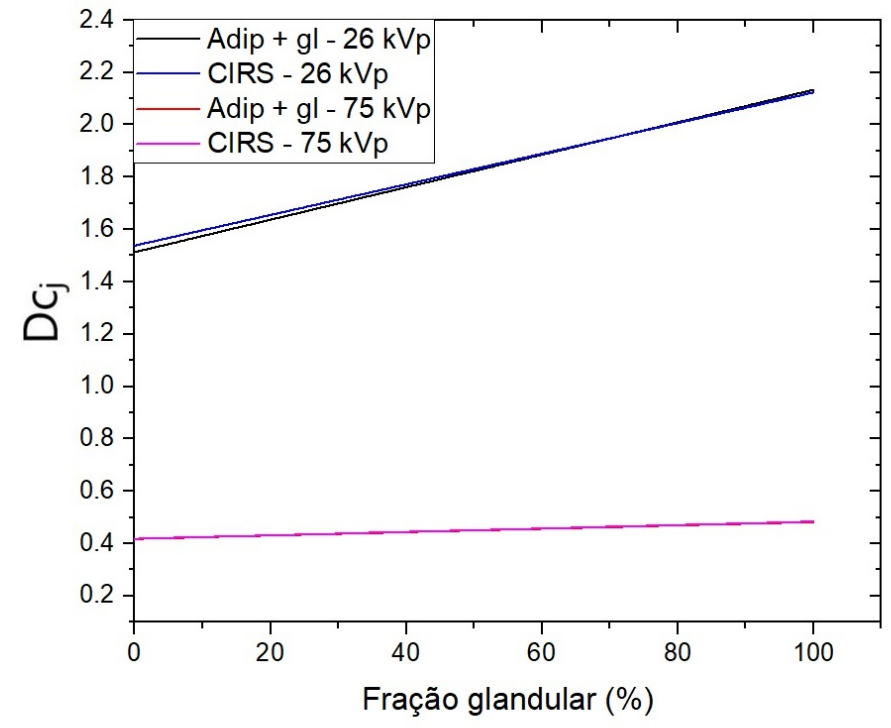

(a)

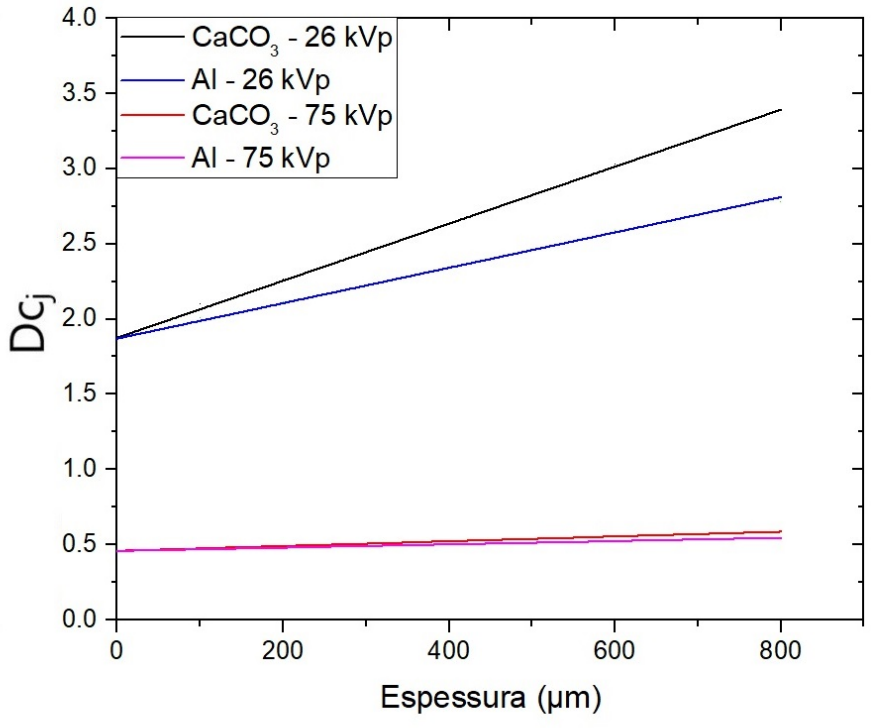

(b)

Figura 4.13: Comparação dos valores de $D c_{j}$, sendo $j=l, h$, obtidos: (a) Em função da fração glandular, considerando tecidos reais e fantomas simuladores CIRS; (b) Em função da espessura de discos de $\mathrm{CaCO}_{3}$ e alumínio. Foi considerado um fantoma de calibração com $6 \mathrm{~cm}$ de espessura.

retas construídas para os discos de $\mathrm{CaCO}_{3}$ e alumínio divergem com o aumento da espessura dos discos. Esta divergência é menor para o feixe de $75 \mathrm{kVp}$. Isto é coerente com a constatação realizada nas análises da figura 4.9, onde é visto que a angulação as retas dependem exclusivamente das diferenças entre os coeficientes de atenuação do objeto observado e o de seu entorno. Como a diferença entre os coeficientes de atenuação do alumínio e do $\mathrm{CaCO}_{3}$ são menores com o aumento da energia do feixe de raios X [106], as retas tendem a convergir. Chen et al. [149] constataram brevemente que um fator deve ser aplicado para se corrigir as discrepâncias entre os coeficientes de atenuação do alumínio e do $\mathrm{CaCO}_{3}$. Foi visto neste trabalho que a razão entre os coeficientes angulares das retas, mostradas na figura 4.13(b), é igual à razão entre os coeficientes de atenuação dos materiais estudados. Assim, conhecendo apenas a energia média do feixe de raios X utilizado, é possível aproximar os valores de $\mathrm{Dc}_{l}$ e $\mathrm{Dc}_{h}$ obtidos para o alumínio, de modo que fiquem coerentes com as características do $\mathrm{CaCO}_{3}$. 


\subsubsection{Aplicação do Algoritmo de Combinação de Imagens}

Nesta etapa é discutida a aplicação do algoritmo de combinação das imagens, através da análise de propagação de ruído nas imagens combinadas e dos valores dos coeficientes de calibração estimados. Os resultados mostrados nesta seção foram obtidos para uma mama com $4 \mathrm{~cm}$ de espessura e $50 \%$ de glandularidade. Foram considerados os grupos de imagens gerados para o estudo da morfologia de microcalcificações, com um detector de $a S e$ e referência CIRS, simulando um tecido $100 \%$ adiposo.

A figura 4.14 mostra a propagação de ruído na combinação de imagens, determinados pelo coeficiente de variação $(C V)$. Os coeficientes de calibração foram adquiridos através da aplicação do método de mínimos-quadrados e pela regularização Tikhonov [122].

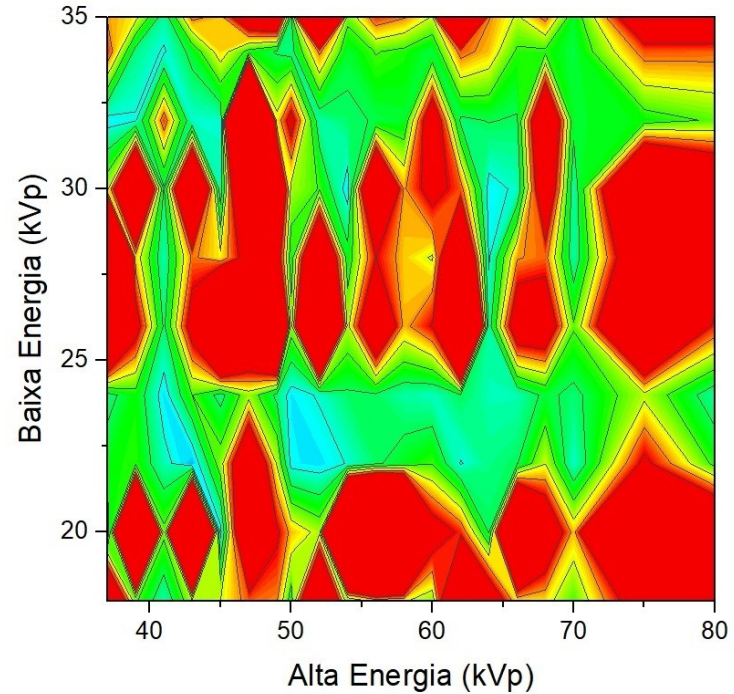

(a)

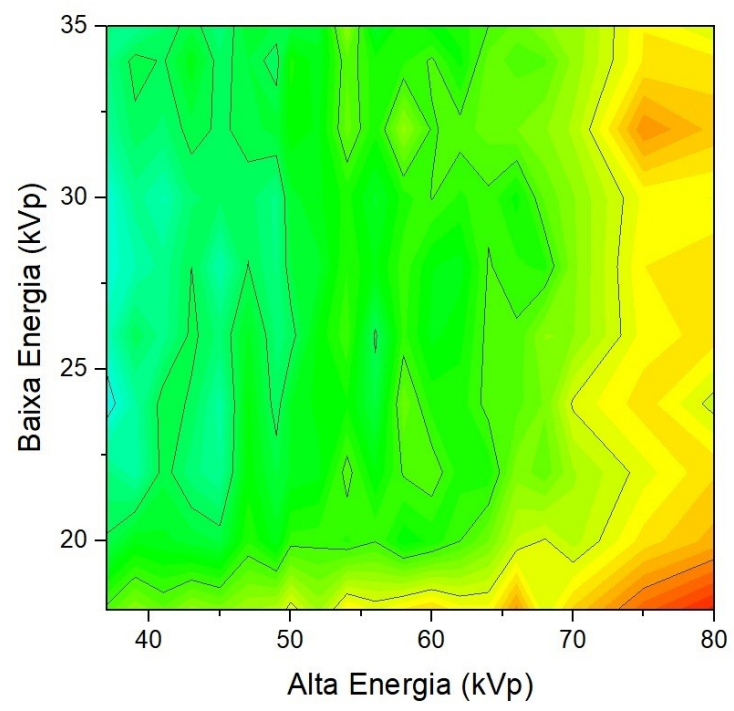

(b)

Figura 4.14: Propagação de ruído em imagens quantitativas, determinados pelo $C V$, geradas através da utilização dos métodos de (a) mínimos quadrados e (b) regressão linear com regularização Tikhonov.

A figura 4.14(a) mostra que a propagação de ruído das combinações de baixa e alta energias não seguem um padrão claro. Além disso, foi observado que para diversas combinações, a visibilidade das microcalcificações, bem como a quantificação de suas morfologias, foram comprometidas. As matrizes construídas com base no polinômio 2.37, para a estimativa dos coeficientes de calibração, podem 
ser caracterizadas como matrizes de Vandermonde [150]. Este tipo de matriz é mal-condicionada para a aplicação do método dos mínimos quadrados, sendo muito sensível à erros e suscetível a "overfitting"[151]. Foi observado neste trabalho, que um número baixo de iterações reduz os problemas citados. Entretanto, a variação do número ótimo de iterações se mostrou muito sensível para cada condição de simulação.

Como discutido na seção 3.4.4, a aplicação da regularização Tikhonov contorna o problema de matrizes mal-condicionadas, penalizando estimativas indevidas. A figura 4.14(b) ilustra como este método é eficaz em padronizar as combinações de imagem, reduzindo o ruído propagado pela estimativa dos coeficientes de calibração. Para se evitar o problema de matrizes mal-condicionadas, todas as combinações de imagens foram realizadas através da regularização do método dos mínimos-quadrados.

A figura 4.15 mostra valores de calibração obtidos para imagens combinadas em 24 e $49 \mathrm{kVp}$ através das duas técnicas propostas. A figura também mostra o perfil do sinal de microcalcificações da imagem construída a partir dos coeficientes de calibração regularizados. Os dados foram obtidos utilizando os mesmos parâmetros descritos para a figura 4.14 .

A 4.15(a) mostra que os coeficientes de calibração obtidos através da regularização Tikhonov são menos dispersivos entre si, se comparado com os valores obtidos através do método por mínimos quadrados. Esta menor dispersão implica em uma menor sensibilidade do sistema a flutuações de sinais ao se construir a imagem quantitativa. É notado também que os coeficientes obtidos por regularização flutuam sempre com valores positivos e em torno de zero. Isto ocorre pois esta técnica gera soluções (coeficientes) proporcionais à mínima variância calculada em cada interação [122, 152], a qual é sempre positiva por natureza. Isto gerou um novo viés, onde a regularização Tikhonov não penaliza o coeficiente linear do sistema, gerando um deslocamento nos valores estimados [153]. A figura 4.15(b) ilustra este fato, porém, é notado que as diferenças entre os sinais dos objetos observados e do background se aproximam dos tamanhos simulados das microcalcificações. Assim, com a aplicação de um simples offset, dependente das características da mama, é possível se ajustar os valores de pixel das imagens de modo que fiquem coerentes com as quantificações 


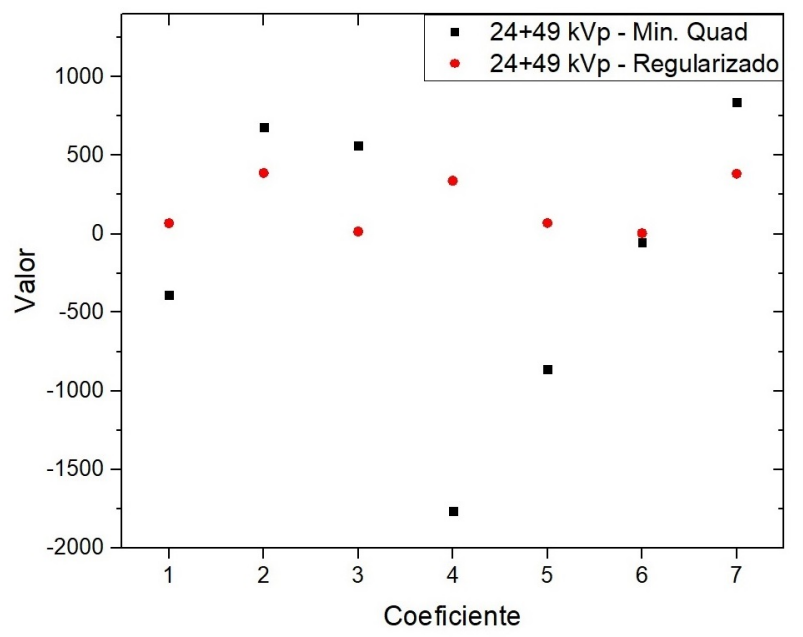

(a)

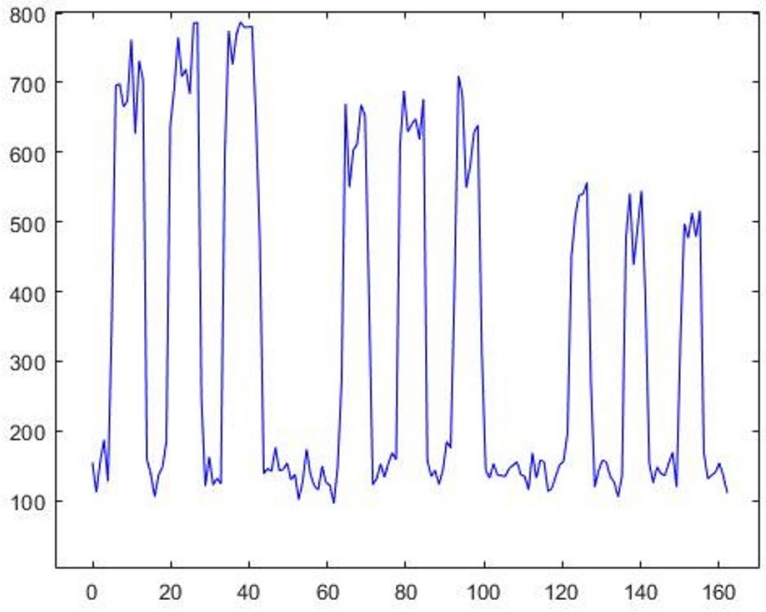

(b)

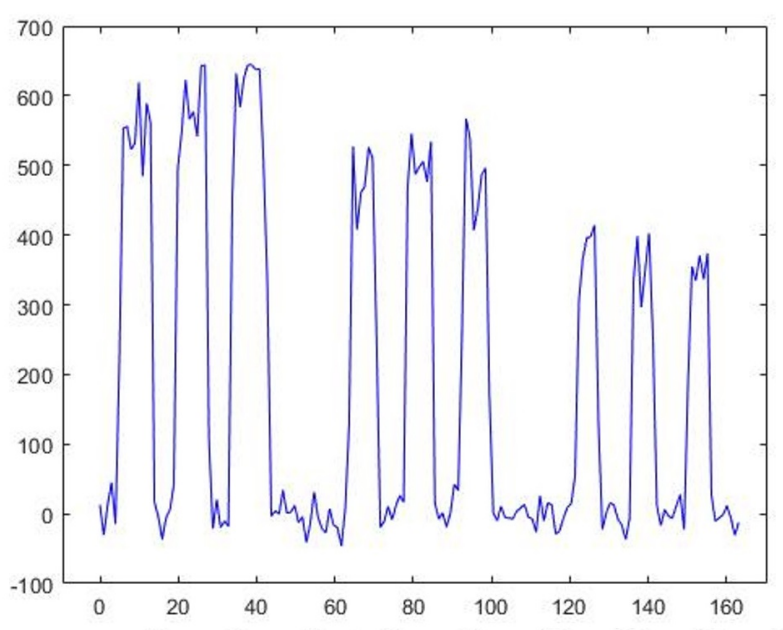

(c)

Figura 4.15: (a) Valores dos coeficientes de calibração para a combinação de 24 + $49 \mathrm{kVp}$ adquiridos através dos métodos de mínimos quadrados e regularização Tikhonov; Perfil do tamanho de microcalcificações em imagens geradas a partir do método regularizado, (b) sem e (c) com a aplicação de um offset.

desejadas, como visto na figura 4.15(c).

Apesar de se corrigir grande parte do ruído propagado pela estimativa dos coeficientes de calibração, flutuações provenientes das imagens combinadas ainda estão presentes. Para isto, foram realizados os estudos envolvendo a propagação dos ruídos provenientes destas imagens e a aplicação de um algoritmo de pós processamento. Estes estudos são mostrados na seção a seguir. 


\subsubsection{Análise da Propagação de Ruídos Aplicação do Algoritmo de Pós-Processamento}

A seguir são mostrados os estudos relacionados à propagação do ruído proporcionado pela combinação das imagens. Além disso, também são comparadas imagens com e sem tratamento para correção de ruído. Todos os resultados mostrados nesta seção foram obtidos com o detector de aSe e o sinal de referência $I_{0}$.

\subsubsection{Propagação de ruído em imagens combinadas}

A figura 4.16 mostra as variância adquiridas do grupo de microcalcificações com $600 \mu \mathrm{m}$ de espessura, em função da contribuição da imagem de baixa energia na dose glandular total absorvida pela mama $\left(\mathrm{Dg}_{l}\right)$. Os resultados foram obtidos para diversas combinações de energias e espessuras da mama.

Pela figura, foi observado que a variância das microcalcificações tende a diminuir com o aumento da separação entre as energias das imagens combinadas. Resultados semelhantes foram encontrados por diversos autores [7, 18, 20, 29, 39, 128].

Foi observado também que a variância das microcalcificações alcançam um valor mínimo para determinado intervalo de contribuição de $\mathrm{Dg}_{l}$. Analisando a figura 4.16(a), pode-se dizer que a mínima variância se encontra em uma contribuição de $\operatorname{Dg}_{l}$ entre 30 e 50\%. Com o aumento da espessura, esta tendência se desloca para maiores contribuições, chegando em $60 \%$ para a mama de $4 \mathrm{~cm}$ de espessura, mostrada na figura 4.16(b) e se aproximando de $70 \%$ para uma mama com $6 \mathrm{~cm}$ de espessura, mostrada na figura 4.16(c). Isto ocorre devido a tendência de mama maiores gerarem imagens mais ruidosas para uma dose fixa, devido ao aumento da atenuação do feixe de radiação incidente. Assim, uma maior contribuição de $\operatorname{Dg}_{l}$ é necessária para compensar esta maior propagação de ruído. Lemacks et al. [7] e Kappadath et al. [18] mostraram resultados semelhantes a este trabalho, onde foi mostrado uma região ótima de contribuição de $\operatorname{Dg}_{l}$ entre 30 e $70 \%$.

Com base no que foi analisado, foi determinado neste trabalho que para mamas com $2 \mathrm{~cm}$ de espessura, seriam combinadas imagens com uma contribuição de $\operatorname{Dg}_{l}$ em 50\%. Já para as mamas com 4 e 6 cm de espessura, a contribuição de 


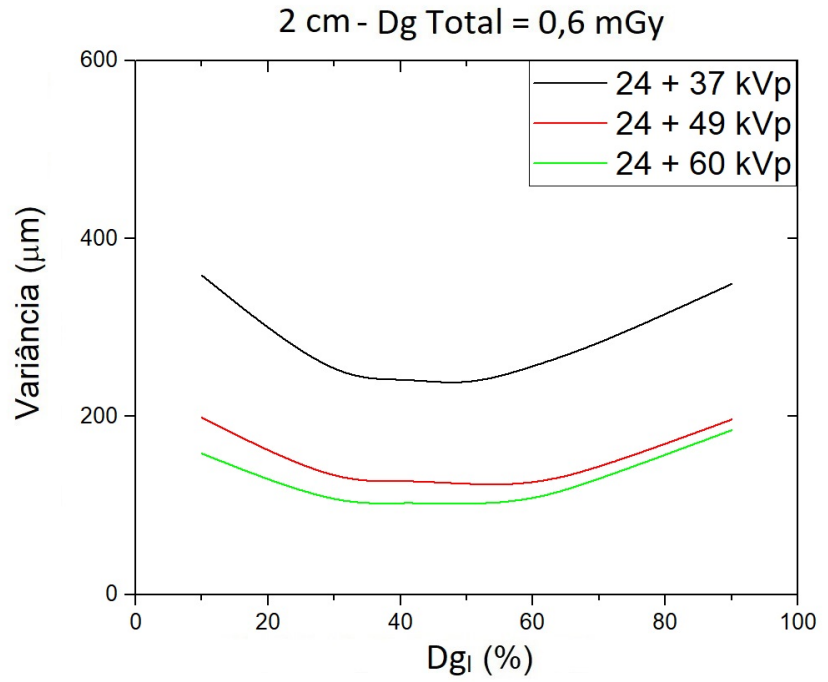

(a)

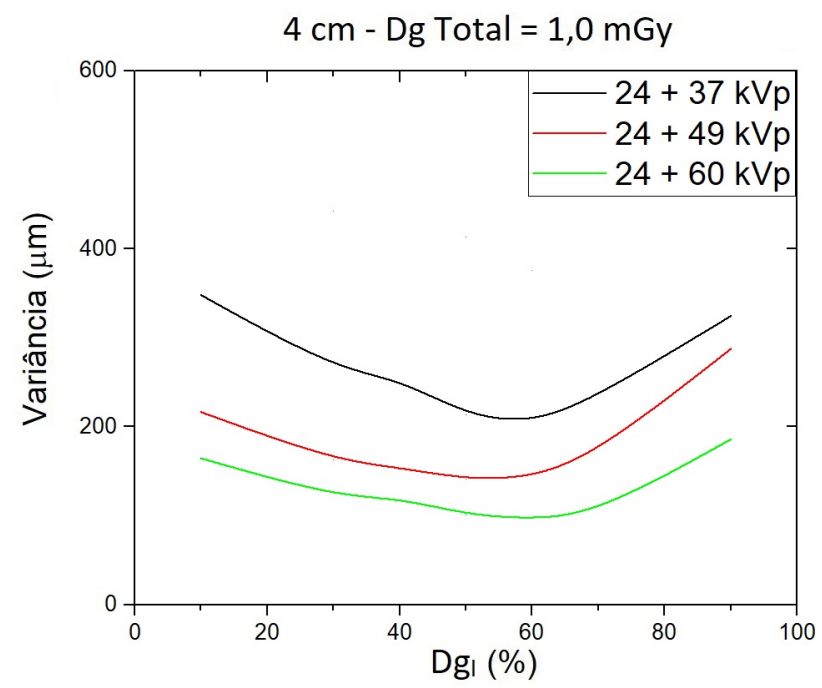

(b)

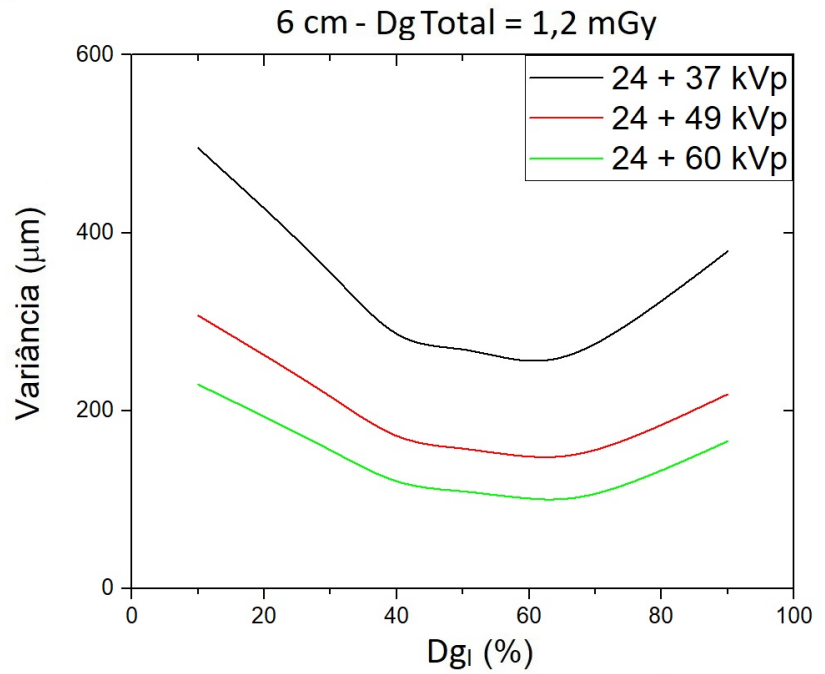

(c)

Figura 4.16: Variância calculadas dos grupos de microcalcificações, em função do percentual de $D g_{l}$ absorvido pelas mamas de (a) $2 \mathrm{~cm}$, (b) $4 \mathrm{~cm} \mathrm{e} \mathrm{(c)} 6 \mathrm{~cm}$.

baixa energia foi fixada em $60 \%$.

\subsubsection{Correção de Ruído}

A figura 4.17 compara, qualitativamente e quantitativamente, a visualização de microcalcificações em imagens quantitativas, com e sem a aplicação do filtro mediana, com um kernel de 3x3 pixels, como descrito na seção 3.4.5. Para estes resultados foi utilizada uma mama com $4 \mathrm{~cm}$ de espessura e $50 \%$ de glandularidade. 


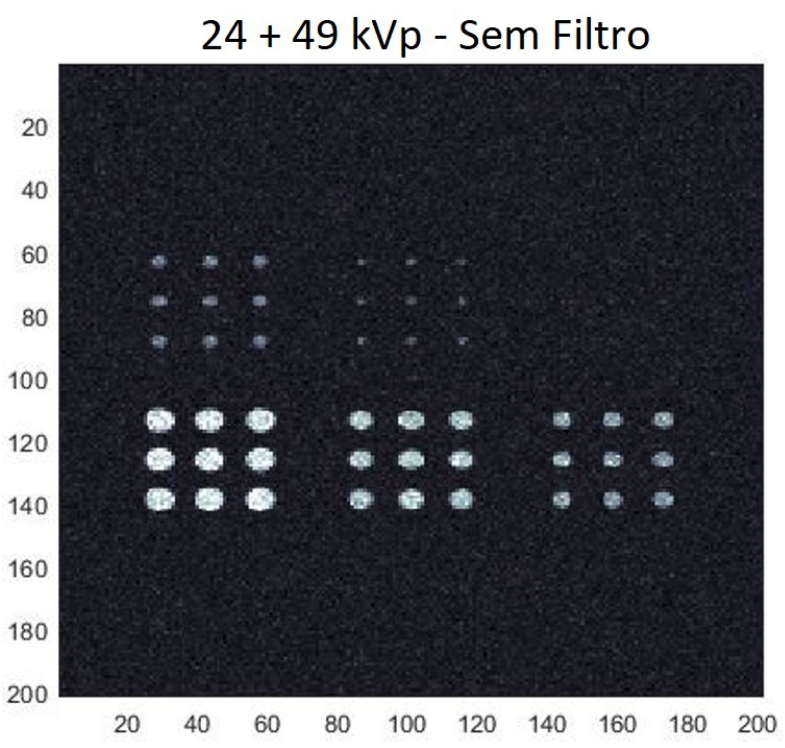

(a)

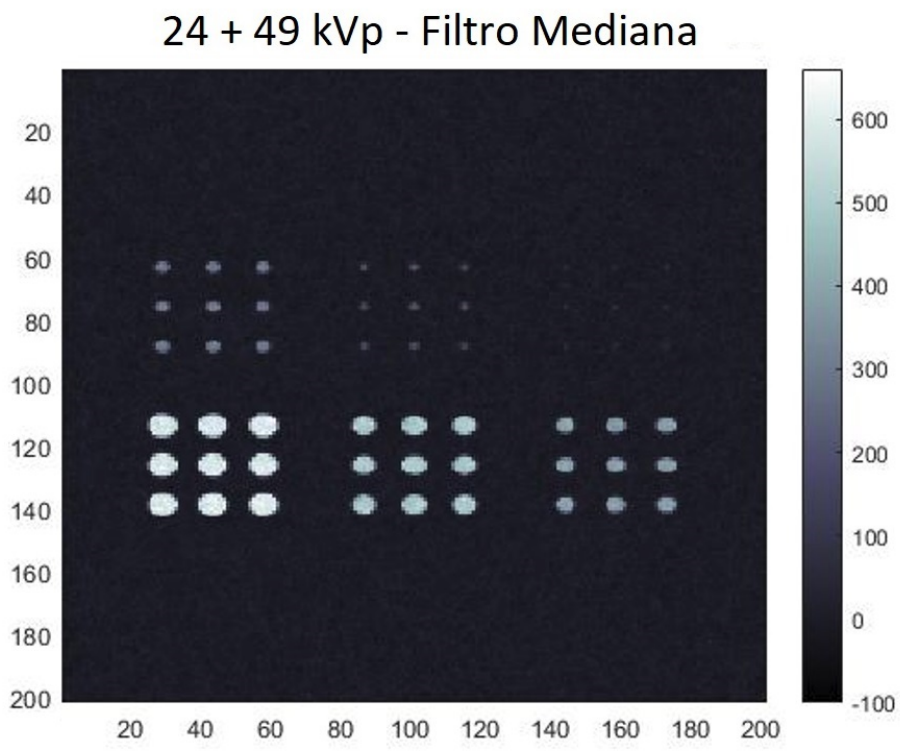

(b)

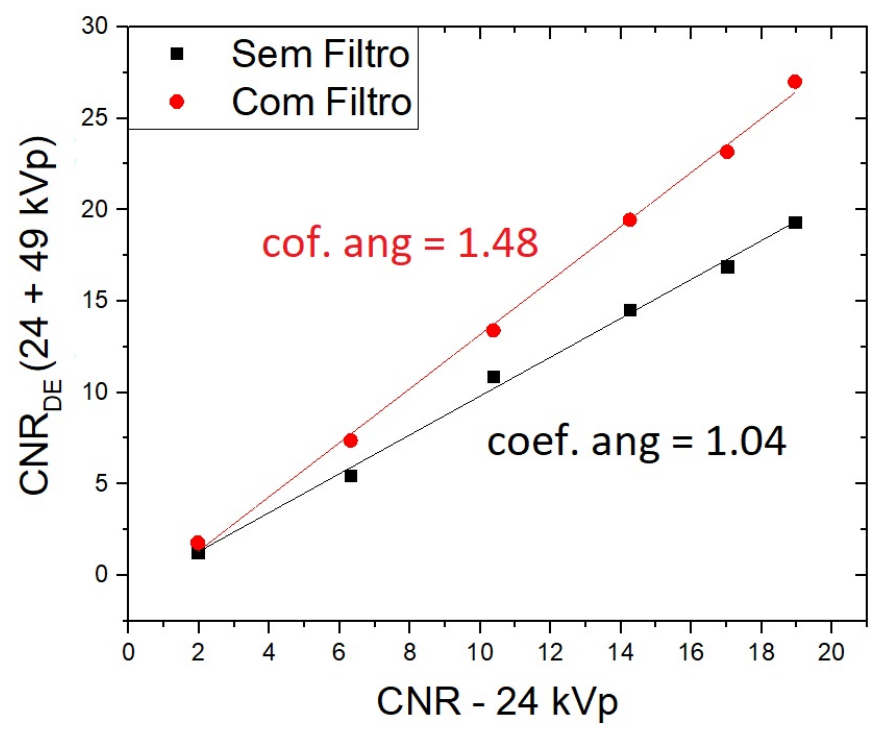

(c)

Figura 4.17: Imagens geradas a partir da combinação de $24+49 \mathrm{kVp}$, (a) sem filtro e (b) com a aplicação do filtro mediana. (c) Valores de CNR das microcalcificações de imagem gerada em $24 \mathrm{kVp}$ e de imagens combinadas com $24+49 \mathrm{kVp}$, com e sem a aplicação do filtro mediana.

Comparando qualitativamente as figuras 4.17(a) e 4.17(b), fica clara a diminuição do ruído após a aplicação do filtro mediana. Como citado brevemente na seção 3.4.5, este filtro suaviza ruídos dentro de um determinado janelamento, 
enquanto preserva a borda de características presentes nas imagens [130, 131, 132]. Assim, o ruído propagado para a imagem combinada foi reduzido, sem que houvesse uma degradação nos sinais das microcalcificações. Foi observado neste trabalho, uma redução média de $60 \%$ no ruído das imagens combinada. Este resultado é similar ao encontrado por Kappadath et al [129].

A figura 4.17(c) mostra que, sem a aplicação do filtro mediana, os valores de CNR das calcificações nas imagens combinadas são próximos aos da imagem de baixa energia. Este fato está de acordo as análises da figura 4.9, onde foi sugerido que a imagem de baixa energia estaria diretamente relacionada à visualização das microcalcificações em imagens combinadas. Após a aplicação do filtro mediana houve um ganho de aproximadamente $42 \%$ na CNR das microcalcificações. Foi observado também que houve um aprimoramento na visibilidade em todos os grupos de microcalcificação, independente de seus tamanhos. Testes feitos com a utilização de tamanhos de kernels de 5x5 e 7x7 pixels mostraram uma grande redução na acurácia da quantificação de microcalcificações menores que $400 \mu \mathrm{m}$. Kappadath et al. [129] constataram que a utilização de um kernel de tamanho igual ou superior a $5 \times 5$ pixels poderia gerar artefatos nas imagens combinadas, prejudicando a quantificação de microcalcificações menores.

Durante a análise dos resultados, foi visto que, após a aplicação do filtro mediana, o realce e a acurácia das quantificações das microcalcificações e das frações glandulares foram mantidas sem variações significantes.

\subsection{Avaliação e Otimização de Imagens Quantitativas em Microcalcificações}

Nesta seção são estudadas as imagens quantitativas em microcalcificações, geradas a partir da função polinomial 2.37 e da calibração feita com discos de alumínio de diversas espessuras, como mostrado na figura 3.8.

\subsubsection{Realce e identificação de microcalcificações}

Nesta etapa será verificada e otimizada a capacidade de realce de microcalcificações em imagens quantitativas. 


\subsubsection{Comparação entre as metodologias de combinação de imagens}

A figura 4.18 compara os valores de $C N R$ em função do tamanho das microcalcificações, obtidos para imagens combinadas a partir dos algoritmos de realce por subtração e de quantificação. Para fins de validação, são apresentados os resultados obtidos por Bliznakova et al [6]. O modelo geométrico e a metodologia de combinação de imagens adotados pelos autores foram reproduzidos fielmente. As imagens foram geradas utilizando feixes de baixa e alta energias de 30 (Mo/Mo) e $50 \mathrm{kVp}$ (Mo/Mo), respectivamente, irradiando uma mama com $4 \mathrm{~cm}$ de espessura. Neste processo foi utilizado um detector de CsI.

Visando manter a fidelidade na reprodução das metodologias adotadas por Bliznakova et al. [6], os resultados adquiridos nesta etapa não passaram por um tratamento de redução de ruído.

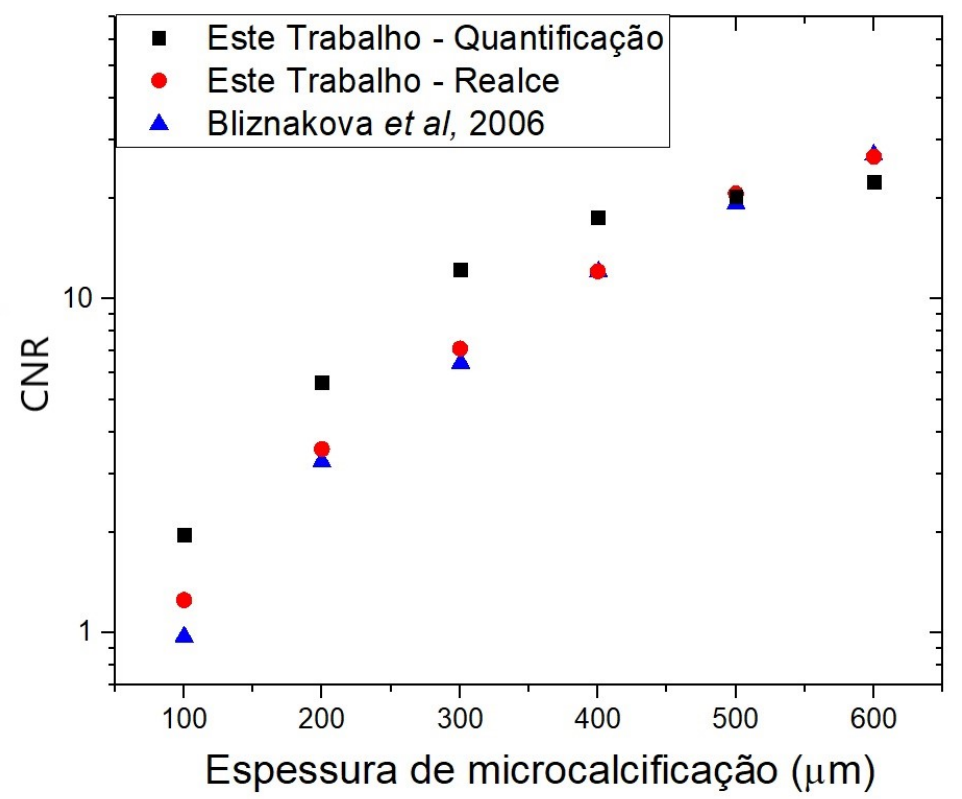

Figura 4.18: Valores de CNR, em função da espessura de microcalcificações, de imagens obtidas através dos algoritmos de realce por subtração e de geração de imagens quantitativas, em conjunto aos resultados apresentados por Bliznakova et al [6].

Primeiramente, é notado pela figura 4.18 que os valores de $C N R$, obtidos neste trabalho com técnica de realce por subtração, apresentaram uma ótima concordância com os resultados de Bliznakova et al. [6], validando sua aplicação. 
Em ambas as metodologias empregadas, é notado que as microcalcificações de $100 \mu \mathrm{m}$ não são visíveis, estando de acordo com as análises da seção 4.2.2. Para as demais espessuras, é visto que, embora ambas as técnicas apresentem capacidades de realce parecidas, o algoritmo de quantificação se mostrou mais eficaz em realçar calcificações menores. Foi observado que para o caso apresentado, ambas as técnicas possuem propagações de ruído parecidas, provenientes das imagens combinadas. Porém, o algoritmo de realce apresentou uma maior atenuação nos sinais de microcalcificações entre 200 e $400 \mu \mathrm{m}$, em comparação ao algoritmo de quantificação.

Com base nestes resultados, pode se afirmar que a técnica de geração de imagens quantitativas se mostrou ser tão eficiente quanto a técnica de subtração no realce e no aumento da capacidade de deteç̧ão de microcalcificações.

A figura 4.19 compara mapas de CNR calculados para um grupo de microcalcificações de $600 \mu \mathrm{m}$ em imagens geradas a partir das técnicas de realce por subtração e de quantificação. Foram considerados os feixes de baixa energia gerados a partir da combinação ânodo/filtro de Mo/Mo. Os feixes de alta energia entre 37 e $50 \mathrm{kVp}$ e entre 52 e $80 \mathrm{kVp}$ foram gerados a partir das combinações $\mathrm{W} / \mathrm{Cu}$ e $\mathrm{W} / \mathrm{Al}+\mathrm{Cu}$, respectivamente. Foram utilizados, uma mama com $4 \mathrm{~cm}$ de espessura, um detector de CsI e por fim, os sinais de referência $I_{0}$, sem a presença de um fantoma.

Analisando o mapa mostrado na figura 4.19(a), nota-se que valores de $C N R$ adquiridos com a técnica de subtração, seguem um perfil bem determinado com as combinações de energia. Este resultado se assemelha aos obtidos por Bliznakova et al. [6] e Brettle et al. [31] e pode ser explicado através da análise da propagação de ruído. De acordo com a equação 2.31, o ruído da imagem subtraída diminui com o aumento do número de fótons absorvidos pelo detector e para uma maior separação entre as escolhas de baixa e alta energias. Observando as escolhas de baixa energia, é notado um pico de $C N R$ na região de $30 \mathrm{kVp}$, seguido de um decréscimo em maiores energias. Conforme a energia do feixe aumenta, mais fótons transmitem pela mama até o detector, diminuindo o ruído propagado. Porém, com a queda da eficiência do detector em maiores energias [55, 76], o ruído das imagens de baixa energia (e por consequência, da imagem combinada), aumenta. Observando agora 


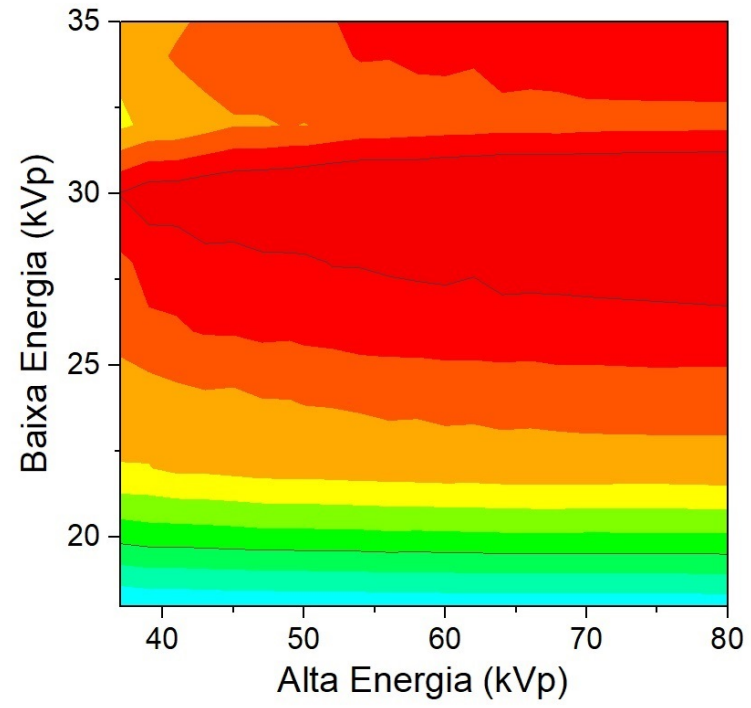

(a)

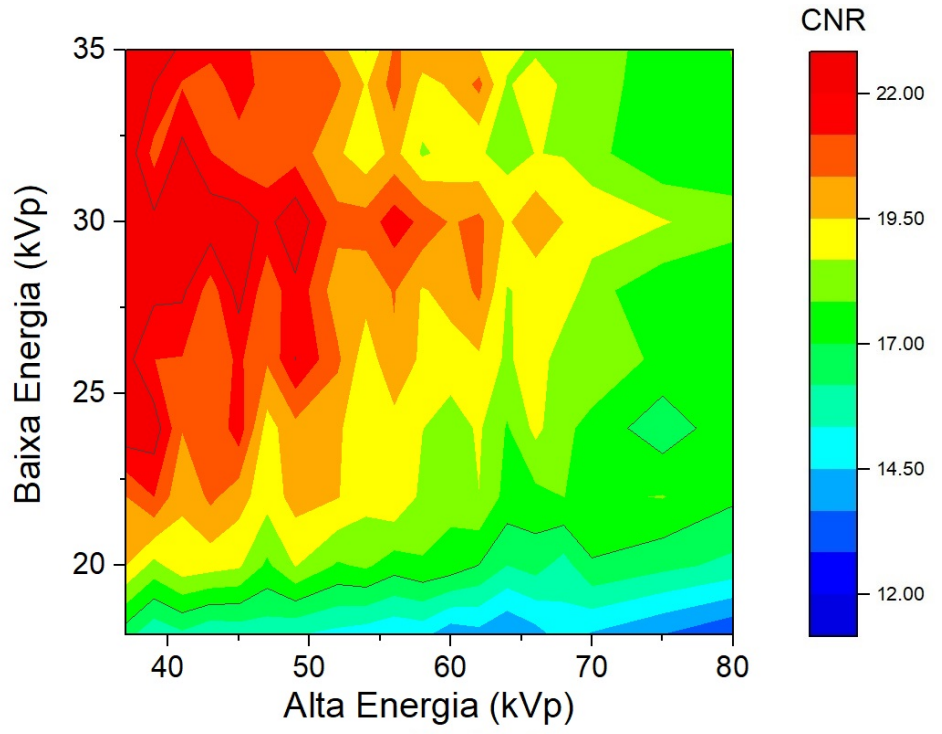

(b)

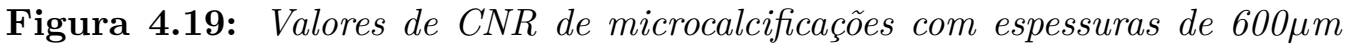
em imagens geradas a partir das técnicas de (a) realce por subtração e (b) quantificação.

as escolhas de alta energia, é visto que o número de fótons absorvidos no detector aumenta suavemente para maiores $\mathrm{kVps}$, como mostrado na figura 4.5. Assim, a diminuição do ruído propagado pelo aumento da escolha de alta energia é menos influente, causando as regiões de valores simétricos de $C N R$ ao longo das escolhas de alta energia. Porém, com o aumento da escolha da alta energia, o valor de $R$ definido na equação 2.29, diminui, reduzindo a influência do ruído propagado pela escolha de baixa energia, o que explica o alargamento da região de valores ótimos.

Observando agora a figura 4.19(b), é notado um padrão mais assimétrico dos valores de $C N R$ em relação às combinações de energias. Com base na equação 2.38, pode ser notado que o ruído propagado depende das qualidades das imagens combinadas e da separação entre as escolhas de baixa e alta energias. O ruído propagado em imagens quantitativas possui dependência com os mesmos fatores que afetam as imagens de realce por subtração, porém, de forma menos trivial. A relação entre as escolhas de baixa energia e o ruído propagado na imagem quantitativa se assemelha às observações da figura 4.19(a). Isto explica o pico de valores de $C N R$ na região próxima de $30 \mathrm{kVp}$. Porém, uma maior separação dos feixes de baixa e alta energias não implica necessariamente em menos ruído propagado na 
imagem combinada. Outro fator que ajuda a explicar o comportamento observado nos valores de $C N R$ é a flutuação estatística propagada na aquisição dos coeficientes de calibração. Apesar das análises realizadas na seção 4.3.4 mostrarem a eficácia da regularização Tikhonov, o ruído propagado pela calibração ainda se mostra influente, dependendo da escolha de alta energia tomada. Análogo ao discutido na figura 4.9, o coeficiente angular da reta formada pelos valores de $D c_{h}$ em função da espessura das microcalcificações diminui com o aumento da energia do feixe de raios X. Isto faz com que estas características sejam menos definidas na hora de se estimar os coeficientes do polinômio da equação 2.37. Com isso, análises mostraram que os coeficientes de calibração correlacionados aos valores de $\mathrm{Dc}_{h}$ são mais dispersivos entre si, causando uma maior sensibilidade do sistema às flutuações presentes em maiores escolhas de alta energia.

Os resultados da figura 4.19(b) destacam que os valores ótimos de $C N R$ se encontram em escolhas de baixa e alta energias já utilizadas por técnicas mamográficas convencionais e não-convencionais (até $49 \mathrm{kVp}$ ) [5, 96].

\subsubsection{Otimização da visualização de microcalcificações}

Vale lembrar que a partir desta etapa, o filtro mediana foi usado no tratamento do ruído dos mapas de $D_{h}$, utilizados na geração de imagens quantitativas. Além disso, como citado na seção 4.3.5.1, a contribuição percentual das escolha de baixa energia na dose glandular total foi de $50 \%$ para a mama de 2 $\mathrm{cm}$ e $60 \%$ para as mamas de 4 e $6 \mathrm{~cm}$.

\section{- Diferentes espessuras de mama}

A figura 4.20 mostra mapas de $C N R$ adquiridos para microcalcificações de $600 \mu \mathrm{m}$, observadas em imagens quantitativas geradas de acordo com o modelo MPT, especificado na tabela 3.4.

Comparando os mapas, é percebido um deslocamento da região ótima da escolha de baixa energia. Para a mama com $2 \mathrm{~cm}$ de espessura, esta região se encontra entre 23 e $27 \mathrm{kVp}$. Para a mama com $4 \mathrm{~cm}$ de espessura, esta região se situa entre 26 e $30 \mathrm{kVp}$. Por fim, a mama com $6 \mathrm{~cm}$ de espessura mostrou valores ótimos de $C N R$ para as escolhas de baixa energia entre 28 e $32 \mathrm{kVp}$. 


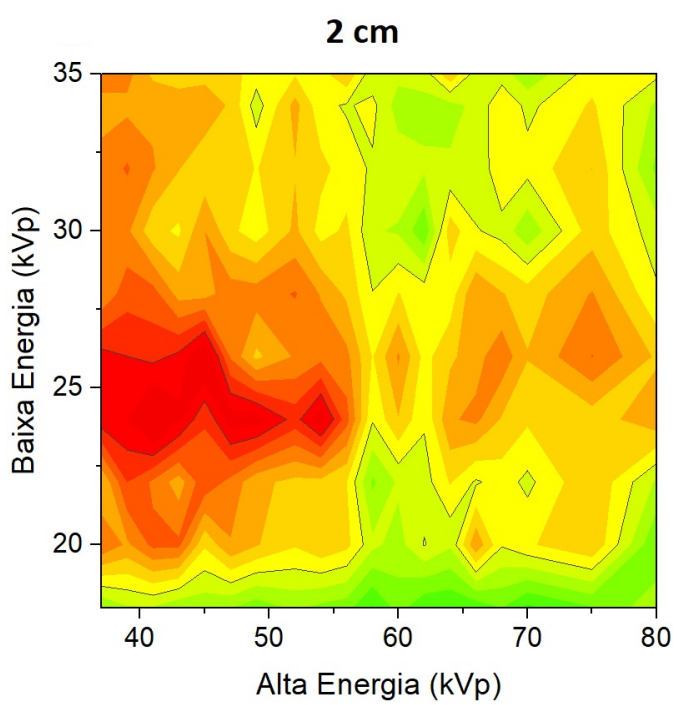

(a)

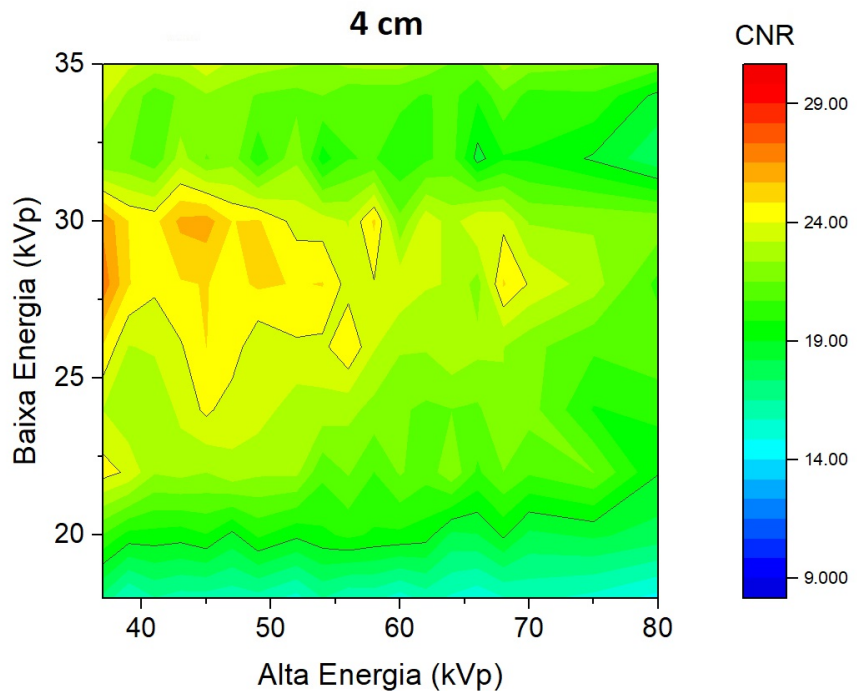

(b)

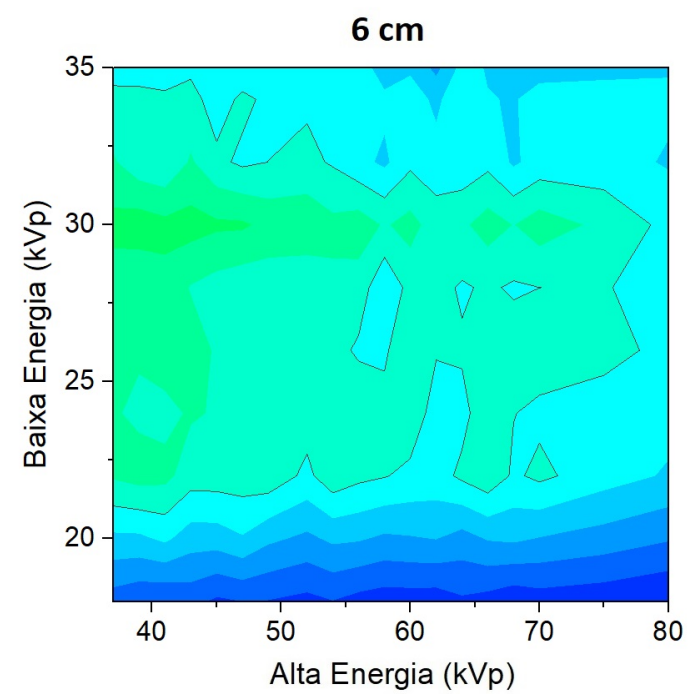

(c)

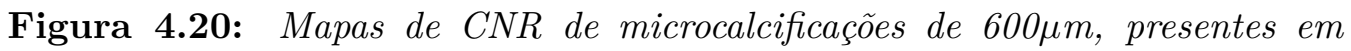
imagens quantitativas de mamas com espessuras de (a) 2, (b) 4 e (c) $6 \mathrm{~cm}$.

O deslocamento das escolhas ótimas de baixa energia é devido ao aumento da atenuação de feixes menos energéticos com o aumento da espessura da mama. Com menos fótons sendo absorvidos pelo detector, é esperado que o ruído quântico na imagem de baixa energia aumente. De acordo com as análises da figura 4.19(b), a flutuação estatística da contribuição de baixa energia é o principal fator influente no ruído propagado para a imagem combinada. Assim, para mamas mais espessas, 
as escolhas de baixa energia com maior $\mathrm{kVp}$ se mostram mais eficazes em destacar as microcalcificações.

Foi notado que as contribuições de alta energia sofreram menos influência da espessura da mama. Isto ocorre pelo grande número de fótons que transmitem pela mama e são absorvidos no detector para todas as escolhas de alta energia utilizadas neste trabalho, fazendo com que suas flutuações possuam baixa contribuição sobre a totalidade do ruído propagado.

Destacando a região das escolhas de baixa energia que apresentam os maiores valores de $C N R$ é visto que todas as contribuições de alta energia até $50 \mathrm{kVp}$, se mostraram ótimas no realce das microcalcificações.

\section{- Diferentes tamanhos de microcalcificações}

Considerando os estudos realizados anteriormente, foi observada uma queda expressiva no $C N R$ com a diminuição do tamanho das calcificações. Isto era esperado, estando de acordo com a dependência entre o tamanho do objeto estudado e seu contraste na imagem, como mostrado na seção 2.3.1.1. Apesar disso, para todas as espessuras de mama, as escolhas ótimas de baixa e alta energias determinadas através da figura 4.20 se mantiveram inalteradas. Este fato implica que ruído propagado para a imagem combinada é o fator determinante das regiões ótimas para o realce de microcalcificações. Para as regiões ótimas determinadas, todas as microcalcificações até $200 \mu \mathrm{m}$ foram identificáveis.

\section{- Diferentes sinais de referência}

Para estudos com o modelo $M P T$, porém, substituindo os sinais de referência CIRS pelos sinais de referência $I_{0}$, foi observado um acréscimo de $20 \%$ nos valores de $C N R$ das microcalcifações de $600 \mu \mathrm{m}$. Isso é devido a uma menor quantidade de ruído propagado por esta referência, dado ao maior número de fótons absorvidos no detector para sua formação. Porém, a modificação do sinal de referência também não afetou a região ótima de valores de $C N R$, estabelecidos na figura 4.20, devido uma redução homogênea do ruído para todas das energias combinadas, com a utilização do sinal de referência $I_{0}$. 
- Diferentes qualidades de feixes

A figura 4.21 mostra mapas de $C N R$ adquiridos para microcalcificações de 600 $\mu \mathrm{m}$, observadas em imagens quantitativas geradas para mamas $4 \mathrm{~cm}$ de espessura. São comparados resultados obtidos através das escolhas de baixa energia gerados por tubos de Mo/Mo e Rh/Rh, descritos na tabela 3.3. As demais configurações são semelhantes às descritas no modelo MPT da tabela 3.4.

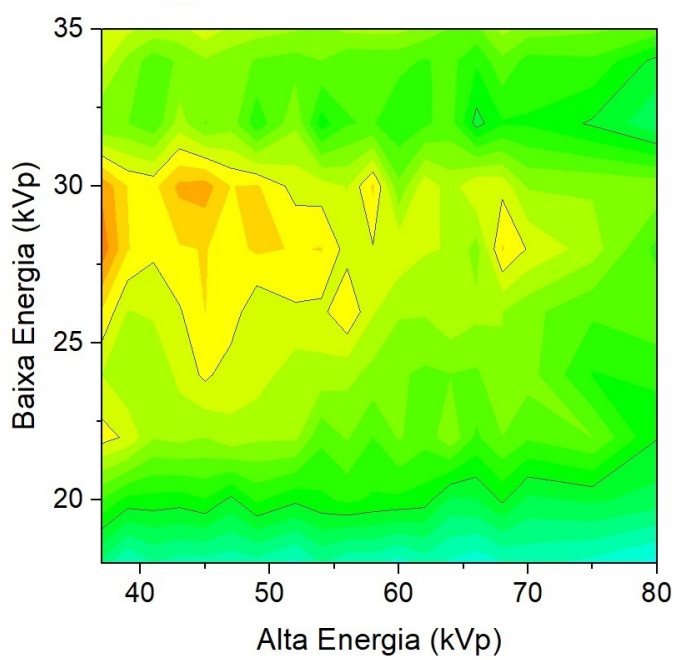

(a)

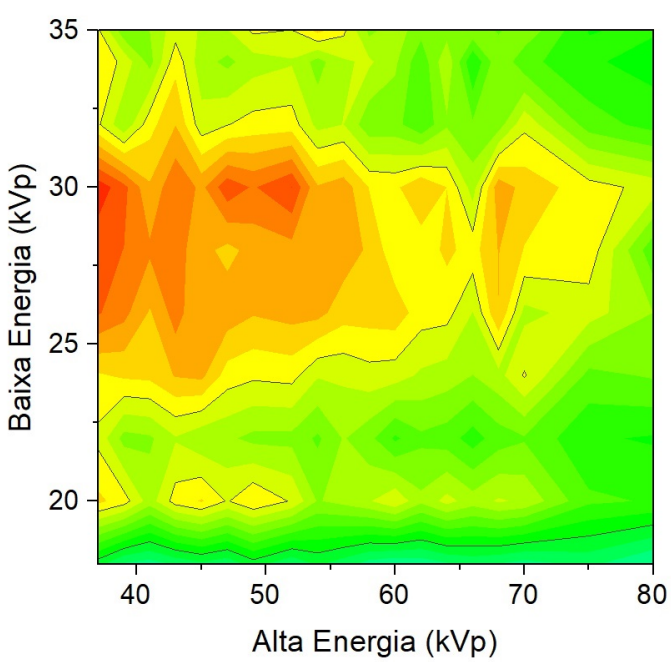

(b)

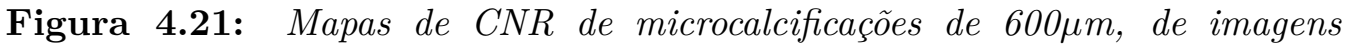
quantitativas adquiridas a partir de escolhas de baixa energia gerados por feixes de (a) Mo/Mo e (b) $R h / R h$.

Os resultados mostram que há uma expansão da região de escolhas de energias consideradas ótimas, com a utilização do feixe de Rh/Rh. Isso ocorre devido ao leve aumento da energia média dos feixes de $\mathrm{Rh} / \mathrm{Rh}$, em comparação ao Mo/Mo, como mostrado na tabela 3.3. Esse aumento na energia média faz com que mais fótons sejam transmitidos pela mama, atingindo o detector e diminuindo o ruído propagado. Além disso, foi observado que o intervalo de energias médias dos feixes utilizados (entre 13,37 e 19,55 keV) se encontram em uma região de pouca variação na eficiência quântica do detector utilizado $(a S e)$. Para as mamas com 2 e $6 \mathrm{~cm}$ de espessura, também foi notado um alargamento nas escolhas de baixa energia, aumentando a região ótima em $\pm 1 \mathrm{kVp}$. 
Outros estudos realizados seguindo os mesmos parâmetros do anterior, porém variando a qualidade dos feixes de alta energia entre 37 e $50 \mathrm{kVp}$, mostraram variações minimamente percetíveis nos valores de $C N R$ e na região de escolhas ótimas. Os feixes utilizados de $\mathrm{W} / \mathrm{Cu}$ e $\mathrm{Rh} / \mathrm{Cu}$, descritos na tabela 3.3, possuem perfis e energias médias muito semelhantes, tornando as imagens geradas a partir destes feixes, praticamente idênticas.

\section{- Diferentes detectores}

Testes realizados com o modelo $M P T$, porém, substituindo o detector de aSe por um de CsI, mostraram que para uma mama com $4 \mathrm{~cm}$ de espessura, houve um aumento de até $10 \%$ na $C N R$. Um alargamento na região de escolhas ótimas de baixa energia também foi observado, expandindo o intervalo determinado anteriormente para 26 a 33 kVp. Isto ocorre devido à maior eficiência do detector de CsI em relação ao aSe para imagens geradas pelos feixes de baixa energia utilizados neste trabalho.

Não houve alterações significantes na região de escolhas ótimas de alta energia. Isto ocorre devido à baixa influência dos ruídos propagados pelas imagens geradas por esses feixes, como discutido anteriormente. Além disso, esta influência é severamente reduzida pela aplicação do filtro mediana em $D_{h}$.

Resultados semelhantes foram encontrados para as mamas com 2 e $6 \mathrm{~cm}$ de espessura.

\section{- Consenso sobre parâmetros de otimização de realce}

A partir das análises feitas acima, pode ser determinada uma região em comum de escolhas ótimas de baixa e alta energias para o realce de microcalcificações, englobando todas as características observadas. Considerando as qualidades de feixes deste trabalho, a escolha ótima de baixa energia foi selecionada em $28 \pm 2 \mathrm{kVp}$. Já as escolhas ótimas de alta energia ficaram em $44 \pm 7 \mathrm{kVp}$. Dentro destas escolhas, foi possível detectar de forma eficaz, calcificações de até $200 \mu \mathrm{m}$.

\subsubsection{Quantificação de microcalcificações}

Nesta etapa é verificada e otimizada a capacidade de quantificação da morfologia de microcalcificações das imagens combinadas. 


\subsubsection{Precisão da quantificação de microcalcificações}

A figura 4.22 mostra mapas de precisão (em \%) da quantificação de espessuras de grupos de microcalcificações de 600 e $200 \mu \mathrm{m}$, presentes em uma mama com $4 \mathrm{~cm}$ de espessura. As imagens combinadas de acordo com as especificações do modelo MPT da tabela 3.4 .

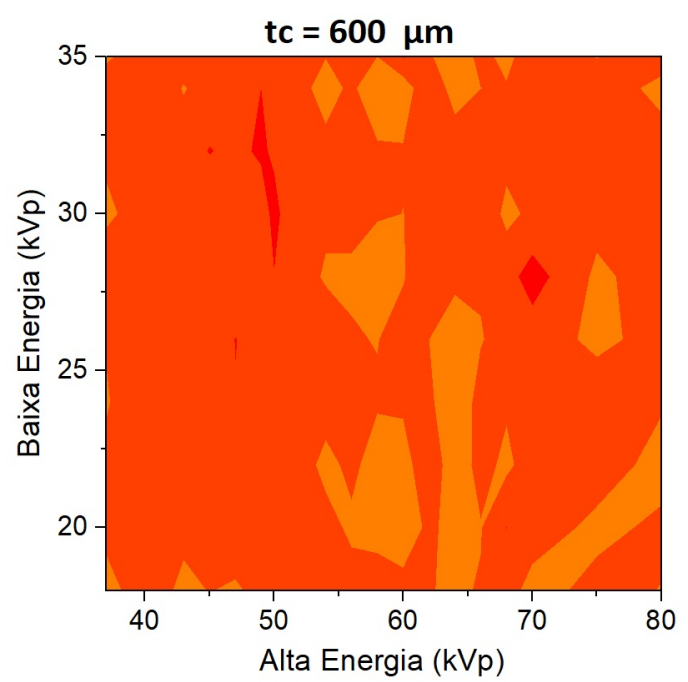

(a)

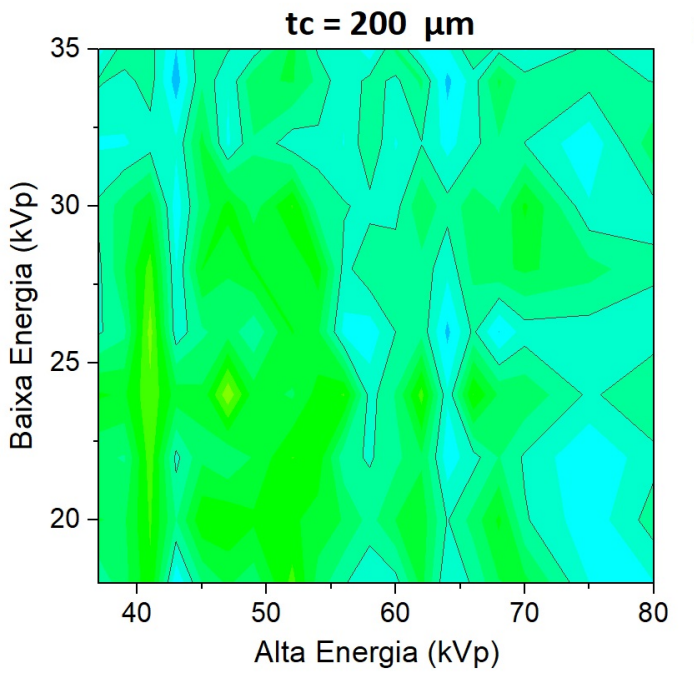

(b)

Figura 4.22: $\quad$ Mapas de precisão da quantificação de espessuras de microcalcificações de (a) $600 \mu \mathrm{m}$ e (b) $200 \mu \mathrm{m}$, presentes em uma mama com $4 \mathrm{~cm}$ de espessura.

É notada, na figura 4.22, uma queda na precisão para calcificações menores. Isso era esperado devido ao menor número de pixels que englobam seus sinais, aumentando assim, a incerteza nos cálculos. Apesar disso, a precisão das quantificações foi maior do que $85 \%$ para todas as configurações de simulação e em todos as espessuras de mama. Com isso, todas as combinações de energias mostraram possuir uma precisão ótima na quantificação das microcalcificações.

\subsubsection{Exatidão da quantificação de microcalcificações}

\section{- Diferentes espessuras de mama}

A figura 4.23 mostra mapas de exatidão (em \%) para a quantificação de microcalcificações de $600 \mu \mathrm{m}$ presentes em mamas com espessuras entre 2 e $6 \mathrm{~cm}$. 
Os testes foram realizados seguindo o modelo MPT da tabela 3.4.

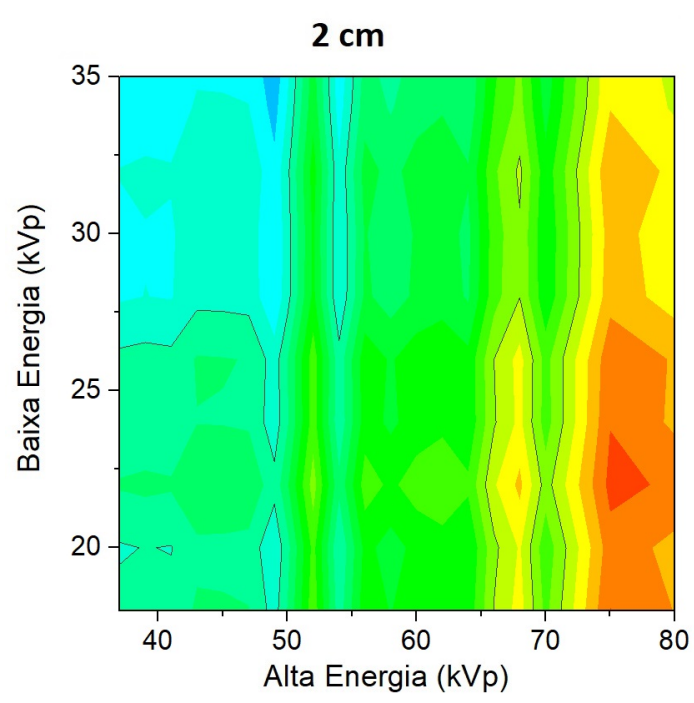

(a)

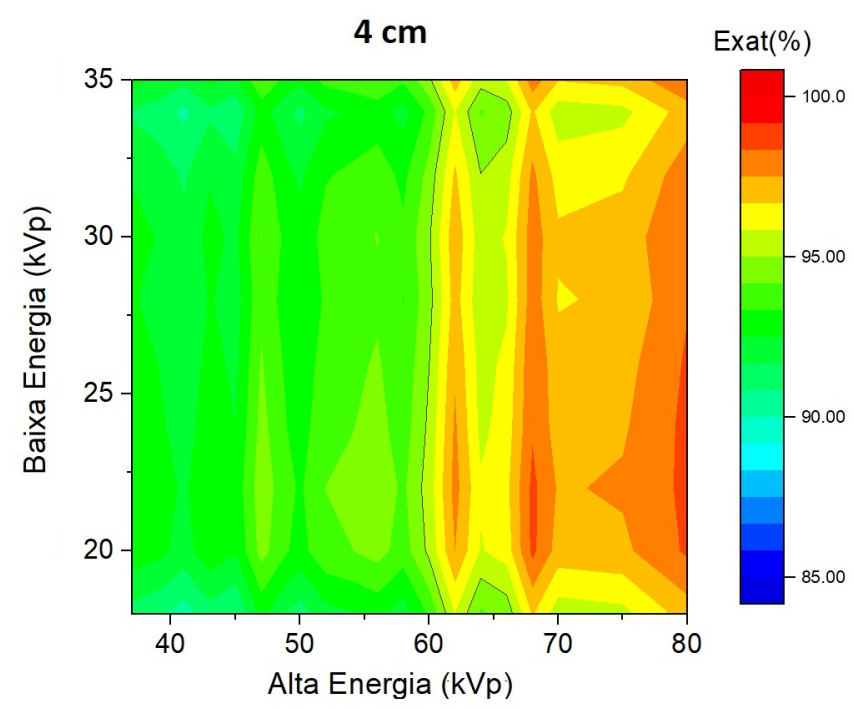

(b)

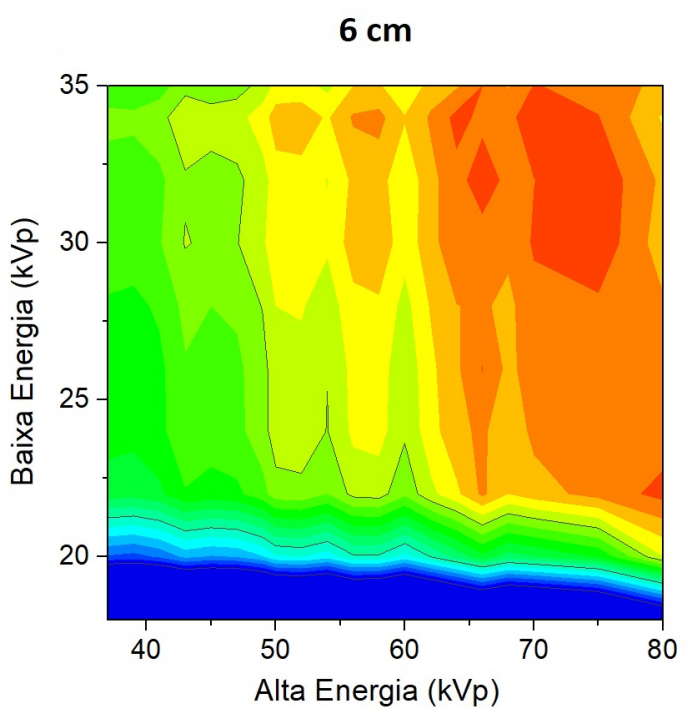

(c)

Figura 4.23: $\quad$ Mapas de exatidão da quantificação de espessuras de microcalcificações de $600 \mu \mathrm{m}$ presentes em mamas com (a) 2, (b) 4 e (c) $6 \mathrm{~cm}$ de espessura.

Primeiramente pode ser notado, pela figura 4.23, que uma maior separação de energias combinadas implica em uma quantificação mais exata das microcalcificações. Isto está de acordo com o previsto na literatura [18, 20].

Com o aumento da espessura da mama, é notada uma melhora na quantificação das microcalcificações, visto através do aumento das regiões com 
exatidão superior à $97 \%$. Isso ocorre devido ao endurecimento do feixe transmitido pela mama até o detector [154]. Com isso, foi observado um aumento da separação entre as energias médias dos feixes combinados. Por outro lado, é notado uma queda na exatidão para as menores escolhas de baixa energia na mama de $6 \mathrm{~cm}$ de espessura. Isso ocorre devido a diminuição da transmissão dos fótons pela mama até o detector, o que contribui para o aumento expressivo do ruído quântico nas imagens formadas. Com isso, a determinação das constantes de calibração e consequentemente, a estimativa o tamanho das microcalcificações são prejudicadas.

Apesar de haver uma vasta gama de combinações com as quais são adquiridas uma exatidão superior à $85 \%$, pode ser determinada uma área ótima em comum para as três espessuras de mama. As escolhas de baixa e alta energias determinadas foram, respectivamente: $26 \pm 3 \mathrm{kVp}$ e $75 \pm 4 \mathrm{kVp}$.

\section{- Diferentes tamanhos de microcalcificações}

Analisando testes realizados a partir do mesmo modelo adotado anteriormente, foi observada uma queda na exatidão do tamanho de microcalcificações menores. Isso ocorre devido a dois fatores: o primeiro se dá pelo processo calibração, onde o sinal dos discos de alumínio de menor espessura se aproximam do sinal de fundo, sem a presença de microcalcificações. Assim, o sistema tende a subestimar calcificações muito pequenas, por não diferenciá-las do entorno de forma eficiente. O segundo fator está relacionada ao tamanho da àrea projetada no detector das microcalcificações menores. Foi observado um aumentando a incerteza da estimativa das espessuras dessas microcalficicações, devido a menor amostragem de pixels a serem observados para a realização dos cálculos. Apesar disso, a região ótima classificada anteriormente não foi modificada.

Para a mama de $2 \mathrm{~cm}$ foi possível estimar os tamanhos de microcalcificações de até $400 \mu \mathrm{m}$, com exatidão superior a 85\%, na região ótima de escolhas de energias. Para mamas com 4 e $6 \mathrm{~cm}$ de espessura foi possível estimar microcalcificações de até $300 \mu \mathrm{m}$ com exatidão acima de $85 \%$.

\section{- Diferentes sinais de referência}


Um breve aumento na exatidão foi observado com a substituição dos sinais de referência CIRS para $I_{0}$. Isto ocorre devido a um menor ruído propagado nas imagens de calibração, melhorando assim, a estimativa dos coeficientes de calibração pelas quais as microcalcificações são representadas. Isto reforça as observações realizadas nos estudos da seção 4.3.3.

Porém, nenhuma variação na região de escolhas ótimas foi observada. Os tamanhos mínimos de microcalcificações estimados com uma exatidão superior à $85 \%$, também não foram alterados para nenhuma espessura de mama.

\section{- Diferentes qualidades de feixes}

Ao substituir os feixes que compõem as escolhas de baixa energia de Mo/Mo para $\mathrm{Rh} / \mathrm{Rh}$, foi observada uma queda da exatidão para imagens combinadas com feixes de baixa energia superiores à $32 \mathrm{kVp}$. Este fato pode ser explicado pela maior energia média dos feixes de $\mathrm{Rh} / \mathrm{Rh}$, se comparados aos de Mo/Mo [72]. Como já discutido neste trabalho, uma maior separação de energias médias dos feixes combinados auxiliam no aumento da acuraria da estimativa das microcalcificações $[18,25]$. Apesar disso, a região ótima classificada anteriormente não apresentou uma queda significativa na exatidão das quantificações, estando abaixo de $1.5 \%$.

Estudos feitos com outros feixes de alta energia não se mostraram influentes nos resultados apresentados.

\section{- Diferentes detectores}

A figura 4.24 mostra mapas de exatidão da quantificação de microcalcificações de $600 \mu \mathrm{m}$, construidos a partir imagens geradas com detectores de aSe e CsI. As simulações respeitaram os parâmetros $M P T$ da tabela 3.4, utilizando uma mama com $4 \mathrm{~cm}$ de espessura.

É possível observar uma mudança no padrão da exatidão das quantificações. Como analisado anteriormente, o detector de CsI é mais eficiente em detectar calcificações em baixas energias. Este fato explica o aumento da região com maiores percentuais de exatidão, vistos em combinações de menores energias na figura 4.24. Porém, o detector de $a S e$ se mostra mais eficaz em diferenciar características presentes nas imagens em maiores energias, como observado nas análises da figura 


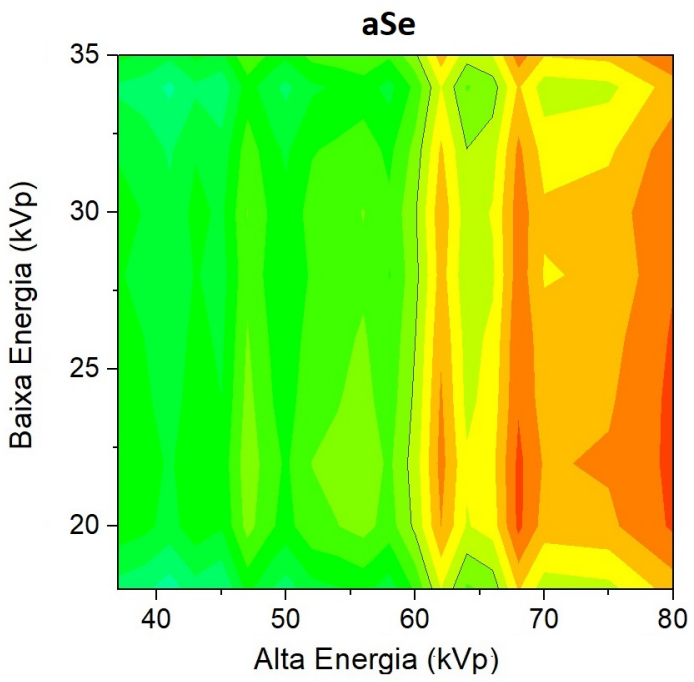

(a)

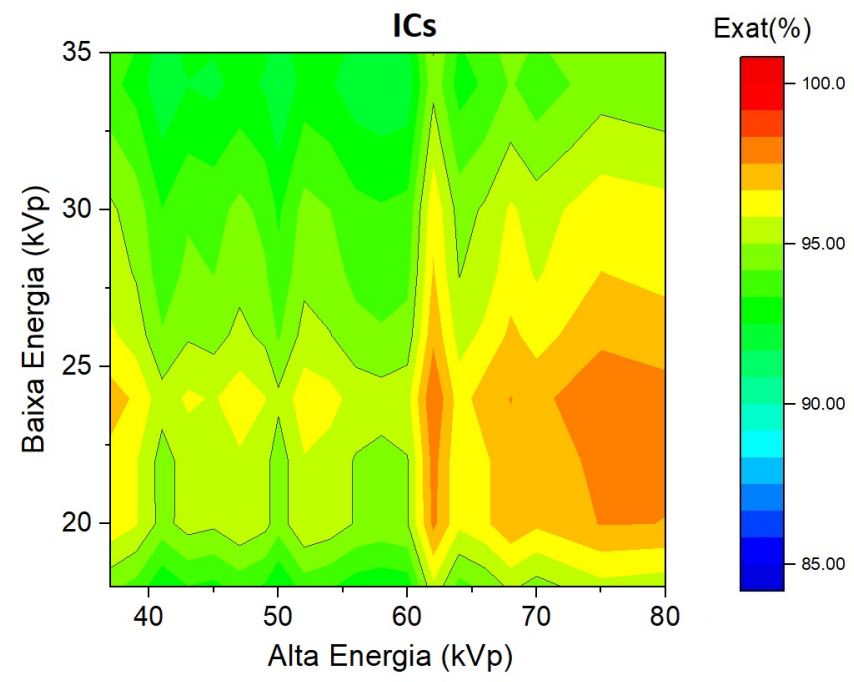

(b)

Figura 4.24: Mapas de exatidão da quantificação de espessuras de microcalcificações de $600 \mu \mathrm{m}$, presentes em uma mama com $4 \mathrm{~cm}$ de espessura. Os mapas mostrados foram construídos a partir de imagens geradas por detectores de (a) aSe e (b) CsI.

4.4. Isso faz com que o detector seja mais eficiente em quantificar microcalcificações com maiores energias combinadas, se comparado ao CsI.

\section{- Consenso sobre parâmetros de otimização de quantificação}

As escolhas de energia ótimas para a quantificação de microcalcificações foi determinada apenas pelos mapas de exatidão, tendo em vista de que todas combinações de energia mostraram altamente precisas.

As escolhas de energias ótimas, comuns para todos os parâmetros de simulação estudados nesta etapa, são os determinados nas análises da figura 4.23. Portanto, as escolhas ótimas de baixa e alta energias são, respectivamente, $26 \pm 3$ $\mathrm{kVp}$ e $75 \pm 4 \mathrm{kVp}$.

Porém, nem todas as microcalcificações foram estimadas de forma aceitável, mesmo na região de escolhas ótimas. Em nenhum caso estudado, calcificações de $200 \mu \mathrm{m}$ de espessura obtiveram uma exatidão maior do que 55\%. Tendo em vista os resultados coletados, pode se dizer que microcalcificações menores (até $300 \mu \mathrm{m}$ ) são quantificadas de forma eficaz, em imagens de mamas mais espessas. 
Tabela 4.3: Escolhas ótimas de baixa e alta energias, propostas por este trabalho e pela literatura

\begin{tabular}{c|c|c|c|c|c|}
\hline \hline \multicolumn{1}{|c|}{ Otimizações } \\
\hline Autores & $\mathbf{d}(\mathbf{c m})$ & $\mathbf{f g}(\%)$ & Metodologia & Detector & Escolhas de energias $(\mathbf{k V p})$ \\
\hline Este Trabalho & $2-6$ & 50 & Simulação & $\begin{array}{c}\text { aSe } \\
\text { CsI }\end{array}$ & $\begin{array}{c}\text { Realce: } 28 \pm 2 \mathrm{kVp}-44 \pm 7 \mathrm{kVp} \\
\text { Quantificação: } 26 \pm 3 \mathrm{kVp}-75 \pm 4 \mathrm{kVp}\end{array}$ \\
\hline Lemacks et al., 2001 & 5 & 50 & Analítico & $\begin{array}{c}\text { CsI } \\
\mathrm{Gd}_{2} \mathrm{O}_{2} \mathrm{~S}\end{array}$ & Realce: $25-50 \mathrm{kVp}$ \\
\hline Brandan et al., 2006 & 5 & 50 & Analítico & CsI & Realce: $25-40 \mathrm{kVp}$ \\
\hline Koukou et al., 2015 & 4 & 50 & Simulação & Ideal & Realce: $40-70 \mathrm{kVp}$ \\
\hline Ghammraoui et al., 2019 & $3-6$ & 50 & Simulação & aSe & Realce: $26-50 \mathrm{kVp}$ \\
\hline
\end{tabular}

\subsubsection{Considerações gerais}

Os resultados avaliados nesta seção mostram que, tanto para o realce quanto para a quantificação de microcalcificações, as escolhas ótimas de baixa energia são influenciadas principalmente pela espessura da mama. Este fato condiz com o previsto um trabalho anterior [40]. Já a escolha de alta energia depende do foco a ser tomado na combinação das imagens. Como citado anteriormente, uma separação maior de energias induz uma quantificação mais acurada, porém, o sistema tem sua sensibilidade à flutuações estatísticas aumentada. Isso faz com que a visibilidade das calcificações seja depreciada.

A tabela 4.3 mostra as escolhas ótimas de energias determinadas por este trabalho, em comparação com as escolhas sugeridas pela literatura $[7,29,155,156]$ :

É importante salientar que todos os trabalhos da literatura otimizaram as combinações de energias através da minimização do ruído, ou seja, do realce das microcalcificações. Comparando a otimização deste trabalho, priorizando o realce, com os trabalhos da literatura, é percebida uma ótima concordância. A única discrepância encontrada está na escolha de energias sugerida por Koukou et al [29]. Porém, a utilização de um detector ideal em seus testes pode ter interferido nestas escolhas.

Priorizando a acurácia da quantificação das microcalcificações, é visto que as escolhas de baixa energia determinadas neste trabalho, se mantém coerente com as escolhas da literatura. Já as escolhas ótimas de alta energia se distanciam 
dos resultados da literatura. Foi observado, neste trabalho, que a acurácia da quantificação é dependente da capacidade do sistema de calibração em diferenciar os sinais do tecido estudado, adquiridos em baixa e alta energias. Esta capacidade se mostrou diretamente proporcional à separação da energia dos feixes, sendo pouco influenciado pelo ruído das imagens combinadas.

Apesar de existirem escolhas ótimas de energias, a aplicação do filtro mediana em $D_{h}$ e a estimativa de coeficientes de calibração realizadas através de métodos regularizados [122], fez com que praticamente todas as energias combinadas obtivessem uma boa qualidade, tanto no realce, quanto na quantificação das microcalcificações. Assim, caso uma análise seja focada em realce, não significa necessariamente que a quantificação será realizada de forma ineficaz. O caso contrário também é valido, já que todas as imagens realçaram de maneira eficiente, calcificações de até $300 \mu \mathrm{m}$.

\subsection{Avaliação e Otimização de Imagens Quantitativas em Frações Glandulares}

Nesta seção são estudadas as imagens quantitativas em frações glandulares, geradas a partir da função polinomial 2.39 e da calibração feita com a utilização de fantomas CIRS (CIRS, Inc., Norfolk, VA), simuladores de tecidos adiposo e glandular, como mostrado na figura 3.8.

A figura 4.25 mostra mapas de exatidão (em \%) da quantificação de um tecido com $50 \%$ de glandularidade, observadas em imagens quantitativas geradas de acordo com o modelo MPT, especificado na tabela 3.4.

De acordo com a figura 4.25, é possível notar que não há um padrão claro de combinações de energias, com as quais se obtêm melhores acurácias na quantificação da fração glandular. Porém, é visto que os valores de exatidão se mantém muito próximos para praticamente quaisquer escolhas de baixa e alta energias. É notado também que o aumento da espessura da mama causou uma leve queda na exatidão das estimativas. Apesar do aumento da espessura da mama auxiliar na separação entre as energias médias dos feixes, a quantificação da fração glandular se mostrou 


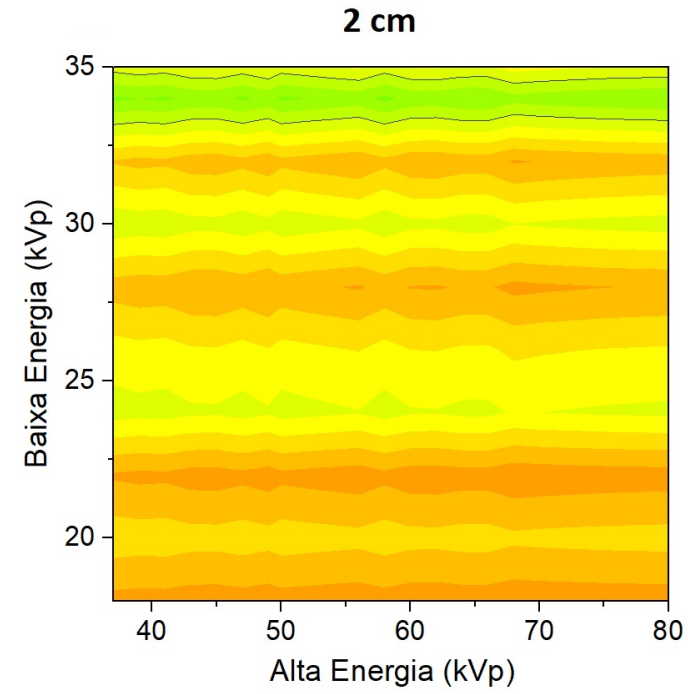

(a)

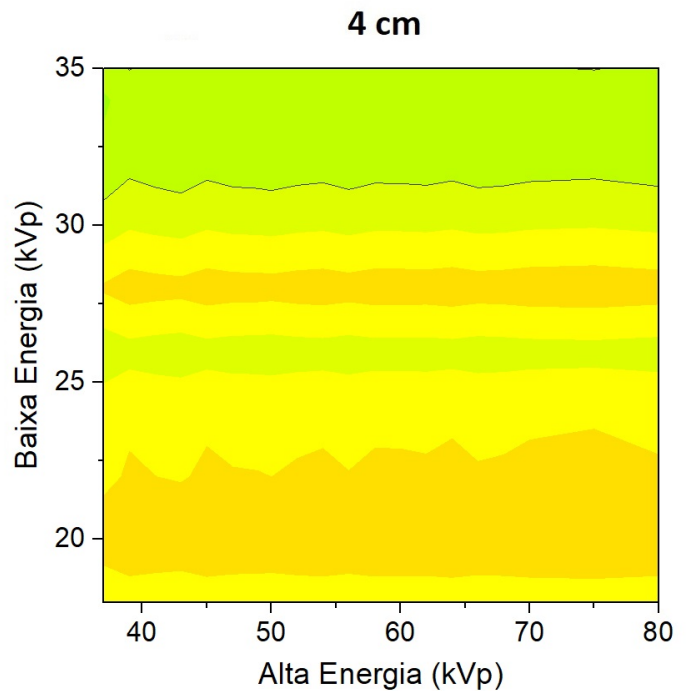

Exat (\%)

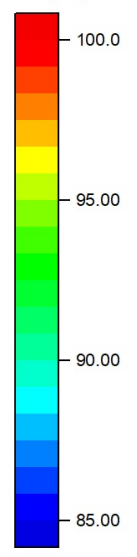

(b)

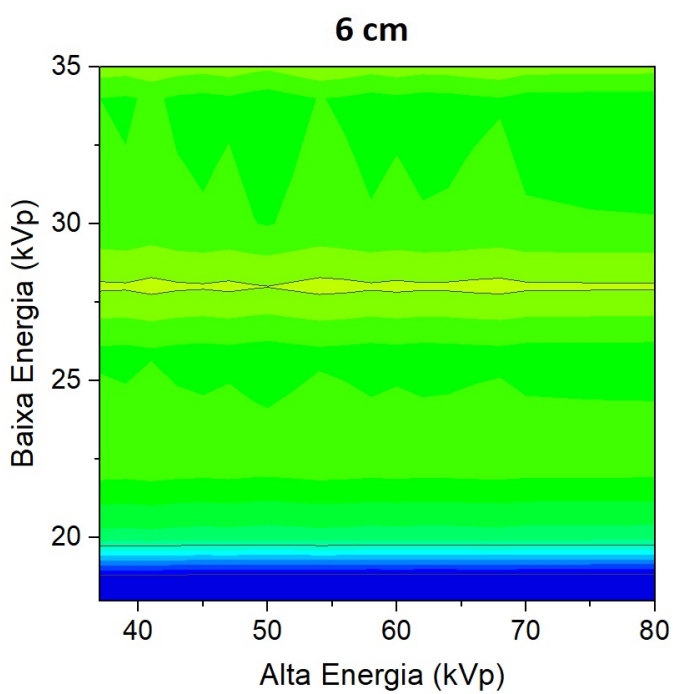

(c)

Figura 4.25: Mapas de exatidão de um tecido com 50\% de glandularidade, em mamas com espessuras de (a) 2, (b) 4 e (c) $6 \mathrm{~cm}$.

menos sensível à este fator. Com base nisso, esta queda na exatidão pode explicada pela quantidade de ruído presente nas imagens de calibração, o qual já se mostrou ser um fator degradante para as imagens quantitativas.

É visto que para a mama de $6 \mathrm{~cm}$ de espessura, imagens quantitativas geradas com energias inferiores à $20 \mathrm{kVp}$ apresentaram uma baixa acurácia na estimativa da fração glandular. Com exceção desta região, pode ser determinado que quaisquer 
escolhas de baixa e alta energias se mostraram altamente eficazes na quantificação do tecido glandular, para todas as espessuras de mama estudadas.

A figura 4.26 mostra a relação entre tecidos de diferentes frações glandulares e a exatidão de suas quantificações. As imagens quantitativas foram geradas a partir das energias de $26+49 \mathrm{kVp}$. Na figura, também são comparadas as influências dos sinais de referência CIRS e $I_{0}$ na quantificação destes tecidos. São mostrados os resultados para uma mama com $4 \mathrm{~cm}$ de espessura. Os demais parâmetros seguiram o modelo MPT.

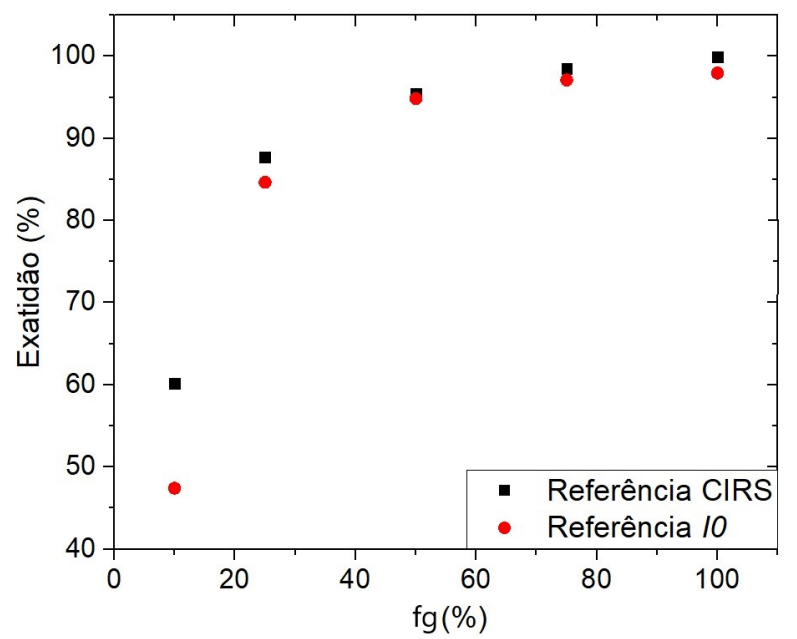

Figura 4.26: Mapas de exatidão de um tecido com $50 \%$ de glandularidade, em mamas com espessuras de (a) 2, (b) 4 e (c) $6 \mathrm{~cm}$.

De acordo com o gráfico da figura 4.26, a exatidão das estimativas é afetada pela diminuição da fração glandular. Analogamente ao comentado nas análises realizadas para imagens de microcalcificação, os sinais observados de tecidos mamários com baixa glandularidade se aproximam do sinal de um tecido $100 \%$ adiposo. Assim, o sistema de calibração apresenta uma perda na eficácia, subestimando baixas glandularidades. Apesar disso, os mapas quantitativos se mostraram altamente acurados ao estimar glandularidades iguais ou superiores à $25 \%$, para todas as espessuras de mama.

Também pode ser observado que o uso do sinal de referência $I_{0}$, causou uma leve queda nos valores de exatidão mensurados para glandularidades de até $25 \%$ e uma queda mais expressiva para a glandularidade de 10\%. Apesar de propagarem mais ruído nas imagens quantitativas, a referência CIRS ajuda à eliminar a 
contribuição do tecido adiposo na formação da imagem, como descrito na seção 2.6.3. Assim, o tecido glandular pode ser quantificado com maior facilidade pelo sistema. Lemacks et al. [7] mostraram em seus estudos, que a eliminação do tecido adiposo auxilia na quantificação analítica do tecido glandular e microcalcificações.

Estudos realizados com demais parâmetros, como tipo de detector e qualidades de feixes, não mostraram variações significantes nos valores de exatidão das quantificações.

A figura 4.27 mostra a propagação de ruído de imagens combinadas a partir da utilização dos sinais de referência CIRS e $I_{0}$. Em conjunto, são mostrados exemplos de imagens quantitativas geradas com feixes de $26(\mathrm{Mo} / \mathrm{Mo})+49(\mathrm{~W} / \mathrm{Cu})$ $\mathrm{kVp}$, utilizando ambos os sinais de referência. Os resultados mostrados foram adquiridos para uma mama de $4 \mathrm{~cm}$ de espessura.

É notado que a utilização de ambas as referências seguem o mesmo padrão de propagação de ruído, diminuindo para uma maior separação de energias. Esta relação é coerente com o padrão encontrado por Ducote \& Molloi [35].

É observado também que a utilização do sinal de referência $I_{0}$ causou uma propagação maior de ruído. Ducote \& Molloi [35] mostraram que imagens quantitativas em fração glandular, dependem fortemente do sinal do tecido adiposo. Ao se eliminar este sinal através da utilização do sinal de referência CIRS, grande parte do ruído também é eliminado. Isto é exemplificado através da comparação entre as figuras $4.27(\mathrm{c})$ e $4.27(\mathrm{~d})$, onde há uma clara suavização dos sinais mensurados, com a utilização da referência CIRS, em relação à referência $I_{0}$.

Apesar disso, todas as combinações apresentaram uma baixa propagação de ruído, não prejudicando significativamente, a visibilidade ou a exatidão da estimativa da fração glandular.

No geral, todas as imagens combinadas foram capazes de quantificar de forma ótima a fração glandular, com exceção da utilização de energias menores que $20 \mathrm{kVp}$, para a mama com $6 \mathrm{~cm}$ de espessura. Assim, a técnica se mostrou ótima para a utilização de todas as energias consideradas neste trabalho, exceto para frações glandulares muito pequenas. Ducote \& Molloi [35] estudaram analiticamente o ruído propagado em imagens geradas para a quantificação de densidade glandular, concluindo que a combinação ótima entre energias pode chegar à $35+110 \mathrm{kVp}$ 


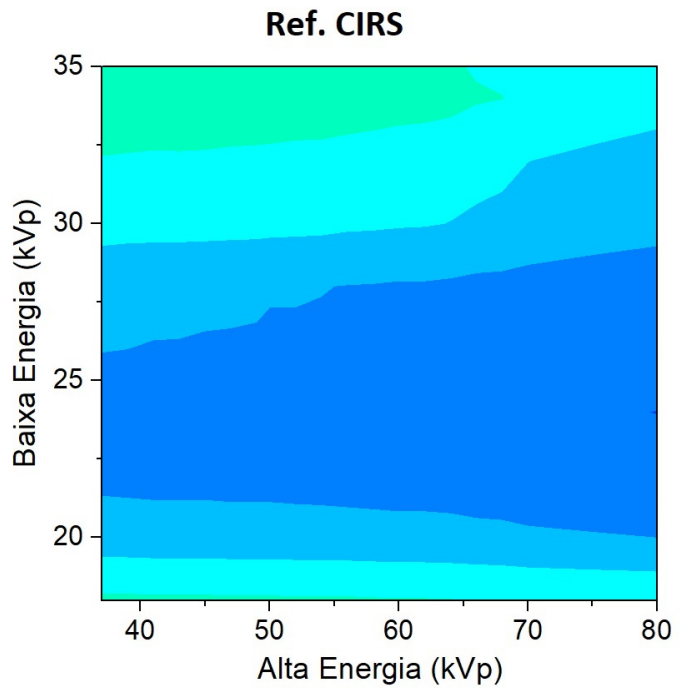

(a)

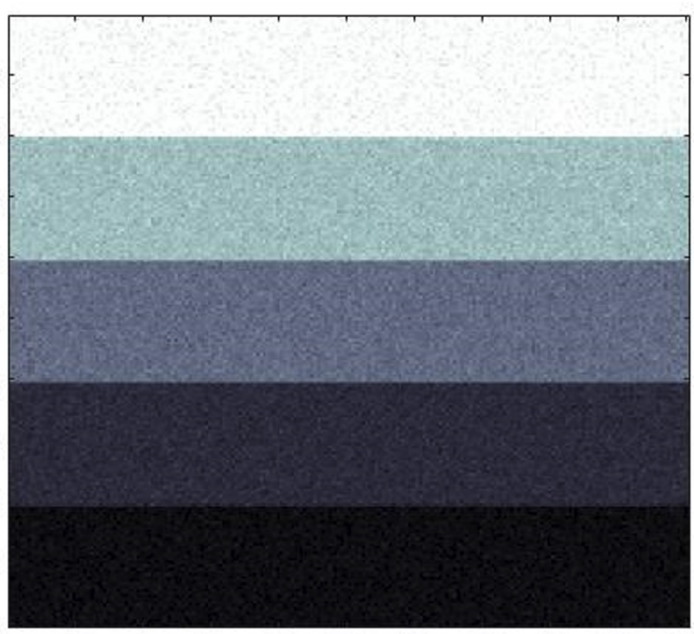

(c)

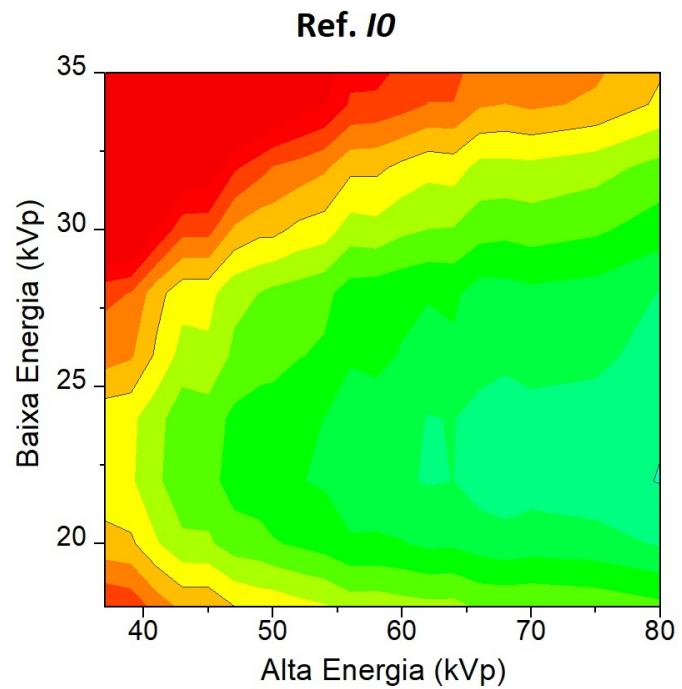

$\mathrm{CV}$

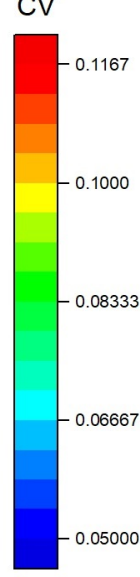

(b)

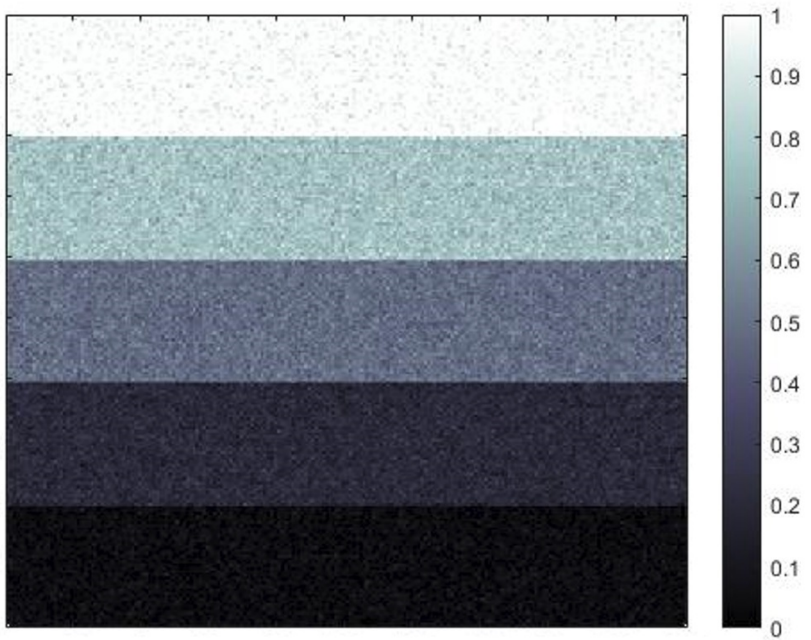

(d)

Figura 4.27: Mapas de coeficiente de variação (CV), para imagens combinadas com a utilização das referências (a) CIRS e (b) $I_{0}$. Em conjunto, são mostradas imagens combinadas por feixes de $26+49 \mathrm{kVp}$, utilizando referências (c) CIRS e (d) $I_{0}$.

para uma mama de $6 \mathrm{~cm}$ de espessura. Este intervalo de energias não é englobado neste trabalho, porém, a utilização de algoritmos de correção de ruído, bem como a aplicação de métodos eficazes de se calibrar o sistema, fez com que todas as energias aqui consideradas, mostrassem ótimos resultados. 


\section{Capítulo 5}

\section{Conclusões e Perspectivas Futuras}

\subsection{Conclusões}

\subsubsection{Sobre a adaptação e utilização do código PENELOPE para a geração de imagens.}

O código PENELOPE adaptado neste trabalho foi devidamente validado, viabilizando seu uso para o cálculo de grandezas dosimétricas e geração de imagens.

A estimativa da dose glandular normalizada $(D g N)$ obteve boa concordância com resultados de outros autores [8, 44]. As discrepâncias encontradas foram devidamente justificadas.

As imagens geradas através da simulação de detectores de CsI e aSe mostraram possuir qualidades próximas àquelas obtidas por trabalhos experimentais. Estes estudos mostraram que o detector de iodeto de césio (CsI) foi mais eficaz em identificar as microcalcificações em imagens geradas por feixes de até $40 \mathrm{kVp}$. Acima deste potencial, o detector de selênio amorfo ( $a S e)$ se mostrou mais eficaz.

\subsubsection{Sobre a aplicação do algoritmo de pré-processamento}

O algoritmo de pré-processamento foi capaz de eliminar aproximadamente 95\% da contribuição dos fótons espalhados na imagem. Esta eficácia foi coerente com a observada na literatura [115], validando sua implementação e uso na imagem combinada.

Este trabalho também ressaltou a eficácia deste algoritmo, na correção do 
espalhamento para vários tamanhos de campo de radiação.

\subsubsection{Sobre o algoritmo de combinação}

Os estudos com os mapas de $D_{l}$ e $D_{h}$, bem como $D c_{l}$ e $D c_{h}$, mostraram que há uma necessidade de se aplicar um fator de correção nos sinais de calibração, de forma que fiquem coerentes com os sinais dos tecidos a serem quantificados.

A estimativa dos coeficientes de calibração mostrou ser uma grande fonte de ruído e caso não seja realizada com cuidado, pode impossibilitar a otimização da técnica de combinação. A aplicação de método de regularização de mínimos quadrados foi capaz de eliminar este problema, fazendo com que o algoritmo de combinação construa imagens quantitativas com alta precisão e baixo ruído.

\subsubsection{Sobre a análise e correção da propagação de ruído}

O ruído propagado pelas imagens combinadas também foi estudado. Este estudo foi capaz de encontrar ponderações de dose entre as imagens de baixa e alta energias, com as quais eram possíveis gerar imagens quantitativas com a menor incerteza possível. A ponderação de doses encontrada foi coerente com diversos outros estudos da literatura [7, 18, 128].

Além disso, a aplicação de um filtro mediana ajudou a reduzir $60 \%$ do ruído, auxiliando no realce das características presentes nas imagens quantitativas, sem prejudicar (suavizar) seus sinais.

\subsubsection{Sobre a otimização das imagens}

\subsubsection{Quantificação de microcalcificações}

Este trabalho mostrou que o algoritmo de combinação para a geração de imagens quantitativas possui uma capacidade de realce de microcalcificações, comparável à técnica de subtração ponderada [6, 27, 31].

As combinações classificadas como ótimas, com enfoque no realce das microcalcificações, mostrou uma boa concordância com observações da literatura [7, 29, 155, 156]. Já a otimização com o enfoque na otimização da acurácia das quantificações, a região de escolhas de energias sofreu um deslocamento esperado. 
Porém, a eliminação prévia das diversas fontes de ruído, fez com que uma vasta gama de escolhas de energia fosse capaz de gerar imagens com bom realce e quantificação das microcalcificações de até $300 \mu \mathrm{m}$.

\subsubsection{Quantificação de frações glandulares}

A estimativa da fração glandular se mostrou altamente eficiente, tendo uma exatidão ótima (>85\%) para todas as energias combinadas, com excessão de regiões de baixa glandularidade $(<20 \%)$.

Foi observado um padrão claro na propagação de ruído das imagens quantitativas, porém, sua variação não teve influência na eficácia do algoritmo de combinação.

Os resultados finais deste trabalho servem como orientação para que futuros estudos sejam implementados em ambiente clínico. Além disso, a otimização da técnica em si, com métodos mais eficazes de calibração ou correção de ruído, podem fazer com que as imagens quantitativas sejam otimizadas para quaisquer combinações de imagens.

\subsubsection{Considerações gerais sobre otimização}

Tendo em vista as análises das sessões 4.4 e 4.5, pode ser afirmado que as escolhas ótimas de energias mostradas na tabela 4.3 podem ser usadas tanto para o realce e quantificação de microcalcificações, quanto para a determinação da fração glandular de uma mama.

A realização deste trabalho foi de grande importância por destacar a necessidade da aplicação de métodos de regularização na estimativas de coeficientes de calibração e em estudar e relacionar os diversos métodos de se otimizar as imagens combinadas, observando tanto o realce, quanto a quantificação de características presentes na mama.

\subsection{Perspectivas Futuras}

A utilização de um modelo geométrico que contempla um equipamento mamográfico completo e as utilizações de feixes polienergéticos e detectores reais, criam a oportunidade para que este trabalho seja aplicado em ambiente clínico. 
Assim, novos estudos experimentais, envolvendo fantomas e aquisições de imagens reais, podem ser planejados, visando a implementação clinica da técnica de formação de imagens quantitativas.

Outros estudos computacionais podem ser desenvolvidos. Os testes realizados por este trabalho podem ser expandidos para mamas mais espessas (8 a $12 \mathrm{~cm}$ de espessura). Fantomas voxelizados também podem ser considerados em simulações futuras, visando expandir os estudos com a consideração de ruídos estruturais e sobreposição de tecidos.

Além disso, pode ser testada e otimizada, a geração de imagens quantitativas em componentes do tecido mamário (proteína, lipídio e água) [34, 41].

Por fim, outros métodos de correção de espalhamento e ruído podem ser aplicados e testados, a fim de se aprimorar ainda mais a qualidade das imagens quantitativas. 


\section{Referências Bibliográficas*}

[1] ZINK, F. E. X-ray tubes. Radiographics : a review publication of the Radiological Society of North America, Inc, v. 17, n. 5, p. 1259-1268, 1997.

[2] BARNES, G. T. Contrast and scatter in x-ray imaging. Radiographics : a review publication of the Radiological Society of North America, Inc, v. 11, n. 2, p. 307-323, 1991.

[3] CARLSSON, G. A. et al. Generalised use of contrast degradation and contrast improvement factors in diagnostic radiology. Application to vanishing contrast. Physics in Medicine $\&$ Biology, v. 31, n. 7, p. 737-749, 1986.

[4] MAHESH, M. AAPM/RSNA physics tutorial for residents: digital mammography: an overview. Radiographics : a review publication of the Radiological Society of North America, Inc, v. 24, n. 6, p. 1747-1760, 2004.

[5] DANCE, D. R.; YOUNG, K. C. Estimation of mean glandular dose for contrast enhanced digital mammography: Factors for use with the UK, European and IAEA breast dosimetry protocols. Physics in Medicine and Biology, v. 59, n. 9, p. $2127-2137,2014$.

[6] BLIZNAKOVA, K.; KOLITSI, Z.; PALLIKARAKIS, N. Dual-energy mammography: simulation studies. Physics in Medicine and Biology, v. 51, n. 18, p. 4497-4515, 2006.

[7] LEMACKS, M. et al. A dual-energy subtraction technique for microcalcification imaging in digital mammography: A signal-to-noise analysis. Medical Physics, v. 29, n. 8, p. 1739, 2002.

\footnotetext{
*De acordo com a Associação Brasileira de Normas Técnicas. NBR 6023.
} 
[8] FEDON, C. et al. GEANT4 for breast dosimetry: Parameters optimization study. Physics in Medicine and Biology, IOP Publishing, v. 60, n. 16, p. 311-323, 2015 .

[9] Instituto Nacional do Câncer. Instituto Nacional do Cancer - Estimativa 2020. Rio de Janeiro, 2020. v. 1, n. 1, 122 p.

[10] Instituto Nacional do Câncer. Instituto Nacional do Cancer - Estimativa 2016. Rio de Janeiro, 2016. v. 1, n. 1, 124 p.

[11] SILVA, J. A. G. da. Diretrizes para a Detecção Precoce do Câncer de Mama no Brasil. Rio de Janeiro, 2015. v. 1, n. 1, 171 p.

[12] NALAWADE, Y. V. Evaluation of breast calcifications. Indian Journal of Radiology and Imaging, v. 19, n. 4, p. 282-286, 2009.

[13] BAKER, R. et al. New relationships between breast microcalcifications and cancer. British Journal of Cancer, Nature Publishing Group, v. 103, n. 7, p. 1034-1039, 2010.

[14] WOLFE, J. N. Breast Patterns As Index of Breast. AJR Am J Roentgenol, v. 126, p. 1130-1139, 1976.

[15] HARVEY, J. A.; BOVBJERG, V. E. Quantitative assessment of mammographic breast density: relationship with breast cancer risk. Radiology, v. 230, n. 1, p. 29-41, 2004.

[16] LAM, A. R.; DING, H.; MOLLOI, S. Quantification of breast density using dual-energy mammography with liquid phantom calibration. Physics in Medicine and Biology, v. 59, n. 14, p. 3985-4000, 2014.

[17] KUCHIKI, M.; HOSOYA, T.; FUKAO, A. Assessment of Breast Cancer Risk Based on Mammary Gland Volume Measured with Ct. Breast Cancer: Basic and Clinical Research, n. 4, p. 57-64, 2010.

[18] KAPPADATH, S. C.; SHAW, C. C. Dual energy digital mammography for calcification imaging: theory and implementation. SPIE, v. 5368, n. 19, p. 751-760, 2004. 
[19] DUCOTE, J. L.; MOLLOI, S. Scatter correction in digital mammography based on image deconvolution. Physics in medicine and biology, v. 55, p. 1295-1309, 2010 .

[20] JOHNS, P. C. et al. Dual-energy mammography: initial experimental results. Medical physics, v. 12, n. 3, p. 297-304, 1985.

[21] JACOBSON, B. Dichromatic absorption radiography. Dichromography. Acta Radiologica, v. 39, n. 6, p. 437-452, 1953.

[22] ROOS, B. O.; SKÖLDBORN, H. Dual photon absorptiometky in lumbar vertebrae: I. Theory and method. Acta Oncologica, v. 13, n. 3, p. 266-280, 1974.

[23] ALVAREZ, R. E.; MACOVSKI, A. Energy-selective Reconstructions in X-ray Computerized Tomography. v. 21, n. 5, p. 733-744, 1976.

[24] LEHMANN, L. A. et al. Generalized image combinations in dual KVP digital radiography. Medical Physics, v. 8, n. 5, p. 659-667, 1981.

[25] JOHNS, P.; YAFFE, M. J. Theoretical optimization of dual-energy x-ray imaging with application to mammography. Medical physics, v. 12, n. 3, p. 289-296, 1985.

[26] ISHIGAKI, T. et al. One-shot dual-energy subtraction imaging. Radiology, v. 161, n. 1, p. 271-273, 1986.

[27] ERGUN, L. et al. Single-exposure dual-energy computed radiography: improved detection and processing. Radiology, v. 1, n. 174, p. 243-249, 1990.

[28] KOUKOU, V. et al. Calcification Detection Optimization in Dual Energy Mammography: Influence of the X-Ray Spectra. IFMBE Proceedings 41, v. 41, p. 459-463, 2014.

[29] KOUKOU, V. et al. Dual Energy Method for Breast Imaging : A Simulation Study. Computational and Mathematical Methods in Medicine, v. 2015, p. 8, 2015.

[30] BOONE, J. M.; SHABER, G. S.; TECOTZKY, M. Dual-energy mammography: a detector analysis. Medical physics, v. 17, n. 4, p. 665-675, 1990. 
[31] BRETTLE, D. S.; COWEN, A. R. Dual-energy digital mammography utilizing stimulated phosphor computed radiography. Phys. Med. Biol., v. 39, n. 11, p. 1989-2004, 1994.

[32] MOLLOI, S. et al. Postmortem validation of breast density using dual-energy mammography. Medical physics, v. 41, n. 8, p. 10, 2014.

[33] DEL LAMA, L. S.; GODELI, J.; POLETTI, M. E. Monte Carlo simulation studies for the determination of microcalcification thickness and glandular ratio through dual-energy mammography. Radiation Physics and Chemistry, Elsevier Ltd, v. 137, p. 157-162, 2017.

[34] MOLLOI, S. et al. Quantification of water and lipid density with dual-energy mammography: validation in postmortem breasts. European Radiology, European Radiology, v. 31, n. 2, p. 938-946, 2021.

[35] DUCOTE, J. L.; MOLLOI, S. Quantification of breast density with dual energy mammography: A simulation study. Medical Physics, v. 35, n. 12, p. 5411-5418, 2008.

[36] PEPLOW, D. E.; VERGHESE, K. Digital mammography image simulation using Monte Carlo. Medical physics, v. 27, n. 3, p. 568-579, 2000.

[37] SAUNDERS, R. et al. Simulation of Mammographic Lesions. Academic Radiology, v. 13, n. 7, p. 860-870, 2006.

[38] MARTINI, N. et al. Dual energy X-ray methods for the characterization, quantification and imaging of calcification minerals and masses in breast. Crystals, v. 10, n. 3, p. 21, 2020.

[39] PATERNÒ, G. et al. Dual-energy x-ray medical imaging with inverse compton sources: A simulation study. Crystals, v. 10, n. 9, p. 1-21, 2020.

[40] GODELI, J. Simulação de Mamografia Digital por Dupla Energia para Imagens Quantitativas. 85 p. Tese (Dissertação (Mestrado em Física Aplicada à Medicina e Biologia)) — Faculdade de Filosofia, Ciências e Letras de Ribeirão Preto, Universidade de São Paulo, 2016. 
[41] LAIDEVANT, A. D. et al. Compositional breast imaging using a dual-energy mammography protocol. Medical physics, v. 37, n. 1, p. 164-74, 2010.

[42] MALKOV, S.; SHEPHERD, J. Combining 3D optical imaging and dual energy absorptiometry to measure three compositional components. Multimodal Biomedical Imaging IX, v. 8937, p. 893714, 2014.

[43] DING, H. et al. Breast tissue characterization with photon-counting spectral CT imaging: A postmortem breast study. Radiology, v. 272, n. 3, p. 731-738, 2014 .

[44] DANCE, D. R. Monte Carlo calculation of conversion factors for the estimation of mean glandular breast dose. Physics in medicine and biology, v. 35, n. 9, p. 1211-1219, 1990.

[45] SPYROUT, G. et al. Monte Carlo generated mammograms : development and validation. Phys. Med. Biol, v. 43, p. 3341-3357, 1998.

[46] HUNT, R. A. et al. Calculation of the properties of digital mammograms using a computer simulation. Radiation Protection Dosimetry, v. 114, n. 1-3, p. 395-398, 2005.

[47] GONG, X. et al. A computer simulation study comparing lesion detection accuracy with digital mammography, breast tomosynthesis, and cone-beam CT breast imaging. Medical physics, v. 33, n. 4, p. 1041-1052, 2006.

[48] TOWBIN, A. J.; PATERSON, B. E.; CHANG, P. J. Computer-based simulator for radiology: an educational tool. Radiographics : a review publication of the Radiological Society of North America, Inc, v. 28, n. 1, p. 309-316, 2008.

[49] AGOSTINELLI, S. et al. GEANT4 - A simulation toolkit. Nuclear Instruments and Methods in Physics Research, Section A: Accelerators, Spectrometers, Detectors and Associated Equipment, v. 506, n. 3, p. 250-303, 2003.

[50] SALVAT, F.; FERNÁNDEZ-VAREA, J. M.; SEMPAU, J. PENELOPE, a code system for Monte Carlo simulation of electron and photon transport. Paris, France, 2007. 339 p. 
[51] BUSHBERG, J. T. et al. The Essential Physics of Medical Imaging. 2. ed. Philadelphia, PA. E.U.A.: Lippincott Williams \& Wilkins, 2002.

[52] VILLAFANA, T. Generators, x-ray tubes, and exposure geometry in mammography. Radiographics : a review publication of the Radiological Society of North America, Inc, v. 10, n. 3, p. 539-554, 1990.

[53] BOONE, J. M.; FEWELL, T. R.; JENnINGS, R. J. Molybdenum, rhodium, and tungsten anode spectral models using interpolating polynomials with application to mammography. Medical physics, v. 24, n. 12, p. 1863-1874, 1997.

[54] DOLENKO, G. N.; POLESHCHUK, O. K.; LATOSIŃSKA, J. N. X-ray emission spectroscopy, methods. Encyclopedia of Spectroscopy and Spectrometry, p. 691-694, 2016.

[55] DANCE, D. R. et al. Diagnostic radiology physics: A Handbook for Teachers and Students. Vienna: IAEA, 2014. 710 p.

[56] KHAN, F. M.; GIBBONS, J. P. Khan's The Physics of Radiation Therapy. 5. ed. [S.l.]: Wolters Kluwer Health, 2014. 624 p.

[57] ATTIX, F. H. Introduction to radiological physics and radiation dosimetry. 4. ed. [S.l.]: WILEY-VCH Verlag GmbH Company, 2004. 628 p.

[58] SUNG, J. S. et al. Performance of dual-energy contrast-enhanced digital mammography for screening women at increased risk of breast cancer. Radiology, v. 293, n. 1, p. 81-88, 2019.

[59] BUSHBERG, J. T. X-ray Interactions. Imaging 8 Therapeutic Thecnology, v. 18, n. 2, p. 457-468, 1998.

[60] Frank Gaillard; AL., E. Photoelectric effect. 2020. Disponível em: $<$ https://radiopaedia.org/articles/photoelectric-effect $>$.

[61] KONG, J. A. Electromagnetic Wave Theory. 2. ed. Minnesota: Wiley, 1990. 704 p. (A Wiley Interscience publication). 
[62] JOHnS, H. E.; CUnNingham, J. R. The Physics of Radiology. 4. ed. Springfield, Illinois. E.U.A.: Charles C. Thomas, 1983.

[63] HUBBEL, J. H. et al. Atomic form factors, incoherent scattering functions, and photon scattering cross sections. The Journal of Physical Chemistry A, v. 4, n. 3, p. $472-538,1975$.

[64] TIPLER, A. P.; MOSCA, G. Physics For Scientists and Engineers. 6. ed. New York: W. H. Freeman and Company, 2008. 1583 p. ISBN 9780716789642.

[65] HOSSAIN, I. Compton scattering of $662 \mathrm{keV}$ gamma rays proposed by klein-nishina formula. Scientific Research and Essays, v. 6, n. 30, p. 6312-6316, 2011.

[66] JACKSON, D. F. Eletrodinâmica Clássica. Rio de Janeiro: Guanabara Dois, 1983. 602 p.

[67] SPRAWLS, P. Physical Principles of Medical Imaging. 2. ed. Madison, Wisconsin. E.U.A.: Medical Physics Publishing, 1995.

[68] AICHINGER, H. et al. Radiation Exposure and Image Quality in X-Ray Diagnostic Radiology. Radiation Exposure and Image Quality in X-Ray Diagnostic Radiology, 2004.

[69] MOTZ, J. W.; DANOS, M. Image information content and patient exposure. Medical Physics, v. 12, n. 1, p. 5-12, 1978.

[70] WAGNER, A. J. Contrast and grid performance in mammography. In screen film mammography: Imaging Considerations and Medical Physics Responsabilities, eds. G.T. Barnes and G.D. Frey. Medical Physics, p. 115-134, 1991.

[71] FAHRIG, R.; YAFFE, M. Optimization of spectral shape in digital mammography: dependence on anode material, breast thickness, and lesion type. Medical Physics, v. 21, n. 9, p. 1473-1481, 1994. 
[72] BOONE, J. M.; SEIBERT, J. A. Monte Carlo simulation of the scattered radiation distribution in diagnostic radiology. Medical Physics, v. 15, n. 5, p. 713-720, 1988.

[73] SECHOPOULOS, I. et al. Scatter radiation in digital tomosynthesis of the breast. Med Phys, v. 34, n. 2, p. 564-576, 2007.

[74] BARNES, G. T.; BREZOVICH, I. A. The intensity of scattered radiation in mammography. Radiology, v. 126, n. 1, p. 243-247, 1978.

[75] HAUS, A. G.; YAFFE, M. J. Screen-film and digital mammography: Image quality and radiation dose considerations. Radiologic Clinics of North America, v. 38, n. 4, p. 871-898, 2000.

[76] YAFFE, M. J. Detectors for Digital Mammography. In: Digital Mammography - Chapter 2. [S.l.: s.n.], 2010.

[77] BEARDEN, J. X-ray Wavelength. American Physical Society, v. 39, n. 78, p. 78-124, 1967.

[78] HAMMERSTEIN, R. G. et al. Absorbed Radiation Dose in Mammography. Radiation Physics, v. 130, p. 485-491, 1979.

[79] STANTON, L. et al. Dosage evaluation in mammography. Radiology, v. 150, p. $577-584,1984$.

[80] DANCE, D. R.; YOUNG, K. C.; Van Engen, R. E. Further factors for the estimation of mean glandular dose using the United Kingdom, European and IAEA breast dosimetry protocols. Physics in Medicine and Biology, v. 54, n. 14, p. 4361-4372, 2009.

[81] WU, X.; BARNES, T.; TUCKER, M. Spectral dependence of glandular tissue dose in screen-film mammography. Radiology, v. 179, n. 1, p. 143-148, 1991.

[82] BOONE, J. Glandular breast dose for monoenergetic and high-energy x-ray beams: Monte Carlo assessment. Radiology, v. 203, p. 23-37, 1999. 
[83] CUNHA, D. M.; TOMAL, A.; POLETTI, M. E. Evaluation of scatter-to-primary ratio, grid performance and normalized average glandular dose in mammography by Monte Carlo simulation including interference and energy broadening effects. Physics in Medicine and Biology, v. 55, n. 15, p. 4335-4359, 2010.

[84] WU, X. et al. Normalized average glandular dose in molybdenum target-rhodium filter and rhodium target-rhodium filter mammography. Radiology, v. 193, p. 83-89, 1994.

[85] ACR. Quality control manual mammography. Reston, VA, 1999.

[86] DANCE, D. R. et al. Additional factors for the estimation of mean glandular breast dose using the UK mammography dosimetry protocol. Physics in Medicine and Biology, v. 45, n. 11, p. 3225-3240, 2000.

[87] ZOETELIEF, J.; JANSEN, J. Calculation of air kerma to average glandular tissue dose conversion factors for mammography. Radiat Prot. Dosim., v. 57, n. 1-4, p. 397-400, 1995.

[88] ENGEN, R. et al. The European protocol for the quality control of the physical and technical aspects of mammography screening. In: . European Commission. 4. ed. [S.1.: s.n.], 2006. p. 57-165. ISBN 92-79-01258-4.

[89] OBEnAUER, S.; HERMAnN, K.; GRABBLE, E. Dose reduction in full-field digital mammography: an anthropomorphic breast phantom study. British Journal of Radiology, v. 76, n. 2, p. 291-303, 2003.

[90] AYMAN, A. E. Calibration of Working Standard Ionization Chambers and Dose Standardization. 76 p. Tese (Dissertação de mestrado) - University of Khartoum, 2011.

[91] BOONE, J. M. Normalized glandular dose (DgN) coefficients for arbitrary $\mathrm{X}$-ray spectra in mammography: computer-fit values of Monte Carlo derived data. Medical physics, v. 29, n. April, p. 869-875, 2002. 
[92] ASAGA, T. et al. Dual-energy subtraction mammography. Journal of Digital Imaging, v. 8, n. 1 Supplement, p. 70-73, 1995.

[93] BARRA, F.; BARRA, R.; SOBRINHO, A. B. Novel functional methods in the evaluation of breast lesions. Radiol. Bras., v. 45, n. 6, p. 340-344, 2012.

[94] ASAGA, T. et al. Breast Imaging: Dual-Energu Projection Radiography with Digital Radiography. Radiology, v. 164, n. 3, p. 869-870, 1987.

[95] LEWIN, J. M. et al. Dual-energy contrast-enhanced digital subtraction mammography: feasibility. Radiology, v. 229, n. 1, p. 261-268, 2003.

[96] SMITH, A.; PH, D. The Principles of Contrast Mammography. [S.l.], 2014. 8 p.

[97] DUCOTE, J. L.; KLOPFER, M. J.; MOLLOI, S. Volumetric lean percentage measurement using dual energy mammography. Medical Physics, v. 38, n. 8, p. 4498-4504, 2011.

[98] CARDINAL, H. N.; FENSTER, A. An accurate method for direct dual-energy calibration and decomposition. Medical Physics, v. 17, n. 3, p. 327-341, 1990.

[99] WHITE, D. R. et al. Report 44. Journal of the International Commission on Radiation Units and Measurements, os23, n. 1, p. 196, 1988.

[100] HUBBELL, J.; SELTZER, S. Tables of X-Ray Mass Attenuation Coefficients and Mass Energy-Absorption Coefficients $1 \mathrm{keV}$ to $20 \mathrm{MeV}$ for Elements $Z=1$ to 92 and 48 Additional Substances of Dosimetric Interest. 1995.

[101] WILKINSON, L.; HEGGIE, J. C. P. Glandular breast dose: potential errors. Radiology, v. 213, n. October, p. 1, 2001.

[102] HEMDAL, B. Forward-scattered radiation from the compression paddle should be considered in glandular dose estimations. Radiation Protection Dosimetry, v. 147, n. 1-2, p. 196-201, 2011.

[103] HIGGINS, P. D. et al. Mass energy-transfer and mass energy-absorption coefficients, including in-flight positron annihilation for photon energies $1 \mathrm{keV}$ to $100 \mathrm{MeV}$. [S.l.], 1992. $4812 \mathrm{p}$. 
[104] TOMAL, A. et al. Monte Carlo simulation of the response functions of CdTe detectors to be applied in x-ray spectroscopy. Applied Radiation and Isotopes, Elsevier, v. 100, p. 32-37, 2015.

[105] MCMASTER, W. H. et al. Compilation of X-ray Cross Sections. [S.1.], 1969.

[106] BERGER, M. J.; HUBBelL, J. H. XCOM: Photon Cross Sections on a Personal Computer. [S.l.], 1987. 87-3597 p.

[107] BALDELLI, P.; PHELAN, N.; EGAN, G. A novel method for contrast-to-noise ratio (CNR) evaluation of digital mammography detectors. European Radiology, v. 19, n. 9, p. 2275-2285, 2009.

[108] JAKUBIAK, R. R. et al. Quality control in breast tomosynthesis. Brazilian Journal of Radiation Sciences, v. 3, n. 1, p. 1-12, 2015.

[109] BALDELLI, P.; PHELAN, N.; EGAN, G. Investigation of the effect of anode/filter materials on the dose and image quality of a digital mammography system based on an amorphous selenium flat panel detector. British Journal of Radiology, v. 83, n. 988, p. 290-295, 2010.

[110] POLETTI, M. E.; GONÇALVES, O. D.; MAZZARO, I. X-ray scattering from human breast tissues and breast-equivalent materials. Physics in Medicine and Biology, v. 47, n. 1, p. 47-63, 2002.

[111] MOU, X. et al. The impact of calibration phantom errors on dual-energy digital mammography. Physics in Medicine and Biology, v. 53, n. 22, p. 6321-6336, 2008 .

[112] BOONE, J. M.; SEIBERT, J. A. An accurate method for computer-generating tungsten anode x-ray spectra from 30 to $140 \mathrm{kV}$. Medical Physics, v. 24, n. 11, p. 1661-1670, 1997.

[113] CARLSSOn, C. A.; CARLSSON, G. A. Basic physics of X-ray imaging. Linkoping, Suécia., 1996. 3-29 p. 
[114] WAGNER, F. C.; MACOVSKI, A.; NISHIMURA, D. C. Dual energy x ray projection imaging: Two sampling schemes for the correction of scattered radiation. Medical Physics, v. 15, n. 5, p. 732-748, 1988.

[115] KAPPADATH, S.; SHAW, C. C. Dual energy digital mammography for calcification imaging: Scatter and nonuniformity corrections. Medical Physics, v. 32, n. 11, p. 3395-3408, 2005.

[116] YAMAMURO, M. et al. Prediction of glandularity and breast radiation dose from mammography results in Japanese women. Medical and Biological Engineering and Computing, Medical \& Biological Engineering \& Computing, v. 57, n. 1, p. 289-298, 2019.

[117] DELIS, H. et al. Mammographic imaging performance: Histogram quantitative metrics using monte carlo generated images. IST 2008 - IEEE Workshop on Imaging Systems and Techniques Proceedings, p. 77-81, 2008.

[118] DANCE, D. R.; PERSLIDEN, J.; CARLSSON, G. A. Calculation of dose and contrast for two mammographic grids. Physics in Medicine and Biology, v. 37, n. 1 , p. 235-248, 1992.

[119] KAHANI, M. et al. A method for Material Decomposition in Dual-energy Contrast Enhancement Digital Mammography. Measurement, Elsevier Ltd, v. 88, p. 87-95, 2016.

[120] LE, H. Q.; MOLLOI, S. Least squares parameter estimation methods for material decomposition with energy discriminating detectors. Medical Physics, v. 38, n. 1, p. 245-255, 2011.

[121] LU, K. M. et al. Quantitative evaluation of breast density using a dual-energy technique on a digital breast tomosynthesis system. Journal of Applied Clinical Medical Physics, v. 20, n. 6, p. 170-177, 2019.

[122] TIKHONOV, A. N. et al. Numerical Methods for the Solution of Ill-Posed Problems. Dordrecht ; Boston: Kluwer Academic Publishers, 1995. 253 p. (Mathematics and Its Applications). 
[123] VIBAL, J. H. W. Determinação de espectros de energia de elétrons clínicos do eixo central a partir de curvas de porcentagem de dose em profundidade de feixes largos. 221 p. Tese (Tese de Doutorado em Física Aplicada à Medicina e Biologia) - Faculdade de Filosofia, Ciências e Letras de Ribeirão Preto, Universidade de São Paulo, Ribeirão Preto, 2018.

[124] DYKES, L. et al. Regularization matrices for discrete ill-posed problems in several space dimensions. Numerical Linear Algebra with Applications, v. 25, n. 4, p. 1-16, 2018.

[125] BAZÁN, F. S. Simple and Efficient Determination of the Tikhonov Regularization Parameter Chosen by the Generalized Discrepancy Principle for Discrete Ill-Posed Problems. Journal of Scientific Computing, v. 63, n. 1, p. 163-184, 2015.

[126] GRUBER, M. H. J. Improving Efficiency by Shrinkage - The James-Stein and Ridge Regression Estimators. Boca Raton: Routledge, 1998. 648 p.

[127] EVERITT, B. S. Cambridge Dictionary of Statistics. [S.l.]: Cambridge University Press, 1998. ISBN 9780521593465.

[128] SHAW, C. C.; GUR, D. Comparison of three different techniques for dual-energy subtraction imaging in digital radiography: A signal-to-noise analysis. Journal of Digital Imaging, v. 5, n. 4, p. 262-270, 1992.

[129] KAPPADATH, S. C.; SHAW, C. C. Dual-energy digital mammography for calcification imaging: Noise reduction techniques. Physics in Medicine and Biology, v. 53, n. 19, p. 5421-5443, 2008.

[130] HUAnG, T. S.; YANG, G. J.; TANG, G. Y. A Fast Two-Dimensional Median Filtering Algorithm. IEEE Transactions on Acoustics, Speech, and Signal Processing, v. 27, n. 1, p. 13-18, 1979.

[131] CHAN, R. H.; HO, C. W.; NIKOLOVA, M. Salt-and-pepper noise removal by median-type noise detectors and detail-preserving regularization. IEEE Transactions on Image Processing, v. 14, n. 10, p. 1479-1485, 2005. 
[132] ARIAS-CASTRO, E.; DONOHO, D. L. Does median filtering truly preserve edges better than linear filtering? Annals of Statistics, v. 37, n. 3, p. 1172-1206, 2009.

[133] CUllen, D.; HUBBELL, J.; KISSEL, L. EPDL97: the Evaluated Photon Data Library. [S.1.], 1997. v. 6, 1-35 p.

[134] STORM, E.; ISRAEL, H. I. Photon Cross Sections from $1 \mathrm{keV}$ to $100 \mathrm{MeV}$ for Elements $Z=1$ to $Z=100$. [S.1.], 1970.

[135] HUBBELL, J. H.; OVERBO, I. Relativistic atomic form factors and photon coherent scattering cross sections. 1979. 69-106 p.

[136] BIRCH, R. et al. Catalogue of Spectral Data for Diagnostic X-rays. [S.1.]: Hospital Physicists' Association, 1979. 142 p.

[137] NISHIKAWA, R. M.; YAFFE, M. J. Effect of various noise sources on the detective quantum efficiency of phosphor screens. Medical Physics, v. 17, n. 5, p. 887-893, 1990.

[138] RAVAGLIA, V. et al. Noise analysis of full field digital mammography systems. Medical Imaging 2009: Physics of Medical Imaging, v. 7258, p. 11, 2009.

[139] POON, E.; VERHAEGEN, F. Accuracy of the photon and electron physics in GEANT4 for radiotherapy applications. Medical Physics, v. 32, n. 6, p. 1696, 2005.

[140] NYQUIST, H. Certain Topics in Telegraph Transmission Theory. Transactions of the American Institute of Electrical Engineers, v. 47, n. 2, p. 617-644, 1928.

[141] NOEL, A.; THIBAULT, F. Digital detectors for mammography: The technical challenges. European Radiology, v. 14, n. 11, p. 1990-1998, 2004.

[142] FUJISAKI, T. et al. Production design and evaluation of a novel breast phantom with various breast glandular fractions. Radiation Medicine - Medical Imaging and Radiation Oncology, v. 24, n. 10, p. 647-652, 2006. 
[143] DUCOTE, J. L.; MOLLOI, S. Quantification of breast density with dual energy mammography: An experimental feasibility study. Medical Physics, v. 37, n. 2 , p. 793-801, 2010.

[144] ROSE, A. The sensitivity performance of the human eye on absolute scale. Journal of the Optical Society of America A, v. 38, p. 196-208, 1948.

[145] DICKERSCHEID, D. et al. Contrast-noise-ratio (CNR) analysis and optimisation of breast-specific gamma imaging (BSGI) acquisition protocols. EJNMMI research, v. 3, n. 21, 2013.

[146] BURGESS, A. E. The Rose model, revisited. Journal of the Optical Society of America A, v. 16, n. 3, p. 633-646, 1999.

[147] TOMAL, A.; POLETTI, M. E.; CALDAS, L. V. Evaluation of subject contrast and normalized average glandular dose by semi-analytical models. Applied Radiation and Isotopes, Elsevier, v. 68, n. 4-5, p. 755-759, 2010.

[148] BURGESS, A. On the noise variance of a digital mammography system. Medical Physics, v. 31, n. 7, p. 1987-1995, 2004.

[149] CHEN, X.; MOU, X.; ZHANG, L. Indicator and calibration material for microcalcifications in dual-energy mammography. ICMB'08: Proceedings of the 1st international conference on Medical biometrics, v. 4901, p. 265-272, 2008.

[150] KITAMOTO, T. On the computation of the determinant of a generalized Vandermonde matrix. Lecture Notes in Computer Science (including subseries Lecture Notes in Artificial Intelligence and Lecture Notes in Bioinformatics), v. 8660, p. 242-255, 2014.

[151] UFRJ. Fatoração QR e Mínimos Quadrados. 2020. Disponível em: $<$ https://www.ufrgs.br/reamat/AlgebraLinear/index.html>.

[152] IZZATULLAH, M. et al. Bayes Meets Tikhonov: Understanding Uncertainty Within Gaussian Framework for Seismic Inversion. Studies in Systems, Decision and Control, v. 320, p. 121-145, 2021. 
[153] HASTIE, T.; TIBSHIRANI, R.; FRIEDMAN, J. The Elements of Statistical Learning. [S.1.]: Springer, 2009. 764 p.

[154] WONG, M. D.; WU, X.; LIU, H. The effects of x-ray beam hardening on detective quantum efficiency and radiation dose. Journal of X-Ray Science and Technology, v. 19, n. 4, p. 509-519, 2011.

[155] BRANDAN, M. E.; RAMÍREZ-R, V. Evaluation of dual-energy subtraction of digital mammography images under conditions found in a commercial unit. Physics in Medicine and Biology, v. 51, n. 9, p. 2307-2320, 2006.

[156] GHAMMRAOUI, B. et al. Classification of breast microcalcifications using dual-energy mammography. Journal of Medical Imaging, v. 6, n. 1, p. 10, 2019. 